Rev. Elev. Méd. Vét. Pays trop., 1968, 21, 2 (227-266).

\title{
Emploi pratique des analyses fourragères pour l'appréciation des pâturages tropicaux
}

\author{
BOUDET (G.), RIVIÈRE (R.). \\ Institut d'élevage et de médecine vétérinaire des pays tropicaux \\ Malsons-Alfort-94
}

\begin{abstract}
RÉSUMÉ
Les taux de matières sèches, de matières azotées brutes, de cellulose et de cendres constituent les éléments de calcul de la valeur bromatologique des fourrages. A partir de résultats expérimentaux, les tables hollandaises donnent directement la valeur bromatologique d'un $\mathrm{kg}$ de matières sèches de fourrage en fonction du taux de cellulose et de cendres pour la valeur énergétıque et en fonction du taux de matières azotées brutes pour les matières azotées digestibles.

Par analogie à l'unité gros bétail (U. G. B.) des pays tempérés, un animal de référence de $250 \mathrm{~kg}$ pour les pays tropicaux peut être adopté comme UnitéBétail tropical (U. B. T.). La consommation journalière théorique étant évaluée à $2,5 \mathrm{~kg}$ de matière sèche pour $100 \mathrm{~kg}$ de poids vif, les besoins de I'U. B. T. sont rapportés au $\mathrm{kg}$ de matière sèche Ingérée sous le nom d'Equivalent-Ration exprimé en unité fourragère et matière azotée digestible.

Le dépouiliement de plus de 500 analyses bromatologiques de plantes fourragères tropicales, a mis en évidence :

- l'ımportance des pâturages aériens comme complément de la ration en matières azotées digestibles au cours de la saison sèche tant sur steppes que sur savanes ;

- l'importance périodique des espèces d'appoint pour assurer la nourriture du bétail sur steppes:

- le nombre limité d'espèces assurant une ration d'entretien pendant une longue période sur steppes:

- l'importance du temps de croissance pour les espèces vivaces de savanes, la valeur bromatologique des repousses dépendant plus de ce facleur que de la date de récolte.
\end{abstract}

L'élevage pratiqué en Afrique tropicale, est généralement de type extensif et les animaux exploitent la végétation naturelle ou secondarisée des terrains de parcours.

Le menu offert aux animaux varie dans le temps et dans l'espace: pousses vertes ou pailles de graminées annuelles, repousses de graminées vivaces, jeunes pousses, feuilles, fleurs, fruits d'arbres et arbustes.
L'étude des pâturages (7) après définition des types de parcours d'une région, doit préciser les plantes consommées, et à quelle époque elles le sont, mais aussi évaluer la charge possible des parcours.

Cette évaluation des charges n'est possible qu'en comparant aux besoins théoriques des animaux, la productivité d'un parcours en matière verte ou matière sèche d'alimenis appé- 
tibles, la valeur de ces alıments étant exprimée en éléments nutritifs, énergie et matières azotées assimilables.

Les expériences de digestibilité sont longues, et exigent de nombreuses répétitions pour apprécier les quantités d'aliments consommés et les coefficients de digestibilité des différents principes nutritifs. Dans un proche avenir, les études entreprises dans ce domaine à Dakar nous feront connaître avec précision l'utilisation que font taurins et zébus des principaux fourrages utilisés en élevage intensif. Mals, il est hors de doute, qu'il faudrait des décennies pour connaître de la même manıère !'utilisation des fourrages consommés sur les parcours naturels d'autant plus que les animaux y pratiquent un broutage sélectif excessivement variable selon le lieu, la saison, et le stade végétatif de la plante rencontrée par l'animal.

Les pays en voie de développement ne peuvent pas attendre aussi longtemps. II leur faut connaître rapidement le potentiel de leurs immenses régions à vocation pastorale afin d'ceuvrer pour en améliorer la productivité et les transformer en protéines animales qui leur font cruellemenf défaut.

Il est donc indispensable d'exploiter les connaissances déjà acquises pour dégrossir le problème de la productivité des pâturages et apprécier au mieux la valeur des fourrages en énergie et matières azotées digestibles.

L'examen des analyses de fourrages prélevés au cours des études entreprises par I'I. E. M.V.T. fait apparaître la nécessité :

10 d'adopter une technique de calcul simple ef généralisable pour l'évaluation d'un fourrage en énergie (unıtés fourragères) et en matières azotées assimilables (matières azotées digestibles) afin de pouvoir classer de façon grossière ces fourrages selon leur valeur ;

$2^{\circ}$ de fixer les besoins théoriques d'un animal de référence, en quantité ingérée, énergie et azote digestible afin de connaître si le fourrage considéré peut ou non satisfaire ces besoins ;

30 de prélever les fourrages des parcours comme le falt l'animal et selon l'appétibilité du moment afin d'avoir des valeurs réellement représentatives.

La technique de travail étant commentée et définie, les principaux résultats obtenus sur pâturages seront exposés.

\section{I. - CALCUL DE LA VALEUR D'UN FOURRAGE}

Trois méthodes de calcul de valeur fourragère ont été appliquées à des échantillons de Digitarı "umfolozi" (9) prélevés à Bamako-Sotuba en zone soudanienne depuis le début des pluies en mai, jusqu'à la pleine saison sèche, en février de l'année suivante (Tableau no 1 ).

Le temps de croissance de ces échantillons varie de 10 jours à 270 jours.

Le taux de matière sèche est de 13 à 14 p. 100 au début des plures, puis évolue pendant la saison des pluies entre 20 et 25 p. 100 ; cet enrichissement en matière sèche est dô à l'âge de la plante (40 à 140 jours) mals est indépendant du déroulement de la saison des pluies, car des échantillons de 10 jours de croissance restent entre 15 et 16 p. 100 de matière sèche tout au long de la saison des pluies. A la fin des pluies, des échantillons de 10 jours ont 25 p. 100 de matière sèche et la plante mise en défens passe progressivement de 35 à 90 p. 100 de matière sèche.

Exprimée en p. 100 de matière sèche, le taux de matières azotées brutes est de 15 à 18 p. 100 pour les jeunes pousses, 11 p. 100 à 40 jours de croissance, 6 p. 100 d̀ 2 mois, 3,5 p. 100 à $3-4$ mois, 2,5 à 2 p. 100 à partir de 7 mois. Une pluie tardive d'octobre ayant permis le départ de jeunes repousses, une valeur accidentelle de 4 p. 100 apparaît alors.

Le taux de cellulose reste voisin de 30 p. 100 pendant le premier mois de croissance, puis oscille entre 35 et 40 p. 100.

\section{Utilisation des tables de Kellner (pays tempé- rés).}

L'évaluation de la valeur bromatologique de l'échantillon analysé s'effectue en affectant les différents composants de la matière organique, des coefficients de digestibilité d'une plante d'espèce botanique aussi voisine que possible et ayant une composition en matière sèche, cellulose ef matières azotées brutes analogues. S'il n'y a pas, dans la table, d'élément ayant une composition en matière sèche similaire, l'échantillon de référence sera choisi dans une gamme de siccité comparable, la composition en cellulose et matières azotées étant analogue par rapport à la matière sèche. 
TABLEAU 1

Digitaria umotozi

\begin{tabular}{|c|c|c|c|c|c|c|c|c|}
\hline Numéros & $\begin{array}{l}\text { Mois } \\
\text { de } \\
\text { rêcolte }\end{array}$ & $\begin{array}{c}\text { Temps } \\
\text { croissance } \\
\text { (jours) }\end{array}$ & $\begin{array}{l}\text { Matières } \\
\text { sčches } \\
\text { p. } 100\end{array}$ & $\begin{array}{l}\text { Matières } \\
\text { azotêes } \\
\text { brutes } \\
\text { p.100 }\end{array}$ & $\begin{array}{c}\text { Ce1lulose } \\
\text { p.100 }\end{array}$ & $\begin{array}{l}\text { Matières } \\
\text { minérales } \\
\text { p.100 }\end{array}$ & $\begin{array}{l}\text { Matières } \\
\text { grasses } \\
\text { p.100 }\end{array}$ & $\begin{array}{c}\text { Extrait } \\
\text { non azotê } \\
\text { p. } 100\end{array}$ \\
\hline 1 & mai & 10 & 13,49 & $\begin{array}{r}2,13 \\
15,78\end{array}$ & $\begin{array}{r}4,42 \\
32,75\end{array}$ & $\begin{array}{r}1,4 \\
10,7\end{array}$ & 0,17 & 5,33 \\
\hline 2 & $\operatorname{ma} 1$ & 20 & 14,33 & $\begin{array}{r}2,59 \\
18,05\end{array}$ & $\begin{array}{r}4,30 \\
29,97\end{array}$ & $\begin{array}{r}1,9 \\
13,2\end{array}$ & 0,34 & 5,20 \\
\hline 3 & octobre & 10 & 26,41 & $\begin{array}{r}2,99 \\
11,30\end{array}$ & $\begin{array}{r}8,13 \\
30,73\end{array}$ & $\begin{array}{r}4,1 \\
15,7\end{array}$ & 0,26 & 10.89 \\
\hline 4 & juig & 40 & 21,00 & $\begin{array}{r}2,43 \\
11,57\end{array}$ & $\begin{array}{r}6,40 \\
30,46\end{array}$ & $\begin{array}{r}2,3 \\
10,9\end{array}$ & 0,41 & 9,47 \\
\hline 5 & juillet & 60 & 20,80 & $\begin{array}{l}1,28 \\
6,14\end{array}$ & $\begin{array}{r}8,30 \\
39,84\end{array}$ & $\begin{array}{l}2,0 \\
9,6\end{array}$ & 0,12 & 9,11 \\
\hline 6 & juillet & 80 & 23,52 & $\begin{array}{l}1,11 \\
4,72\end{array}$ & $\begin{array}{r}9,18 \\
39,02\end{array}$ & $\begin{array}{r}2,9 \\
12,5\end{array}$ & 0,21 & 10,08 \\
\hline 7 & août & 100 & 26,81 & $\begin{array}{l}1,00 \\
3,72\end{array}$ & $\begin{array}{r}9,85 \\
36,64\end{array}$ & $\begin{array}{r}3,4 \\
12,7\end{array}$ & 0,25 & 12,31 \\
\hline 8 & août & 120 & 25,49 & $\begin{array}{l}0,94 \\
3,68\end{array}$ & $\begin{array}{r}3,89 \\
34,85\end{array}$ & $\begin{array}{r}3,3 \\
12,8\end{array}$ & 0,25 & 12,14 \\
\hline 9 & septembre & 140 & 26,02 & $\begin{array}{l}0,93 \\
3,57\end{array}$ & $\begin{array}{r}8,95 \\
34,37\end{array}$ & $\begin{array}{r}4,5 \\
17,4\end{array}$ & 0,27 & 11,33 \\
\hline 10 & octobre & 160 & 38,99 & $\begin{array}{l}1,27 \\
3,25\end{array}$ & $\begin{array}{l}14,99 \\
38,37\end{array}$ & $\begin{array}{r}5,6 \\
14,3\end{array}$ & 0,33 & 16,82 \\
\hline 11 & octobre & 180 & 36,12 & $\begin{array}{l}1,52 \\
4,20\end{array}$ & $\begin{array}{l}13,18 \\
36,38\end{array}$ & $\begin{array}{r}5,4 \\
15,0\end{array}$ & 0,37 & 15,62 \\
\hline 12 & naveribre & 200 & 51,94 & $\begin{array}{l}1,60 \\
3,07\end{array}$ & $\begin{array}{l}18,55 \\
35,62\end{array}$ & $\begin{array}{r}8,2 \\
15,7\end{array}$ & 0,41 & 23,20 \\
\hline 13 & décembre & 220 & 67,64 & $\begin{array}{l}1,75 \\
2,57\end{array}$ & $\begin{array}{l}25,16 \\
36,99\end{array}$ & $\begin{array}{r}9,9 \\
14,6\end{array}$ & 0,53 & 30,27 \\
\hline 14 & décembre & 240 & 74,41 & $\begin{array}{l}1,84 \\
2,47\end{array}$ & $\begin{array}{l}26,59 \\
35.63\end{array}$ & $\begin{array}{l}10,4 \\
14,0\end{array}$ & 0,57 & 34,97 \\
\hline 15 & janvier & 260 & 86,31 & $\begin{array}{l}2,02 \\
2,32\end{array}$ & $\begin{array}{l}31,53 \\
36,26\end{array}$ & $\begin{array}{l}12,5 \\
14,4\end{array}$ & 0,61 & 39,61 \\
\hline 16 & fëvrier & 270 & 90,18 & $\begin{array}{l}2,15 \\
2,37\end{array}$ & $\begin{array}{l}33,03 \\
36,33\end{array}$ & $\begin{array}{l}14,4 \\
15,8\end{array}$ & 0,63 & 40,02 \\
\hline
\end{tabular}

Pour l'exemple no 1 , l'analyse de référence adoptée est le Millet fourrage (in 39 p. 160) à 13 p. 100 de M. S., 1,3 p. 100 de M. A. brutes et 4,1 p. 100 de ceilulose.

Les 4 principes nutritifs principaux sont d'abord évalués sous forme digestible en p. 1.000 en leur appliquant le rapport

$\frac{\text { Principes digestibles }}{\text { Principes bruts }}$

Principes bruts :
Matières azotées digestibles $: 21,3 \times \frac{0,7}{1,3}=11,40$

Cellulose digestible

$: 44,2 \times \frac{2,2}{4,1}=23,70$

Matières grasses digestibles : $1,7 \times \frac{0,1}{0,2}=0,85$

Extractif non azoté digestible : $53,3 \times \frac{3,8}{6,2}=32,60$
L'ensemble des élémenis nuiritıfs digestibles (T. D. N.) est la somme des résultats précédents, les matières grasses digestibles étant multipliées par 2,25:

T. D. N. $=11,40+2370+(0,85 \times 2,25)+32,60$ $=69,61$.

L'énergie métabolisable pour les ruminants est obtenue avec le produit : T. D. N. $\times 3,65$ soit $69,61 \times 3,65=254,08$ calories.

L'énergie nette est ensuite calculée en soustrayant à l'énergie métabolisable, l'énergie de transformation estimée, pour les ruminants, à 1 calorie par gramme de M. S. :

$$
254,08-134,90=119,18 \text { calories. }
$$


La valeur fourragère, en unités fourragères, est enfin obtenue en comparant l'énergie nette de l'échantillon ainsi déterminée à l'énergie nette de $1 \mathrm{~kg}$ d'orge calculée par le même procédé et évaluée à 1.880 calories pour les ruminants soit : $\frac{119,18}{1.880}=0,06 \mathrm{UF} / \mathrm{kg}$.

Le taux de matières azotées digestibles, calculé précédemment, est de $11,4 \mathrm{~g}$ par $\mathrm{Kg}$.

\section{$2^{\circ}$ Utilisation des tables de Schneider.}

La technique de calcul est identique ainsi que les moyens de recherche de l'analyse de référence, l'avantage de ces tables étant que la plupart des coefficients de digestibilité ont été obtenus expérimentalement en pays tropicaux avec des animaux de races tropicales.

Pour l'exemple no 1, l'élément de référence est un mélange d'herbe d'Europe à un stade de floraison avancée (12 p. 186), ce fourrage de référence ayant 15 p. 100 de M. S., 2,7 p. 100 de M. A. B. et 3,5 p. 100 de cellulose.

Le calcul des unités fourragères est le suivant:

$$
\begin{aligned}
& \text { M. A. D. }: 21,3 \times \frac{74}{100}=15,76 \\
& \text { Cellulose dig. }: 44,2 \times \frac{72}{100}=31,82 \\
& \text { M. g. d. }: 1,7 \times \frac{52}{100}=0,88 \\
& \text { E. N. A. d. }: 53,3 \times \frac{74}{100}=39,44 . \\
& \text { T. D. N. }=15,76+31,82+(0,88 \times 2,25)+39,44 \\
& =89,00
\end{aligned}
$$

Energie métabolisable :

$$
89,00 \times 3,65=324,85 \text { calories }
$$

Energie nette :

$$
324,85-134,90=189,95 \text { calories }
$$

Valeur fourragère $: \frac{189,95}{1.880}=0,10$ U. F. $/ \mathrm{kg}$

Matières azotées digestibles:

$$
\frac{21,3}{100} \times 74=15,8 \mathrm{~g} / \mathrm{kg} \text { de M.P. D. }
$$

\section{Utilisation des tables hollandaises transposées (tableaux 5 à 8).}

Les tables hollandaises (28) sont exprımées en U. A. (unité amidon) pour $100 \mathrm{~kg}$ de matière sèche de produit et nous avons transformé les valeurs U. A. en U. F. en leur appliquant le rapport $U . F_{1}=U . A_{1} \times 1,33$.

Les tables «graminées fraîches » ou «luzerne fraîche »sont utilisées selon la nature botanique de l'échantıllon.

Dans ces tables, les unités fourragères sont obtenues en fonction des teneurs en cellulose brute et cendres en $\mathrm{p}$. 100 de matière sèche la valeur étant ensuite exprimée, pour l'aliment, en multiplıant la valeur obtenve par le pourcentage de matière sèche.

Dans la table «gramınées fraîches », expri. mant les U. F. pour $100 \mathrm{~kg}$ de M. S., à 32,5 p. 100 de cellulose et 10 p. 100 de cendres correspond : 61,2 U. F. ; à 33,0 p. 100 de cellulose et 11 p. 100 de cendres correspond : $57,2 \mathrm{U}$. F, et l'appréciation des valeurs proportionneiles conduit d̀ : 58,0 U. F. pour 32,75 p. 100 de cellulose et 10,7 p. 100 de cendres.

Soit pour le fourrage $n^{0} 1$ à 13,49 p. 100 de M. S. :

$$
\frac{13,49}{100} \times \frac{58,0}{100}=0,08 \text { U. F. par kg. }
$$

Dans la table «matières azotées digestibles de graminées frâiches $\gg$, à 15,7 p. 100 de M. A. B. M. S. correspond 11,4 p. 100 de M. A. D. ; à 15,8 p. 100 de M. A. B./M. S. correspond 11,5 p. 100 de M. A. D. donc à 15,76 p. 100 de M. A. B. correspondra 114,8 p. 1000 de M. A. D. M. S. Soit pour le fourrage no 1 :

$$
\frac{13,49}{100} \times 114,8=15,5 \mathrm{~g} \text { de M. A. D. par } \mathrm{kg} \text {. }
$$

\section{Comparaison des résultats (tableau 2).}

Pour la valeur en unités fourragères, les tables de KELLNER fournissent des valeurs faibles pour les fourrages riches en equ, bien que riches en matières czotées et 'pauvres en cellulose. Pour des fourrages riches en matıère sèche et cellulose les valeurs en unités fourragères seront fortes.

Les tables hollandaises fournissent des valeurs bien étalées, par suite du principe de calcul : à un taux de cellulose élevé correspondant une valeur fable.

Les tables de SCHNEIDER donnent des valeurs sensiblement comparables d̀ celles fournies par les tables hollandases. Dans la série d'échantillons, donnée en exemple, 5 analyses aboutissent à des résultats aberrants : no 5-6-11-12-13. 
TABLEAU 2

Valeur fourragère

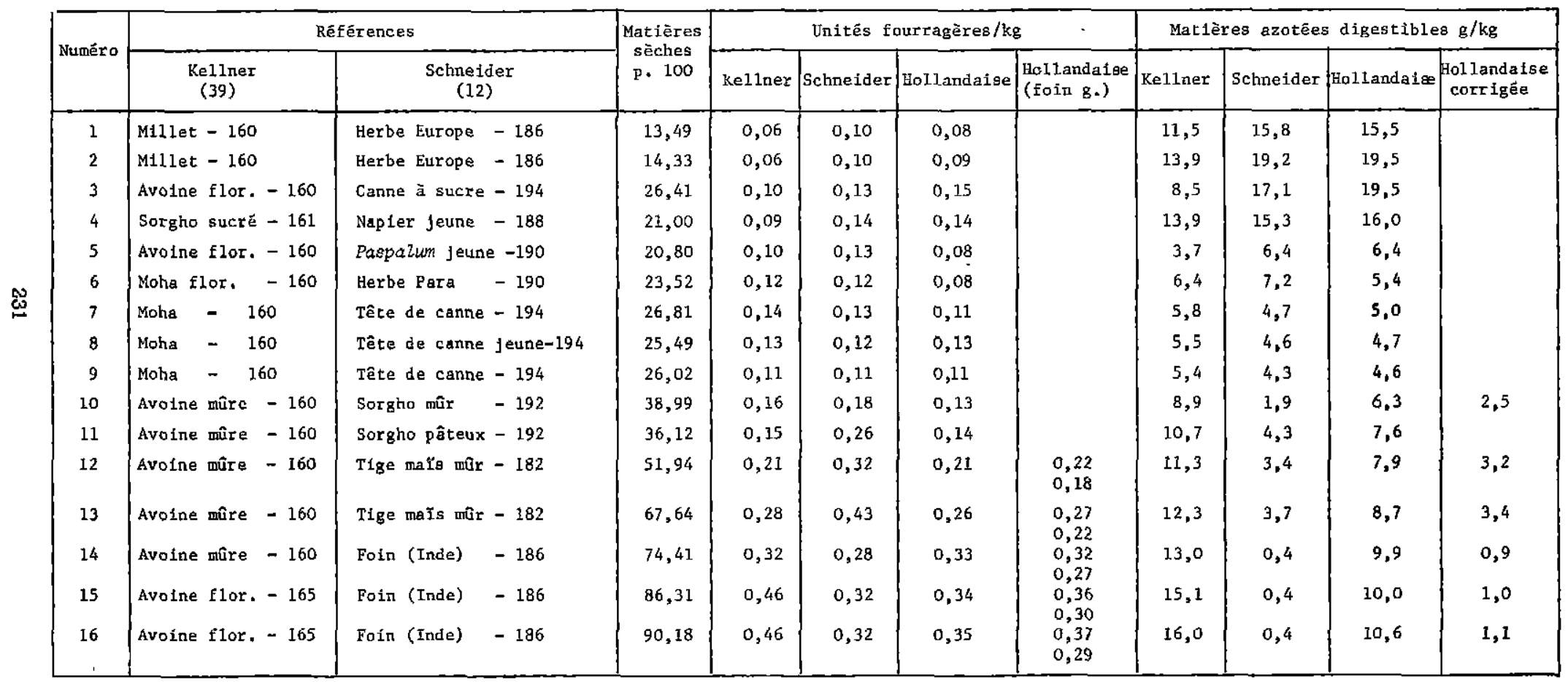


Ces variatıons apparaissent pour des échantillons riches ou très riches en cellulose ef les coefficients de digestibilıté de la cellulose sont toujours élevés dans les tables de SCHNEIDER : 73 p. 100 pour les tiges de mals mûr, 72 p. 100 pour l'herbe d'Europe, aux environs de 60 p. 100 pour les autres éléments de référence.

II semble que les tables hollandaises ne surestiment pas les fourrages, tout en leur assurant une classification correcte en fonction de leur valeur énergétique en unités fourragères. Elles ont par ailleurs, le grand avantage de la simplicité du calcul.

Pour les échantillons contenant plus de 50 p.100 de matıère sèche, I'utilisation dans lestables hollandaises, de la table «foın de gramınées» fournit une valeur en énergie comparable à celle des «graminées fraîches » mais seulement dans la mesure où il n'est pas tenu compte des corrections pour cendres.

Les valeurs sans correction (1re ligne) et avec corrections (2e ligne) sont indiquées dans le tableau $n^{\circ} 2$. Ces valeurs étant obtenues sans tenir compte de la composition en matières azotées, forte pour le foin et faible pour de tels fourrages, il paraît préférable de ne point les utiliser.

Pour la valeur en matıères azotées digestıbles, les tables de KELLNER semblent sous-estimer la valeur des échantillons riches en matières azotées ( $n^{0} 1$ à 5 ) et surestimer celle des échantillons pauvres ( $n^{\circ} 10$ à 16). Les tables hollandaises et les tables de SCHNEIDER aboutissent à des résultats comparables à la condition d'extrapoler les tables hollandaises transposées «graminées fraiches » de la manière suivante :

- de 8 à 3,5 p. 100 de matières azotées brutes, adopter un coefficient de transformation de 1/2, ıdentıque à celui des dernières valeurs de la table,

- de 3,5 à 2,5 p. 100 de matières azotées brutes, adopter un coefficient de transformation de $1 / 5$,

- pour les valeurs inférieures à 2,5 p. 100 , adopter le coefficient 1/20.

Les valeurs de matières azotées digestibles obtenues par ces calculs figurent au tableau 2, dans la colonne «tables hollandaises corrigées».

Elles reflètent assez bien les variations du coefficient de digestibilité expérimental des tables de Schneider qui, pour les exemples proposés, passe de 74 à 47 p. 100 puis brusquement à 38,21 et 2 p. 100 .

Il n'est pas question d'attribuer aux résultats, obtenus par cette méthode, une valeur absolve, mais les tables hollandaises transposées constıtuent un moyen d'approche suffisant et satisfaisant pour l'appréciation de la valeur des pâturages, ainsi que l'ont montré de nombreuses. observations.

\section{II. - CHOIX D'UN ANIMAL DE RÉFÉRENCE. L'U. B. T.}

A partir de l'analyse d'un échantillon de fourrage, 3 critères sont susceptibles d'être pris en considération pour son appréciation :

- matière sèche du fourrage,

- valeur énergétique exprimée en unités fourragères par kilogramme de produit,

- valeur exprimée en grammes de matières azotées digestibles par kilogramme de produit.

Il est très difficile de classer une série de fourrages d'après leur valeur bromatologique à partir de ces 3 critères. II est nécessaire de fare intervenir un subterfuge permettant la synthèse de ces 3 données et ceci peut être obtenu par l'intermédiaire d'une ration théorique d'un animal type.

Les bovins africains adultes pesant entre 200 et $350 \mathrm{~kg}$, l'animal de référence adopté est un bovin de $250 \mathrm{~kg}$ correspondant à peu près à une demi-Unité Gros Bétail des pays tempérés, bien que la ration d'entretien correspondante ne dolve servir qu'à la classification des fourrages. Cet animal de référence de $250 \mathrm{~kg}$ pourrait être appelé U. B. T. (unité bovin tropical).

\section{Poids de la ration journalière :}

Cette ration correspondra à $6,25 \mathrm{~kg}$ de matière sèche. En effet VOISIN (37 p. 122) pense qu'un animal peut ingérer 10 p. 100 de son poids d'herbe à 20 ou 25 p. 100 de matières sèches et CRAPLET (15 p. 257) prend comme base de calcul une consommation journalière moyenne de $2,5 \mathrm{~kg}$ de matières sèches par $100 \mathrm{~kg}$ de poids vif.

A la suite d'essais d'affouragement en cage à digestibilité, réalısé en 1958 au Centre de Recherches Zootechniques de Bamako-Sotuba, J. NUGUES (14) conclut qu'un taurillon N'dama de $160 \mathrm{~kg}$ consomme, en foin, $2,277 \mathrm{~kg}, 3,880 \mathrm{~kg}$ 
ou $4,891 \mathrm{~kg}$ selon la qualité du produit soit $2,0 \mathrm{~kg}, 3,57 \mathrm{~kg}$ ou $4,26 \mathrm{~kg}$ de matière sèche représentant : $1,24 \mathrm{~kg}, 2,21 \mathrm{~kg}$ ou $2,64 \mathrm{~kg}$ de matière sèche par $100 \mathrm{~kg}$ de poids vif.

PEYRE de FABREGGUES (32 p. 86) relève une consommation de pailie à 94 p. 100 de M. S. sur parcours sahélıens, de 6 et $8 \mathrm{~kg}$ par jour pour des animaux de 265 et $350 \mathrm{~kg}$ solt 5,64 et $7,52 \mathrm{~kg}$ de matière sèche ou 2,20 et $2,14 \mathrm{~kg}$ de matière sèche pour $100 \mathrm{~kg}$ de poids vif.

GRANIER et LAHORE (23), trouvent, pour des animaux demi-sang Brahman $\times$ Zébu, sur pôturage artificiel de Stylosanthes gracilis, Chloris gayana ef Brachiaria brizantha, une consommation journalière d'herbe de 10,5 à 11 p. 100 du poids vif correspondant à 1,5 ou $2 \mathrm{~kg}$ de matière sèche pour $100 \mathrm{~kg}$ de poids vif.

Ces quelques résultats concordent avec les travaux de LANDER (26 in 25) qui précise que les animaux peuvent avorr une ration moins encombrante en pays tropicaux, et avec la notion de rassasiement de CRAPLET (15 p. 257) : « la quantité ingérée pouvant être très différente de la quantité distribuée, notamment pour les aliments peu appétants tel le foin de luzerne avec lequel I'animal laisse d'abondants refus 》.

Au cours d'une première expérience en République Centrafricaine, BILLE a trouvé que les zébus-bororos consommaient plus de $2,5 \mathrm{~kg}$ de M. S. par $100 \mathrm{~kg}$ de poids vif lorsque l'herbe se lıgnifie et que le taux de matière sèche dépasse $30 \mathrm{p} .100$. Ses premiers résultats corroborent ceux obtenus en élevage intensif ( 29 p. 68) où plus le système fourrager est organısé, plus les possibilités de libre choix sont réduites pour l'animal et moins les quantités consommées sont élevées :

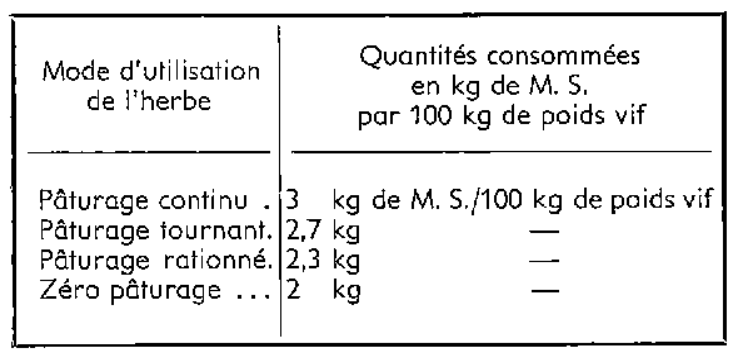

Une consommation journalière moyenne de $2,5 \mathrm{~kg}$ de matière sèche pour $100 \mathrm{~kg}$ de poids vif peut donc être adoptée bien que :

- devant un aliment très appétıble, l'animal peut consommer davantage,
- devant un aliment grossier, l'animal peut avoir moins d'appétit et consommer moins,

- des variations peuvent apparaître selon les individus,

- digérant mieux la cellulose comme en témoignent les tables de SCHNEIDER, les zébus pourraient consommer plus d'herbe lignifiée à taux de matière sèche élevé.

$2^{\circ}$ Besoins journaliers de l'U. B.T. : (Tableau no 3)

Pour les besoins d'entretien en énergie de cet animal, LEROY et DELAGE prévoient 2,3 U. F. mais CRAPLET (15 p. 244) propose la formule :

$$
E=1,5+\frac{\text { poids en } \mathrm{kg},}{200}
$$

portant les besoins à $2,7 \mathrm{U}$. F.

Les besolns d'entretien en matières azotées digestıbles sont évalués à $0,5 \mathrm{~g}$ par $\mathrm{kg}$ de poids vif, soit 125 grammes.

Les déplacements des bovins, toujours importants en pâturage naturel, nécessitent une consommation d'énergie évaluée à $0,022 \mathrm{U}$. F. par kilomètre parcouru pour $100 \mathrm{~kg}$ de poids vif ; solt $0,055 \mathrm{U}$. F. $\mathrm{km}$ pour l'unité bovin de $250 \mathrm{~kg}$. Les besoins pour déplacement peuvent donc être évalués à $0,4 \cup$. F. correspondant à un parcours moyen de $7,5 \mathrm{~km}$ en zones soudanienne et guinéenne et pour la saison des pluies de zone sahélienne. Pour cette dernière, les besoins seraient de 0,8 U. F. en saison sèche, correspondant à $15 \mathrm{~km}$ de parcours.

Bien que les dépenses azotées solent habituellement négligées pour les déplacements (15 p. 245), (37 p. 127), Il semble logique de prévoir une dépense azotée proportionnelle, d̀ un travail léger. LEROY (in 39 p. 180-4), évalue les dépenses d'un bovin effectuant un traval léger à $1 / 2$ ratıon d'énergie et $0,3 \mathrm{~g}$ de matıères protéiques digestibles par $\mathrm{kg}$ de poids vif : soit pour un animal de $250 \mathrm{~kg}, 1,15$ U. F. et $75 \mathrm{~g}$ de M. A. D.

Les besoins en énergie, évalués par ailleurs à 0,4 et $0,8 \cup$. F., les besolns correspondants en M. A. D. seraient de $\frac{0,4 \times 75}{1,15}=26 \mathrm{~g}$ de M. A. D. pour des déplacements faibles et de $52 \mathrm{~g}$ de M. A. D. pour les grands déplacements.

Ces besoins d'entretıen comparés aux possibilıtés de la ration théorique de $6,25 \mathrm{~kg}$ de matıères sèches permettent de classer les four- 
TABLEAU

Evaluation des besolns de I'animal de référence

\begin{tabular}{|c|c|c|c|c|c|c|}
\hline \multirow{2}{*}{ Besoins } & \multicolumn{3}{|c|}{ Petits dêplacements } & \multicolumn{3}{|c|}{ Grand; déplacements } \\
\hline & U.F. & M.A.D. & $\frac{\text { M.A.D. }}{\text { U.F. }}$ & U.F. & M.A.D. & $\frac{\mathrm{M} \cdot \mathrm{A} \cdot \mathrm{D} .}{\mathrm{U} \cdot \mathrm{F}}$ \\
\hline Entretien & 2,3 & 125 & 54 & 2,3 & 125 & 54 \\
\hline Déplacement & 0,4 & 26 & 65 & 0,8 & 52 & 65 \\
\hline Entretien + Déplacement & 2,7 & 151 & 56 & 3,1 & 177 & 57 \\
\hline \multicolumn{7}{|l|}{ Gain de poids : } \\
\hline$+100 \mathrm{~g} \mathrm{gain} / \mathrm{jour}$ & 3,0 & 168 & 56 & 3,4 & 195 & 57 \\
\hline$+200 \mathrm{~g} \mathrm{gain} /$ jour & 3,4 & 186 & 55 & 3,8 & 212 & 56 \\
\hline$+300 \mathrm{~g} \mathrm{gain} /$ jour & 3,7 & 204 & 55 & 4,1 & 230 & 56 \\
\hline$+500 \mathrm{~g}$ gain/jour & 4,3 & 239 & 56 & 4,7 & 265 & 56 \\
\hline \multicolumn{7}{|l|}{ Production Iaitière } \\
\hline $0,51 /$ jour & 2,9 & 181 & 62 & 3,3 & 207 & 63 \\
\hline $1 \quad 1 /$ jour & 3,1 & 211 & 68 & 3,5 & 237 & 68 \\
\hline $21 /$ jour & 3,5 & 271 & 77 & 3,9 & 297 & 76 \\
\hline $2,51 /$ jour & 3,7 & 301 & 81 & 4,1 & 327 & 80 \\
\hline $31 /$ jour & 3,8 & 331 & 87 & 4,2 & 357 & 85 \\
\hline
\end{tabular}

rages selon leur valeur bromatologique. La ration pourra être excédentaire, déficitaire ou équilibrée pour chacun ou l'ensemble des deux critères considérés, $U$. F. et $M$. A. D. Dans l'hypothèse d'une ration excédentaire, l'élément le plus défavorable, facteur limitant, servira à définir le gain possible de poids vif, à raison de $0,33 \mathrm{U}$. F. ef $17,5 \mathrm{~g}$ de M. A. D. pour un gain journalier de 100 grammes de poids vif, $\left({ }^{*}\right)$ ou la production laıtière possible à raison de $0,38 \mathrm{U}$. F. et $60 \mathrm{~g}$ de M. A. D. par litre de lait.

Un fourrage acceptable permet d'entretenir l'animal en lui fournissant une ration de 2,7 U. F. ef $151 \mathrm{~g}$ de M. A. D. dans le cas de petıts déplacements ou 3,1 U. F. et $177 \mathrm{~g}$ de M. A. D. pendant

* Ces besoins énergétiques et azotés des animaux en croissance ou d̀ l'engrais ont été définis en se référant aux normes établies par Leroy (27 p. 50 et 73 ) pour des animaux de races améliorées de pays tempérés.

Des résultats de travaux récents, non publiés, effectués à Madagascar, semblent montrer que les besoins énergétiques sont nettement supérieurs : 0,5 à $0,65 \mathrm{U}$. F. chez des métis Brahman-zébu local ef 0,7 à 1 U. F. chez les zébus locaux peu précoces (non compris les besoins d'entretien) pour un gain quotidien de $100 \mathrm{~g}$ de poids vif.

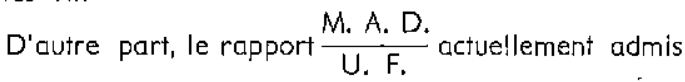

la saison sèche sur un parcours de steppes, et ces besoins d'entretien correspondent à un rapport M. A. D.

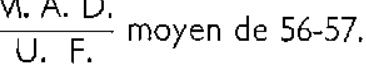

Si la ration présente un excédent d'énergie et de protéines susceptible d'assurer un gain de polds, ce rapport se maintient au même niveau. En revanche, une ration équilibrée pouvant assurer une production laitière acceptable en élevage extensif tropical aura un rapport $\frac{M . A . D}{U . F}$. voisin de 80 .

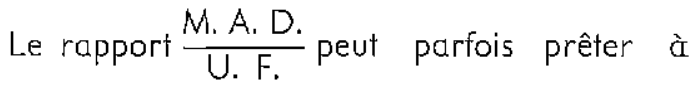

pour des boyins à l'engrais, est de 80 à 90 . Si l'on adopte le rapport le plus faible, les besoins azotés deviennent, pour un gain journalier de $100 \mathrm{~g}$ de poids vif :

$25 \mathrm{~g}$ de M. A. D. pour $0.33 \mathrm{U}$. F.

40 à $52 \mathrm{~g} \quad$ pour des zébus améliorés

56 à $80 \mathrm{~g}$ pour des animaux peu précoces

L'utilisation d'autres normes, selon les races d'animaux, que celles qui ont été choisies pour cette étude, entraîne des modifications des tableaux en ce qui concerne les besoins (tableau 3), les équivalents ration pour les gains de poids (tableau 4) et les colonnes « bilan» (tableaux 10-11-12). La méthade de travail demeure la même. 
confusion car il exprime la proportion relative des éléments du fourrage.

Un fourrage riche en énergie mais déséquilibré pourra avoir un rapport inférieur à 56 touł en assurant un gain de poids si le taux de matières azotées digestibles est suffisant, mais if y aura néanmoins un apport excessif d'énergie que l'animal ne pourra utiliser pour fabriquer de la viande ou du lait. Même s'il assure un gain de poids ou une production de laif, cet aliment ne pourra pas servir à compléter une ration en protéines.

Avec un rapport $\frac{M . A . D .}{U . F .}$ supérieur ou égal à 80 , un aliment pourra être pauvre en énergie bien que relativement riche en matières azotées. II pourra constituer un complément protéique alors que seul, il constituerait une ration déficitaire. $3^{\circ}$ Besoins de I'U. B. T. rapportés à la matière sèche ingérée. Equivalent-ration d'un $\mathrm{kg}$ de M.S.

Les besoins de l'U. B. T. correspondant à une ratıon journalière de $6,25 \mathrm{~kg}$ de $M$. S., peuvent être rapportés au $\mathrm{kg}$ de $\mathrm{M}$. S. ingérée. Les besoins ainsi exprimés pourraient être appelés : «Equivalent-ration » d'un $\mathrm{kg}$ de M. S. (tableau 4).

Les méthodes de calcul ne fournissant que des valeurs approchées, la précision de la valeur de l'équivalent-ration ne peut être que relative.

L'équivalenti-ration suffisant pour assurer l'entretien de l'animal sera de :

- $0,43 \mathrm{U}$. F. et $24 \mathrm{~g}$ de M. A. D. $(4,8 \mathrm{p} .100$ de $M$. A. B.) pour les petits déplacements.

$-0,50$ U. F. et $28 \mathrm{~g}$ de M. A. D. (5,6 p. 100 de $M$. A. B.) pour les grands déplacements.

TABLEAU 4

Eqquivalent - ration d'un kg de matiōres sèches

\begin{tabular}{|c|c|c|c|c|c|c|}
\hline \multirow[b]{2}{*}{ Besolns } & \multicolumn{3}{|c|}{ Petıts déplacements } & \multicolumn{3}{|c|}{ Grands dēplacements } \\
\hline & U, F. & $\begin{array}{c}\text { M.A.D. } \\
\text { g/kg } \\
\text { M.S. }\end{array}$ & $\begin{array}{l}\text { M.A.B. } \\
\text { en P. } 100 \\
\text { / kg M.S. } \\
\text { (Gramin.) }\end{array}$ & U.F. & M.A.D. & $\begin{array}{l}\text { M.A.B. } \\
\text { en } P .100 \\
/ \mathrm{kg} \mathrm{M,S.} \\
\text { (Gramin, ) }\end{array}$ \\
\hline Entretien & 0,37 & 20 & 4,0 & 0,37 & 20 & 40 \\
\hline Déplacement & 0,06 & 4,2 & & 0,13 & $B, 3$ & \\
\hline $\begin{array}{l}\text { Entretien + Dëplacement } \\
\frac{\text { Gain de poids }}{\text { M.A.D. par } 100 \mathrm{~g})}\end{array}$ & 0,432 & 24,2 & 4,8 & 0,496 & 28,3 & 5,6 \\
\hline$+100 \mathrm{~g} \mathrm{gain/jour}$ & 0,49 & 27,0 & 5,4 & 0,55 & 31,1 & 6,2 \\
\hline$+200 \mathrm{~g} \mathrm{gain/jour}$ & 0,54 & 29,8 & 6,0 & 0,60 & 33,9 & 6,8 \\
\hline$+300 \mathrm{~g} g a i n / j o u r$ & 0,59 & 32,6 & 6,5 & 0,66 & 36.7 & 7,4 \\
\hline$+400 \mathrm{~g} \mathrm{galn} / \mathrm{jout}$ & 0,64 & 35,4 & 7,1 & 0,71 & $39,5:$ & 7,9 \\
\hline + $500 \mathrm{~g} \mathrm{gain/jour}$ & 0,70 & 38.2 & 7,6 & 0,76 & 42,3 & 8,1 \\
\hline$+600 \mathrm{~g} \mathrm{gain} / \mathrm{jour}$ & 0,75 & 41,0 & 8,0 & 0,81 & 45,1 & 8,4 \\
\hline $\begin{array}{l}+700 \text { g gain/jour } \\
\text { Production laitière } \\
\text { et } 9,6 \text { g de M.A.D. par }\end{array}$ & 0,80 & 43,8 & 8,3 & 0,87 & 47,9 & 8,7 \\
\hline $0,51 /$ jour & 0,46 & 29,0 & 5,8 & 0,53 & 33,1 & 6,6 \\
\hline $1 \quad 1 /$ jour & 0,49 & 33,8 & 6,7 & 0,56 & 37,9 & 7,6 \\
\hline $2 \quad 1 /$ jour & 0,55 & 43,4 & 8,2 & 0,62 & 47,5 & 8,6 \\
\hline $2,51 /$ jour & 0,58 & 48,2 & 8,7 & 0,65 & 52,3 & 9,1 \\
\hline $3 \quad 1 /$ jour & 0,62 & 53,0 & 9,2 & 0,68 & 57,1 & 9,6 \\
\hline $4 \quad 1 /$ jour & 0,68 & 62,6 & 10,2 & 0,74 & 66,7 & 10,7 \\
\hline $5 \quad i /$ jour & 0,74 & 72,2 & 11,2 & $0, B O$ & 76,3 & 11,6 \\
\hline $6 \quad 1 /$ jour & 0,80 & 81,8 & 12,3 & 0,86 & 85,9 & 12.7 \\
\hline
\end{tabular}




\section{4) Tables hollandaises transposées ef Equiva- lent-ration.}

Les tables hollandaises transposées étant exprimées en U. F. pour $100 \mathrm{~kg}$ de matière sèche, la lecture de l'équivalent-ration en énergie est immédiate. Il est également possible de délimiter les valeurs au-dessous desquelles, la ration d'entretien n'est pas satisfaisante tant pour les petits que pour les grands déplacements.

Les tables hollandaises sont établies:

- pour les graminées d'après la formule de DIJKSTRA (19) :

$Z=0,970(100-m)-0,3238 y-\frac{2,65771}{100-m} y^{2}$ où

$Z$ = équivalent amidon pour $100 \mathrm{~kg}$ de M. S. $\mathrm{m}=$ cendres en $\mathrm{p} .100$ de M. S.

$y=$ cellulose en p. 100 de M. S.

l'unité fourragère équivalant à 1,33 unité amidon, l'énergie en U. F. est égale à : U. $F .=1,33 \mathrm{Z}$,

- pour les légumineuses, d'après la formule de DIJKSTRA (20) établie pour la luzerne fraîche :

$Z=0,7882(100-m)+0,1044 y-\frac{2,551}{100-m} y 2$ et $U . F .=1,33 Z$.

Les matières azotées digestibles sont obtenues au moyen de formules établies également par DIJKSTRA :

Graminées fraiches (18)

$V=0,948(x-18)+0,038(m-10)+13,62$.

Luzerne froiche $(20)$

$V=0,999(x-22)+0,046(m-11)+17,86$ où

$V=$ mat. azot. dig. en p. 100 de M. S.

$x=$ mat. azot. brutes en p. 100 de M. S.

$\mathrm{m}=$ cendres en p. 100 de M. S.

Les tables de matières azotées digestibies n'allant pas au-dessous de 8 p. 100, pour les graminées :
- de 8 à 3,5 p. 100 ,

prendre M.A.D. $=\frac{M . A . B .}{2}$

- de 3,5 à 2,5 p. 100,

prendre M. A. D. $=\frac{\text { M. A. B. }}{5}$

- en dessous de 2,5 p. 100 ,

prendre M. A. D. $=\frac{\text { M. A. B. }}{20}$

Les diverses tables hollandaises transposées utilisées dans les calculs sont présentées cidessous :

Tableau 5 : unités fourragères pour les graminées.

Tableau 6 : matières azotées digestibles pour les graminées.

Tablequ 7 : unités fourragères pour la luzerne.

Tableau 8 : matières azotées digestibles pour la luzerne.

\section{$5^{\circ}$ Cas parficulier des fourrages souillés de} terre :

Il est excessivement rare de rencontrer un fourrage contenant plus de 10 p. 100 d'insoluble chlorhydrique (silice). Seuls les fourrages se développant sur sol hydromorphe inondé, à feuilles et tiges coupantes, comme les riz sauvages ou cultivés et Leersio hexandra peuvent contenir jusqu'à 17 p. 100 de silice. Mais en début de saison des pluies, les jeunes pousses sont souillées de sable par l'action mécanique des grosses gouttes d'eau et en saison sèche, le vent et le passage répété du bétail ont également pour effet d'entraîner de fins grains de sable dans les gaines des pailles.

Ce sable, matériau inerte, n'intervient pas dans la composition de la plante mass il est néanmoins ingéré par l'animal.

Deux échantillons de pailles de steppes ont été prélevés en saison sèche, à proximité l'un de l'autre, sur une parcelle protégée des animaux et sur un parcours fréquenté par le bétail (2) :

Mélange de pailles de Schoenefeldia gracilis et Aristida funiculata récolté en janvier (saison sèche)

\begin{tabular}{|c|c|c|c|c|c|c|c|c|c|}
\hline & \multirow{2}{*}{$\begin{array}{l}\text { M.S. } \\
\text { p. } 100\end{array}$} & \multirow{2}{*}{$\begin{array}{l}\text { M. A. B. } \\
\text { P. } 100 \\
\text { M. S. }\end{array}$} & \multirow{2}{*}{$\begin{array}{l}\text { Cell. } \\
\text { P. } 100 \\
\text { M. S. }\end{array}$} & \multirow{2}{*}{$\begin{array}{c}\text { Mat. min. } \\
\text { P. } 100 \\
\text { M. S. }\end{array}$} & \multirow{2}{*}{$\begin{array}{c}\text { Ins. ClH. } \\
\text { p. } 100 \\
\text { M. S. }\end{array}$} & \multicolumn{2}{|c|}{ Valeur fourragère } & \multicolumn{2}{|c|}{ Equivalent-ration } \\
\hline & & & & & & $\begin{array}{l}\text { U. F. } \\
/ \mathrm{kg}\end{array}$ & $\begin{array}{c}\text { M. A. D. } \\
\mathrm{g} / \mathrm{kg}\end{array}$ & U. F. & M. A. D. \\
\hline $\begin{array}{l}\text { Défens ... } \\
\text { Pốturé ... } \\
\text { Corrigé... }\end{array}$ & $\begin{array}{l}96,10 \\
97,40 \\
97,40\end{array}$ & $\begin{array}{l}4,07 \\
3,56 \\
5,30\end{array}$ & $\begin{array}{l}36,10 \\
20,90 \\
31,14\end{array}$ & $\begin{array}{l}12,1 \\
43,1 \\
15,2\end{array}$ & $\begin{array}{r}8,5 \\
37,9 \\
10,0\end{array}$ & $\begin{array}{l}0,45 \\
0,38 \\
0,54\end{array}$ & $\begin{array}{l}19,5 \\
17,8 \\
25,8\end{array}$ & $\begin{array}{l}0,46 \\
0,39 \\
0,55\end{array}$ & $\begin{array}{l}20 \\
18 \\
27\end{array}$ \\
\hline
\end{tabular}


TABLEAU 5

Graminếes : U.F./100 kg de matières sèches

\begin{tabular}{|c|c|c|c|c|c|c|c|c|c|c|c|c|c|c|c|c|c|c|c|c|c|}
\hline$\underbrace{\text { Cendres }}_{\text {Cel. }}$ & 5,0 & 6,0 & 7,0 & 8,0 & 9,0 & 10,0 & 11,0 & 12,0 & 13,0 & 14,0 & 15,0 & 16,0 & 17,0 & 18,0 & 19,0 & 20,0 & $2 I, 0$ & 22,0 & 23,0 & $24,0 \quad 25,0$ & $\begin{array}{c}\text { Cendres } \\
\text { Cel.b. }\end{array}$ \\
\hline 15,0 & 107,7 & 106,4 & 105 & 103,7 & 102,4 & 101,1 & 99,8 & 98.4 & 97,1 & 95,8 & 94,4 & 93,1 & 90,4 & 89,1 & 87,8 & 86,5 & $85, I$ & 83,8 & 82,5 & $81,179,8$ & 15,0 \\
\hline 15,5 & 106,4 & 105 & $103, ?$ & 102,4 & 101,1 & 99,8 & 98,4 & 97,1 & 95,8 & 94,4 & 93,1 & 91,8 & 90,4 & 89,1 & 87,8 & 86,5 & 85,1 & 82,5 & 81,1 & $79,8 \quad 78,5$ & 15,5 \\
\hline 16,0 & 106,4 & 105 & 103,7 & 102,4 & 101,1 & 99,8 & 98,4 & 97,1 & 94,4 & 93,1 & 91,8 & 90,4 & 89,1 & 87,8 & 86,5 & 85,1 & 83,8 & 82,5 & 81,1 & $79,8 \quad 78,5$ & 16,0 \\
\hline 16,5 & 105 & 103,7 & 102,4 & 101,1 & 99,8 & 98,4 & 97,1 & 95,8 & 94,4 & 93,1 & 91,8 & 90,4 & 89,1 & 86,5 & 85,1 & 83,8 & 82,5 & 81,1 & 79,8 & $78,5 \quad 77,1$ & 16,5 \\
\hline 17,0 & 105 & 103,7 & 101,1 & 99,8 & 98,4 & 97,1 & 95,8 & 94,4 & 93,1 & 91,8 & 90,4 & 89,1 & 87,8 & 86,5 & 85,1 & 83,8 & 81,1 & 79,8 & 78,5 & $77,175,8$ & 17,0 \\
\hline 17,5 & 103,7 & 102,4 & 101,1 & 99,8 & 98,4 & 97,1 & 95,8 & $93, i$ & 91,8 & 90,4 & 89,1 & 87,8 & 86,5 & 85,1 & 83,8 & 82,5 & 81,1 & 78,5 & 77,1 & $75,8 \quad 74,5$ & 17,5 \\
\hline 18,0 & 102,4 & 101,1 & 99,8 & 98,4 & 97,1 & 95,8 & 94,4 & 93,1 & 91,8 & 90,4 & 89,1 & 86,5 & 85,1 & 83,8 & 82,5 & 81,1 & 79,8 & 78,5 & 77,1 & $75,8 \quad 73,2$ & 18,0 \\
\hline 18,5 & 102,4 & 101,1 & 98,4 & 97,1 & 95,8 & 94,4 & 93,1 & 91,8 & 90,4 & 89,1 & 87,8 & 86,5 & 85,1 & 82,5 & 81,1 & 79,8 & 78,5 & 77,1 & 75,8 & $74,5 \quad 73,2$ & 18,5 \\
\hline 19,0 & 101,1 & 99,8 & 98,4 & 97,1 & 95,8 & 94,4 & 91,8 & 90,4 & 89,1 & 87,8 & 86,5 & 85,1 & 83,8 & 82,5 & 81,1 & 78,5 & 77,1 & 75,8 & 74,5 & $73,271,6$ & 19,0 \\
\hline 19,5 & 99.8 & 98,4 & 97,1 & 95,8 & 94,4 & 93,1 & 91,8 & 90,4 & 87,8 & 86,5 & 85,1 & 83,8 & 82,5 & 81,1 & 79,8 & 78,5 & 77.1 & 74,5 & 73,2 & $71,870,5$ & 19,5 \\
\hline 20,0 & 98,4 & 97,1 & 95,8 & 94,4 & 93,1 & 91.8 & 90,4 & 89,1 & 87,8 & 86,5 & $85, I$ & 82,5 & 81,1 & 79,8 & 78,5 & 77,1 & 75,8 & 73,2 & 71,8 & $70,569,2$ & 20,0 \\
\hline 20,5 & 98.4 & 97,1 & 95.8 & 93,1 & 91,8 & 90,4 & 89,3 & 87,8 & 86,5 & 85,1 & 83,8 & 82,5 & 79.8 & 78,5 & 77,1 & 75,8 & 74,5 & 73,2 & 71,8 & $69,2 \quad 67,8$ & 20,5 \\
\hline 21,0 & 97,1 & 95,8 & 94,4 & 93,1 & 91,8 & 90,4 & 87,3 & 86,5 & 85,1 & 83,8 & 82,5 & 81,1 & 79,8 & 77,1 & 75,8 & 74,5 & 73,2 & 71,8 & 70,5 & $67,8 \quad 66,5$ & 21,0 \\
\hline 21,5 & 95,8 & 94,4 & 93,1 & 91,8 & 90,4 & 89,1 & 87,8 & 85,1 & 83,8 & 82,5 & 81,1 & 79,8 & 78,5 & 77,1 & 74,5 & 73,2 & 71,8 & 70,5 & 69,2 & $67,8 \quad 65,2$ & 21,5 \\
\hline 22,0 & 95,8 & 93,1 & 91,8 & 90,4 & 89,1 & 87,8 & 86,5 & 85,1 & 82,5 & 81,1 & 79,8 & 78,5 & 77,1 & 75,8 & 74,5 & 71,8 & 70,5 & 69,2 & 67,8 & $66,5 \quad 63,8$ & 22,0 \\
\hline 22,5 & 94.4 & $93, I$ & $.91,8$ & 89,1 & 87,8 & 86,5 & 85,1 & 83,8 & 82,5 & 79,8 & 78,5 & 77,1 & 75,8 & 74,5 & 73,2 & 71,8 & 69,2 & 67.8 & 66,5 & $65,2 \quad 63,8$ & 22,5 \\
\hline 23,0 & 93,1 & 91,8 & 90,4 & 87,8 & 86,5 & 85,1 & 83,8 & 82,5 & 81,1 & 79,8 & 77,1 & 75,8 & 74,5 & 73,2 & 71,8 & 70,5 & 67,8 & 66,5 & 65,2 & $63,8 \quad 62,5$ & 23,0 \\
\hline 23,5 & 91,8 & 90,4 & 89,11 & 187,8 & 85,1 & 83,8 & 82,5 & 81,1 & 79,8 & 78,5 & 77,1 & 74,5 & 73,2 & 71,8 & 70,5 & 69,2 & 66,5 & 65,2 & 63,8 & $62,5 \quad 61,2$ & 23,5 \\
\hline 24,0 & 90,4 & 89.1 & 87,8 & 86,5 & 85,1 & 82,5 & 81,1 & 79,8 & 78,5 & 77,1 & 75,8 & 73,2 & 71,8 & 70,5 & 69,2 & 67,8 & 66,5 & 63,8 & 62,5 & $61,259,9$ & 24,0 \\
\hline 24,5 & 89,1 & 87,8 & 86,5 & 85,1 & 83,8 & 82,5 & 79,8 & 78,5 & 77,1 & 75,8 & 74,5 & 71,8 & 70,5 & 69,2 & 67,8 & 66,5 & 65,2 & 62,5 & 61,2 & $59,958,5$ & 24,5 \\
\hline 25,0 & 87,8 & 86,5 & 85,1 & 83,8 & 82,5 & 81,1 & 79,8 & 77,1 & 75,8 & 74,5 & 73,2 & 71,8 & 69,2 & 67,8 & 66,5 & 65,2 & 63,8 & 61,2 & 59,9 & $58,5 \quad 57,2$ & 25,0 \\
\hline 25,5 & 87,8 & 85,1 & 83,8 & 82,5 & 81,1 & 79,8 & 78,5 & 77,1 & 74,5 & 73,2 & 71,8 & 70,5 & 67,8 & 66,5 & 65,2 & 63,8 & 62,5 & 59,9 & 58,5 & $57,2 \quad 54,5$ & 25,5 \\
\hline 26,0 & 86,5 & 85,1 & 82,5 & 81,1 & 79,8 & 78,5 & 77,1 & 74,5 & 73,2 & 71,8 & 70,5 & 69,2 & 66,5 & 65,2 & 63,8 & 62,5 & 61,2 & 58,5 & 57,2 & $55,953,2$ & 26,0 \\
\hline 26,5 & 85,1 & 83,8 & 82,5 & 79,8 & 78,5 & 77,1 & 75,8 & 74,5 & 71,8 & 70,5 & 69,2 & 67,8 & 66,5 & 63,8 & 62,5 & 61,2 & 58,5 & 57,2 & 55,9 & $54,5 \quad 51,9$ & 26,5 \\
\hline 27,0 & 83,8 & 82,5 & 81,1 & 78,5 & 77,1 & 75,8 & 74,5 & 73,2 & 70,5 & 69,2 & 67,8 & 66,5 & 63,8 & 62,5 & 61,2 & 59,9 & 57,2 & 55,9 & 54,5 & $51,9 \quad 50,5$ & 27,0 \\
\hline
\end{tabular}


TABLEAU 5 (sulte)

\begin{tabular}{|c|c|c|c|c|c|c|c|c|c|c|c|c|c|c|c|c|c|c|c|c|c|c|}
\hline Cendres & 5,0 & 6,0 & 7,0 & 8,0 & 9,0 & 10,0 & 11,0 & 12,0 & 13,0 & 14,0 & 15,0 & 16,0 & 27,0 & 18,0 & 19,0 & 20,0 & 21,0 & 22,0 & 23,0 & 24,0 & 25,0 & $\underbrace{\text { Cendres }}_{\text {Cel.b. }}$ \\
\hline 27,5 & 82,5 & 81,1 & 79,8 & 77,1 & 75,8 & 74,5 & 73,2 & 71,8 & 69,2 & 67,8 & 66,5 & 65,2 & 62,5 & $6 \mathrm{I}, 2$ & 59,9 & 58,5 & 55,9 & 54,5 & 53,2 & $50,5]$ & {$[\overline{49}, 2$} & 27,5 \\
\hline 28,0 & 81,1 & 79,8 & 78,5 & 77,1 & 74,5 & 73,2 & 71,8 & 70,5 & 67,8 & 66,5 & 65,2 & 63,8 & 61,2 & 59,9 & 58,5 & 57,2 & 54,5 & 53,2 & 51,9 & 49,2 & 47,9 & 28,0 \\
\hline 28,5 & 79,8 & 78,5 & 77,1 & 74,5 & 73,2 & 71,8 & 70,5 & 69,2 & 66,5 & 65,2 & 63,8 & 61,2 & 59,9 & 58,5 & 57,2 & 54,5 & 53,2 & 51,9 & 49,2 & 47,9 & 46,6 & 28,5 \\
\hline 29,0 & 78,5 & 77,1 & 75,8 & 74,5 & 71,8 & 70,5 & 69,2 & 67,8 & 65,2 & 63,8 & 62,5 & 59.9 & 58,5 & 57,2 & 55,9 & 53,2 & 51,9 & 50,5 & 47,9 & 46,6 & 45,2 & 29,0 \\
\hline 29,5 & 77,1 & 75,8 & 74,5 & 71,8 & 70,5 & 69,2 & 67,8 & 66,5 & 63,8 & 62,5 & 61,2 & 58,5 & 57,2 & 55,9 & 53,2 & 51,9 & 50,5 & 47,9 & 46,6 & 45,2 & 42,6 & 29,5 \\
\hline 30,0 & 75,8 & 74,5 & 73,2 & 71,8 & 69,2 & 67,8 & 66,5 & 63,8 & 62,5 & 61,2 & 59,9 & 57,2 & 55,9 & 54,5 & 51,9 & 50,5 & 49,2 & 46,6 & 45,2 & 43,9 & 41,2 & 30,0 \\
\hline 30,5 & 74,5 & 73,2 & 71.8 & 69,2 & 67,8 & 66,5 & 65,2 & 62,5 & 61,2 & 59,9 & 58,5 & 55,9 & 54,5 & 53,2 & 50,5 & 49,2 & 47,9 & 45,2 & 43,9 & 41,2 & 39,9 & 30,5 \\
\hline 31,0 & 73,2 & 71,8 & 70,5 & 67,8 & 66,5 & 65,2 & 63,8 & 61,2 & 59,9 & 58,5 & 55,9 & 54,5 & 53,2 & 50,5 & 49,2 & 47,9 & 45,2 & 43,9 & 42,6 & 39,9 & 38,6 & 31,0 \\
\hline 31,5 & 71,8 & 70,5 & 69,2 & 66,5 & 65,2 & 63,8 & 61,2 & 59,9 & 58,5 & 57,2 & 54,5 & 53,2 & 51,2 & $4 \overline{9}, 2$ & 47,9 & 45,2 & 43,9 & 42,6 & 39,9 & 38,6 & 35,9 & 31,5 \\
\hline 32,0 & 70,5 & 69,2 & 67,8 & 65,2 & 63,8 & 62,5 & 59,9 & 58,5 & 57,2 & 54,5 & 53,2 & 51,2 & $49, \overline{2}$ & 47,9 & 46,6 & 43,9 & 42,6 & 39,9 & 38,6 & 37,2 & 34,6 & 32,0 \\
\hline 32,5 & 69,2 & 67,8 & 66,5 & 63,8 & 62,5 & 61,2 & 58,5 & 57,2 & 55,9 & 53,2 & 51,2 & $50,5]$ & 47,9 & 46,6 & 43,9 & 42,6 & 41,2 & 38,6 & 37.2 & 34,6 & 33,3 & 32,5 \\
\hline 33,0 & 67,8 & 66,5 & 63,8 & 62,5 & 61,2 & 58,5 & 57,2 & 55,9 & 53,2 & 51,2 & 50,5 & 47,9 & 46,6 & 45.2 & 42,6 & 41,2 & 38,6 & 37,2 & 34.6 & 33.3 & 31,9 & 33,0 \\
\hline 33,5 & 66,5 & 63,8 & 62.5 & 61,2 & 59,9 & 57,2 & 55,9 & 54,5 & 51,2 & 50,5 & 47,9 & 46,6 & 45,2 & 42,6 & 41,2 & 38,6 & 37,2 & 34,6 & 33,3 & 31,9 & 29,3 & 33,5 \\
\hline 34,0 & 65,2 & 62,5 & 61,2 & 59.9 & 58,5 & 55,9 & 54,5 & 51,2 & 50,5 & 49,2 & 46,6 & 45,2 & 42,6 & 41,2 & 39,9 & 37,2 & 35,9 & 33,3 & 31,9 & 29,3 & 27,9 & 34,0 \\
\hline 34,5 & 63,8 & 61,2 & 59,9 & 58,5 & 55,9 & 54,5 & 53,2 & 50,5 & 49,2 & 47,9 & 45,2 & 43,9 & 41,2 & 39,9 & 37,2 & 35.9 & 33,3 & 31,9 & 29,3 & 27.9 & 25,3 & 34,5 \\
\hline 35,0 & 61,2 & 59,9 & 58,5 & 55.9 & 54.5 & 53,2 & 50,5 & 49,2 & 47,9 & 45,2 & 43,9 & 41,2 & 39,9 & 37,2 & 35,9 & 34,6 & 31,9 & 29,3 & 27,9 & 26,6 & 25,3 & 35,0 \\
\hline 35,5 & 59,9 & 58,5 & 57.2 & 54,5 & 53,2 & 51,2 & 49,2 & 47,9 & 45,2 & 43,9 & 42,6 & 39,9 & 38,6 & 35,9 & 34,6 & 31,9 & 30,6 & 27,9 & 26,6 & 23,9 & 22,6 & 35.5 \\
\hline 36,0 & 58,5 & 57,2 & 55,9 & 53,2 & 51,2 & $\{49,2$ & 47,9 & 46,6 & 43,9 & 42,6 & 39,9 & 38,6 & 35,9 & 34,6 & 31,9 & 29,3 & 27,9 & 26,6 & 23,9 & 22,6 & 20,0 & 36,0 \\
\hline 36,5 & 57,2 & 55,9 & 53,2 & 51,2 & 50,5 & 47,9 & 46,6 & 43,9 & 42,6 & 39,9 & 38,6 & 35,9 & 34,6 & 33,3 & 30,6 & 29,3 & 26,6 & 23,9 & 22,6 & 20,0 & 18,6 & 36,5 \\
\hline 37,0 & 55,9 & 53,2 & 51,2 & $50,5]$ & 47,9 & 46,6 & 43,9 & 42,6 & 41,2 & 38,6 & 37,2 & 34,6 & 33,3 & 30,6 & 29,3 & 26.6 & 25,3 & 22,6 & 20,0 & 18,6 & 16,0 & 37,0 \\
\hline 37,5 & 54,5 & 51,2 & 50,5 & 47,9 & 46,6 & 45,2 & 42,6 & 41,2 & 39,9 & 37,2 & 34,6 & 33,3 & 30,6 & 29,3 & 26,6 & 25,3 & 22,6 & 20,0 & 18,6 & 16,0 & 14,6 & 37,5 \\
\hline 38,0 & 51,2 & 50,5 & 49,2 & 46,6 & 45,2 & 42,6 & 41,2 & 39,9 & $-37,2$ & 34,6 & 33,3 & 30,6 & 29,3 & 26,6 & $.25,3$ & 22,6 & 21,3 & 18.6 & 17,3 & 14.6 & 12,0 & 38,0 \\
\hline 38,5 & 50,5 & 49,2 & 46,6 & 45,2 & 42,6 & 41,2 & 39,9 & 37,2 & 35,9 & 33,3 & 31,9 & 29,3 & 27,9 & 25,3 & 22,6 & 21.3 & 18,6 & 17.3 & 14,6 & 12,0 & 10,7 & 38,5 \\
\hline 39,0 & 49,2 & 47,9 & 45,2 & 43,9 & 41,2 & 39,9 & 37,2 & 35,9 & 33,3 & 31,9 & 29,3 & 27,9 & 25,3 & 23.9 & $2 I, 3$ & 18,6 & 17,3 & 14,6 & 13,3 & 10,7 & 8,0 & 39,0 \\
\hline 39,5 & 47,9 & 45,2 & 43,9 & 41,2 & 39,9 & 37,2 & 35,9 & 34,6 & $3 \mathrm{I}, 9$ & 29,3 & 27,9 & 25,3 & 23,9 & 21,3 & 20,0 & 17,3 & 14,6 & 13,3 & 10,7 & 8,0 & 6,7 & 39,5 \\
\hline 40,0 & 45,2 & 43,9 & 42,6 & 39,9 & 38,6 & 35,9 & 34,6 & 31,9 & 30,6 & 27,9 & 25,3 & 23,9 & 21,3 & 20,0 & 17,3 & 16,0 & 13,3 & 10.7 & 9,3 & 6,7 & 4,0 & 40,0 \\
\hline
\end{tabular}

- Valeur limite d'entretien pour petits déplacements de $I^{\prime} U . B . T$.

---Valeur limite d'entretien pour grands déplacements de l'U,B.T. 
TABLEAU 6

Graminées (Matières azotées digestibles)

\begin{tabular}{|c|c|c|c|c|c|c|c|c|c|}
\hline M.A.B. & M.A.D. & M.A.B. & $M, A, D$ & M.A.B. & M.A.D. & M.A,B. & M.A.D, & M.A.B': & M.A.D. \\
\hline 8,0 & 4,1 & 12,6 & & 16,7 & 12,4 & 20,8 & 16,3 & 24,9 & 20,2 \\
\hline 8,2 & 4,3 & 12,7 & 8,6 & 16,8 & 12,5 & 20,9 & 16,4 & 25,0 & 20,3 \\
\hline 8,4 & 4,5 & 12,8 & 8.7 & 16.9 & 12,6 & 21,0 & 16,5 & $25,1:$ & 20,4 \\
\hline 8,6 & 4,7 & 12,9 & 8,8 & 17,0 & 12,7 & 21,1 & 16,6 & 25,2 & 20,5 \\
\hline 8,8 & 4,9 & 13,0 & 8,9 & 17,1 & 12,8 & 21,2 & 16,7 & 25,3 & 20,5 \\
\hline 9,0 & 5,1 & 13,1 & 9,0 & 17,2 & 12,9 & 21,3 & 16.8 & $25,4^{\prime}$ & 20,6 \\
\hline 9,1 & 5,2 & 13,2 & 9,1 & 17,3 & 13,0 & 21.4 & 16,8 & $25,5_{i}^{\prime}$ & 20,7 \\
\hline 9,2 & 5,3 & 13,3 & 9,2 & 17,4 & 13,1 & 21,5 & 16,9 & 25,6 & 20,8 \\
\hline 9,3 & 5,4 & 13,4 & 9,3 & 17,5 & 13,2 & 21,6 & 17,0 & 25,7 & 20,9 \\
\hline 9,4 & 5,5 & 13,5 & 9,4 & 17,6 & 13,2 & 21,7 & 17,1 & 25,8 & 21,0 \\
\hline 9,5 & 5,6 & 13,6 & 9,5 & 17,7 & 13,3 & 21,8 & 17,2 & 25,9 & 21,1 \\
\hline 9,6 & $5, ?$ & 13,7 & 9,5 & 17,8 & 13,4 & 21,9 & 17,3 & 26,0 & 21,2 \\
\hline 9,7 & 5,8 & 13,8 & 9,6 & 17,9 & 13,5 & 22,0 & 17,4 & 26,1 & 21,3 \\
\hline 9,8 & 5,9 & 13,9 & 9,7 & 18,0 & 13,6 & 22,1 & 17,5 & 26,2 & 21,4 \\
\hline 9,9 & 6,0 & 14,0 & 9,8 & 18,1 & 13,7 & 22,2 & 17,6 & 26,3 & 21,5 \\
\hline 10,0 & 6,0 & 14,1 & 9,9 & 18,2 & 13,8 & 22,3 & 17,7 & $26,4^{\prime}$ & 21,6 \\
\hline 10,1 & 6,1 & 14,2 & 10,0 & 18,3 & 13,9 & 22,4 & 17,8 & 26,5 & 21,7 \\
\hline 10,2 & 6,2 & 14,3 & 10,1 & 18,4 & 14,0 & 22,5 & 17,9 & 26,6 & 21,8 \\
\hline 20,3 & 6,3 & 14,4 & 10,2 & 18,5 & 14,1 & 22,6 & 18,0 & 26,7 & 21,9 \\
\hline 10,4 & 6,4 & 14,5 & 10,3 & 18,6 & 14,2 & 22,7 & $I B, 1$ & 26,8 & 22,0 \\
\hline 10,5 & 6,5 & 14,6 & 10,4 & 18,7 & 14,3 & 22,8 & 18,2 & 26,9 & 22,1 \\
\hline 10,6 & 6,6 & 14,7 & 10,5 & 18,8 & 14,4 & 22,9 & 18,3 & 27,0 & 22,2 \\
\hline 10,7 & 6,7 & 14,8 & 10,6 & 18,9 & 14,5 & 23,0 & 18,4 & 27,1 & 22,3 \\
\hline 10,8 & 6,8 & 14,9 & 10,7 & 19,0 & 14,6 & 23,1 & 18,5 & 27,2 & 22,3 \\
\hline 10,9 & 6,9 & 15,0 & 10,8 & 19,1 & 14,7 & 23,2 & 18,6 & 27,3 & 22,4 \\
\hline 11,0 & 7,0 & 15,1 & 10,9 & 19,2 & 14,8 & 23,3 & 18,6 & 27,4 & 22,5 \\
\hline 11,1 & 7,1 & 15,2 & 11,0 & 19,3 & 14,9 & 23,4 & 18,7 & 27,5 & 22,6 \\
\hline 11,2 & 7,2 & 15,3 & 11,0 & 19,4 & 15,0 & 23,5 & 18,8 & 27,6 & 22,7 \\
\hline 11,3 & 7,3 & 15,4 & 11,2 & 19,5 & 15,0 & 23,6 & 18,9 & 27,7 & 22,8 \\
\hline 11,4 & 7,4 & 15,5 & 11,3 & 19,6 & 15,1 & 23,7 & 19,0 & 27,8 & 22,9 \\
\hline 11,5 & 7,5 & 15,6 & 11,3 & 19,7 & 15,2 & 23,8 & 19,1 & 27,9 & 23,0 \\
\hline 11,6 & 7,6 & 15,7 & 11,4 & 19,8 & 15,3 & 23,9 & 19,2 & 28,0 & 23,1 \\
\hline 11,7 & 7,7 & 15,8 & 11,5 & 19,9 & 15,4 & 24,0 & 19,3 & 28,2 & 23,3 \\
\hline 11,8 & 7,7 & 15,9 & 11,6 & 20,0 & 15,5 & 24,1 & 19,4 & $2 B, 4$ & 23,5 \\
\hline 11,9 & 7,8 & 16,0 & 11,7 & 20,1 & 15,6 & 24,2 & 19,5 & $2 B, 6$ & 23,7 \\
\hline 12,0 & 7,9 & 16,1 & 11,8 & 20,2 & 15,7 & 24,3 & 19,6 & $2 B, 8$ & 23,9 \\
\hline 12,1 & 8.0 & 16,2 & 11,9 & 20,3 & 15,8 & 24,4 & 19,7 & 29,0 & 24,1 \\
\hline 12,2 & 8,1 & 16,3 & 12,0 & 20,4 & 15,9 & 24,5 & 19,8 & 29,2 & 24,2 \\
\hline 12,3 & 8,2 & 16,4 & 12,1 & 20,5 & 16,0 & 24,6 & 19.9 & 29,4 & 24,4 \\
\hline 12,4 & 8,3 & 16,5 & 12,2 & 20,6 & 16,1 & 24,7 & 20,0 & 29,6 & 24,6 \\
\hline 12,5 & 8,4 & 16,6 & 12,3 & 20,7 & 16,2 & 24,8 & 20,1 & $\begin{array}{l}29,8 \\
30,0\end{array}$ & $\begin{array}{l}24,8 \\
25,0\end{array}$ \\
\hline
\end{tabular}


TABLEAU 7

Lëgumineuses : U.F./100 kg de matières sẽches

\begin{tabular}{|c|c|c|c|c|c|c|c|c|c|c|c|c|c|c|c|c|c|c|c|c|c|c|}
\hline Cel.b. & 5,0 & 6,0 & 7,0 & 8,0 & 9,0 & 10,0 & 11,0 & 12,0 & 13,0 & 14,0 & 15,0 & 16,0 & 17,0 & 18,0 & 19,0 & 20,0 & 21,0 & 22,0 & 23,0 & 24,0 & 25,0 & Cel. B. \\
\hline 18,0 & 90,4 & 89,1 & 87,8 & 86,5 & 85,1 & 85,1 & 83,8 & 82,5 & 81,1 & 79,8 & 78,5 & 77,1 & 75,8 & 74,5 & 74,5 & 71,8 & 71,8 & 70.5 & 69.2 & 67.8 & 66,5 & 18,0 \\
\hline 18,5 & 90,4 & 89,1 & 87,8 & 86,5 & 85,1 & 83,8 & 82,5 & 81,1 & 79,8 & 79,8 & 78,5 & 77,1 & 75,8 & 74,5 & 73,2 & 71,8 & 70,5 & 69,2 & 67,8 & 66,5 & 65,2 & 18,5 \\
\hline 19,0 & 89,1 & 87,8 & 86,5 & 85,1 & 85,1 & 83,8 & 82,5 & $81, I$ & 79,8 & 78,5 & 77,1 & 75,8 & 74,5 & 73,2 & 71,8 & 71,8 & 70,5 & 69,2 & 67,8 & 66,5 & 65,2 & 19,0 \\
\hline 19,5 & 89,1 & 87,8 & 86,5 & 85,1 & 83,8 & 82,5 & 81,1 & 79,8 & 79,8 & 77,1 & 77,1 & 75,8 & 74,5 & 73,2 & 71,8 & 70,5 & 69,2 & 67,8 & 66.5 & 65,2 & 63,8 & 19,5 \\
\hline 20,0 & 87,8 & 86,5 & 85,1 & 85,1 & 83,3 & 82,5 & 81,1 & 79,8 & 78,5 & 77,1 & 75,8 & 74,5 & 73,2 & 71,8 & 70,5 & 69,2 & 67,8 & 66,5 & 66,5 & 65,2 & 63,8 & 20,0 \\
\hline 20,5 & 87,8 & 86,5 & 85,1 & 83,8 & 82,5 & 81,1 & 79,8 & 78,5 & 77,1 & 75,8 & 74,5 & 74,5 & 73,2 & 71,8 & 70,5 & 69,2 & 67,8 & 66,5 & 65,2 & 63,8 & 62,5 & 20,5 \\
\hline 21,0 & 86,5 & 85,1 & 83,8 & 82,5 & 82,5 & 81,1 & 79,8 & 78,5 & 77,1 & 75,8 & 74,5 & 73,2 & 71,8 & 70,5 & 69,2 & 67,8 & 66,5 & 65,2 & 63,8 & 62,5 & 61,2 & 21,0 \\
\hline 21,5 & 86,5 & 85,1 & 83,8 & 82,5 & 81,1 & 79,8 & 78,5 & 77,1 & 75,8 & 74,5 & 73,2 & 71,8 & 71,8 & 69,2 & 69,2 & 67,8 & 66,5 & 65,2 & 63,8 & 62,5 & 61,2 & 21,5 \\
\hline 22,0 & 85,1 & 83,8 & 82,5 & 81,1 & 79,8 & 79,8 & 78,5 & 77,1 & 75,8 & 74,5 & 73,2 & 71,8 & 70,5 & 69,2 & 67,8 & 66,5 & 65,2 & 63,8 & 62,5 & 61,2 & 59,9 & 22,0 \\
\hline 22,5 & 85,1 & 83,8 & 82,5 & 81,1 & 79,8 & 78,5 & 77,1 & 75,8 & 74,5 & 73,2 & 71,8 & 70,5 & 69,2 & 67,8 & 66,5 & 65,2 & 63,8 & 62,5 & 61,2 & 59,9 & 58,5 & 22,5 \\
\hline 23,0 & 83,8 & 82,5 & 81,1 & 79,8 & 78,5 & 77,1 & 75,8 & 74,5 & 74,5 & 71,8 & 71,8 & 69,2 & 69,2 & 67,8 & 66,5 & 65,2 & 63,8 & 62,5 & 61,2 & 58,5 & 58,5 & 23,0 \\
\hline 23,5 & 82,5 & 82,5 & 81,1 & 79,8 & 78,5 & 77,1 & 75,8 & 74.5 & 73,2 & 71,8 & 70.5 & 69,2 & 67,8 & 66,5 & 65,2 & 63,8 & 62,5 & 61,2 & 59,9 & 58,5 & 57,2 & 23,5 \\
\hline 24,0 & 82,5 & 81,1 & 79.8 & 78,5 & 77,1 & 75,8 & 74.5 & 73,2 & 71,8 & 70,5 & 69,2 & 67,8 & 66,5 & 65,2 & 63,8 & 62,5 & 61,2 & 59,9 & 58,5 & 57,2 & 55,9 & 24,0 \\
\hline 24,5 & 81,1 & 79,8 & 78,5 & 77,1 & 77,1 & 75,8 & 73,2 & 71,8 & 71,8 & 69,2 & 69,2 & 66,5 & 66,5 & 63,8 & 63,8 & 61,2 & 59,9 & 58,5 & 57,2 & 55,9 & 54,5 & 24,5 \\
\hline 25,0 & 81,1 & 79,8 & 78,5 & 77,1 & 75,8 & 74,5 & 73,2 & 71,8 & 70,5 & 69,2 & 67,8 & 66,5 & 65,2 & 63,8 & 62,5 & 61,2 & 59,9 & 58,5 & 57,2 & 55,9 & 53,2 & 25,0 \\
\hline 25,5 & 79,8 & 78,5 & 77,1 & 75,8 & 74,5 & 73,2 & 71,8 & 70,5 & 69,2 & 67,8 & 66,5 & 65,2 & 63,8 & 62,5 & 61,2 & 59,9 & 58,5 & 57,2 & 55,9 & 54,5 & 53,2 & 25,5 \\
\hline 26,0 & 79,8 & 77,1 & 77,1 & 74,5 & 74,5 & 71,8 & 71,8 & 69,2 & 69,2 & 66,5 & 65,2 & 63.8 & 62,5 & 61,2 & 59,9 & 58,5 & 57,2 & 55,9 & 54,5 & 53,2 & 51,2 & 26,0 \\
\hline 26,5 & 78,5 & 77,1 & 75,8 & 74,5 & 73,2 & 71,8 & 70,5 & 69,2 & 67,8 & 66,5 & 65,2 & 63,8 & 62,5 & 61,2 & 58,5 & 57,2 & 55,9 & 54,5 & 53,2 & 51,2 & 50,5 & 26,5 \\
\hline 27,0 & 77,1 & 75,8 & 74,5 & 73,2 & 71,8 & 70,5 & 69,2 & 67,8 & 66,5 & 65,2 & 63,8 & 62,5 & 61,2 & 59,9 & 58,5 & 57,2 & 55,9 & 53,2 & 51,2 & 50,5 & 49,2 & 27,0 \\
\hline 27,5 & 77,1 & 74,5 & 73,2 & 71.8 & 70,5 & 69,2 & 67,8 & 66,5 & 65,2 & 63,8 & 62,5 & 61,2 & 59,9 & 58,5 & 57,2 & 55,9 & 54,5 & 53,2 & 50,5 & 49,2 & 47,9 & 27,5 \\
\hline 28,0 & 75,8 & 74,5 & 73,2 & 71,8 & 70,5 & 69,2 & 67,8 & 66,5 & 63,8 & 62,5 & 61,2 & 59,9 & 58,5 & 57,2 & 55,9 & 54,5 & 53,2 & 51,2 & 50,5 & 47,9 & 46,6 & 28,0 \\
\hline 28,5 & 74,5 & 73,2 & 71,8 & 70,5 & 69,2 & 67,8 & 66,5 & 65,2 & 63,8 & 62,5 & 61,2 & 58,5 & 58,5 & 55,9 & 54,5 & 53,2 & $5 I, 2$ & 50,5 & 49,2 & 47,9 & 45,2 & 28,5 \\
\hline 29,0 & 73,2 & 71,8 & 70,5 & 69,2 & 67,8 & 66,5 & 65,2 & 63,8 & 62,5 & 61,2 & 59,9 & 58,5 & 57,2 & 55,9 & 53,2 & 51,2 & 50,5 & 49,2 & 47,9 & 46,6 & 45,2 & 29,0 \\
\hline 29,5 & 73,2 & 71,8 & 69,2 & 69,2 & 66,5 & 65,2 & 63.8 & 62,5 & 61,2 & 59,9 & 58,5 & 57,2 & 55,9 & 54,5 & 53,2 & 50,5 & 49,2 & 47,9 & 46.6 & 45,2 & 43,9 & 29,5 \\
\hline 30,0 & 71,8 & 70,5 & 69,2 & 67,8 & 66,5 & 65,2 & 62,5 & 61,2 & 59,9 & 58,5 & 57,2 & 55,9 & 54,5 & 53,2 & 51,2 & 50,5 & 47,9 & 46,6 & 45,2 & 43,9 & 42,6 & 30,0 \\
\hline
\end{tabular}


TABLEAU 7 (suite)

\begin{tabular}{|c|c|c|c|c|c|c|c|c|c|c|c|c|c|c|c|c|c|c|c|c|c|c|}
\hline Cendres & 5,0 & 6,0 & 7,0 & 8.0 & 9,0 & 10,0 & 21,0 & 12,0 & 13,0 & 14,0 & 15,0 & 16,0 & 17.0 & 18,0 & 19,0 & 20,0 & 21,0 & 22.0 & 23,0 & 24,0 & 25,0 & endres \\
\hline 30,5 & 70,5 & 69,2 & 67,8 & 66,5 & 65,2 & 63,8 & 62,5 & 61,2 & 58,5 & 57,2 & 55,9 & 54,5 & 53,2 & $5 \mathrm{I}, 2$ & 50,5 & 49,2 & 46,6 & 45,2 & 43,9 & 42,6 & 41,2 & 30,5 \\
\hline 31.0 & 69,2 & 67,8 & 66,5 & 65,2 & 63,8 & 62.5 & $6 \mathrm{~L}, 2$ & 59,9 & 58,5 & 55,9 & 54,5 & 53.2 & 51,2 & 50,5 & 49,2 & 47,9 & 46,6 & 43,9 & 42,6 & 41,2 & 39,9 & 31,0 \\
\hline 31.5 & 69.2 & 66.5 & 65,2 & 63,8 & 62.5 & 61.2 & 59,9 & 58,5 & 57,2 & 55,9 & 53,2 & 51.2 & 50,5 & 49,2 & 47.9 & 46.6 & 45,2 & 42,6 & 41,2 & 39,9 & 38,6 & 31,5 \\
\hline 32,0 & 67,8 & 66,5 & 65,2 & 63,8 & 61,2 & 59,9 & 58,5 & 57,2 & 55,9 & 54,5 & 53,2 & $50,5 !$ & 49,2 & 47,9 & 46,6 & 45,2 & 43,9 & 41,2 & 39,9 & 38,6 & 37,2 & 32,0 \\
\hline 32,5 & 66,5 & 65,2 & 63,8 & 62,5 & 61,2 & 58,5 & 57,2 & 55,9 & 54,5 & 53,2 & 51,2 & 49,2 & 47,9 & 46,6 & 45,2 & 43,9 & 42,6 & 39,9 & 38,6 & 37,2 & 35,9 & 32,5 \\
\hline 33.0 & 65,2 & 63,8 & 62,5 & 61,2 & 59,9 & 58,5 & 55,9 & 54.5 & 53,2 & 51,2 & 50,5 & 47,9 & 46,6 & 45.2 & 43,9 & 42,6 & 41,2 & 38,6 & 37,2 & 35,9 & 34,6 & 33,0 \\
\hline 33,5 & 63,8 & 62,5 & 61,2 & 59,9 & 58,5 & 57,2 & 55,9 & 53,2 & 51,2 & 50,5 & 49,2 & 47,9 & 45,2 & 43,9 & 42,6 & 41,2 & 39,9 & 37.2 & 35,9 & 34,6 & 31,9 & 33,5 \\
\hline 34,0 & 63,8 & 61,2 & 59,9 & 58,5 & 57,2 & 55,9 & 54,5 & 51,2 & 50,5 & 49,2 & 47,9 & 46,6 & 43,9 & 42,6 & 41,2 & 39.9 & 38,6 & 35.9 & 34,6 & 33,3 & 30,6 & 34,0 \\
\hline 34,5 & 62,5 & 59,9 & 58,5 & 57,2 & 55,9 & 54,5 & 53.2 & 50,5 & $4 \overline{9}, 2$ & 47,9 & 46,6 & 45,2 & 42,6 & 41,2 & 39,9 & 38.6 & 35,9 & 34.6 & 33,3 & 31,9 & 29,3 & 34,5 \\
\hline 35,0 & 61,2 & 58,5 & 57.2 & 55,9 & 54,5 & 53,2 & 51,2 & 49,2 & 47,9 & 46,6 & 45,2 & 43,9 & 41,2 & 39,9 & 38,6 & 37,2 & 34,6 & 33,3 & 31,9 & 29,3 & 27,9 & 35,0 \\
\hline 35,5 & 59,9 & 58,5 & 55,9 & 54,5 & 53,2 & 51,2 & 50,5 & 47,9 & 46,6 & 45,2 & 43,9 & 42,6 & 39,9 & 38,6 & 37,2 & 35,9 & 33,3 & 31,9 & 30,6 & 27,9 & 26,6 & 35,5 \\
\hline 36,0 & 58,5 & 57,2 & 55,9 & 43,2 & 51,2 & 50,5 & 49,2 & 47,9 & 45,2 & 43,9 & 42,6 & 41,2 & 38,6 & 37,2 & 35,9 & 34,6 & 31,9 & 30,6 & 29,3 & 26,6 & 25,3 & 36,0 \\
\hline 36,5 & 57,2 & 55,9 & 54.5 & 51,2 & 50,51 & 49,2 & 47,9 & 46.6 & 43,9 & 42,6 & 41,2 & 39,9 & 37,2 & 35,9 & 34.6 & 31,9 & 30,6 & 29,3 & 26,6 & 25,3 & 23,9 & 36,5 \\
\hline 37,0 & 55,9 & 54,5 & 53,2 & 50,5 & 49.2 & 47,9 & 46,6 & 45,2 & 42,6 & 41,2 & 39,9 & 37,2 & 35,9 & 34,6 & 33,3 & 30,6 & 29,3 & 27,9 & 25,3 & 23,9 & 21,3 & 37,0 \\
\hline 37,5 & 54,5 & 53,2 & $5 i, 2$ & 49,2 & 47,9 & 46,6 & 45,2 & 42,6 & 41,2 & 39,9 & 38,6 & 35,9 & 34.6 & 33,3 & 31,9 & 29,3 & 27,9 & 25,3 & 23,9 & 22,6 & 20,0 & 37,5 \\
\hline 38,0 & 53,2 & 51,2 & 50,5 & 47,9 & 46,6 & 45,2 & 43,9 & 41,2 & 39.9 & 38,6 & 37,2 & 34,6 & 33,3 & 31,9 & 29,3 & 27,9 & 26,6 & 23,9 & 22,6 & 20,0 & 18,6 & 38,0 \\
\hline 38,5 & 51,2 & 50,5 & 49,2 & 46,6 & 45,2 & 43,9 & 42,6 & 39,9 & 38,6 & 37,2 & 35.9 & 33,3 & 31,9 & 30.6 & 27,9 & 26,6 & 23,9 & 22,6 & 21,3 & 18,6 & 17,3 & 38,5 \\
\hline 39,0 & 50,5 & 49,2 & 47,9 & 45,2 & 43,9 & 42,6 & 41,2 & 38,6 & 37,2 & 35,9 & 34,6 & 31,9 & 30,6 & 27,9 & 26,6 & 25,3 & 22,6 & 21,3 & 18,6 & 17,3 & 16,0 & 39.0 \\
\hline 39,5 & 49,2 & 47,9 & 46,6 & 43,9 & 42,6 & 41,2 & 39,9 & 37,2 & 35,9 & 34,6 & 31,9 & 30,6 & 29,3 & 26.6 & 25,3 & 22,6 & 21,3 & 20,0 & 17.3 & 16,0 & 13,3 & 39,5 \\
\hline 40,0 & 47,9 & 46,6 & 45,2 & 42.6 & 41,2 & 39,9 & 37,2 & 35,9 & 34,6 & 31,9 & 30,6 & 29,3 & 26,6 & 25,3 & 23,9 & 21,3 & 20,0 & 17,3 & 16,0 & 13,3 & 12,0 & 40,0 \\
\hline 40,5 & 46,6 & 45,2 & 43,9 & 41,2 & 39,9 & 38,6 & 35,9 & 34,6 & 33,3 & 30,6 & 29,3 & 27,9 & 25,3 & 23,9 & 21,3 & 20,0 & 18,6 & 16,0 & 14,6 & 12,0 & 10,6 & 40,5 \\
\hline 41,0 & 45,2 & 43,9 & 42,6 & 39.9 & 38.6 & 37,2 & 34,6 & 33,3 & 31,9 & 29,3 & 27,9 & 25,3 & 23,9 & 22,6 & 20,0 & 18,6 & 16,0 & 14,6 & 12,0 & 10,6 & 8,0 & 41,0 \\
\hline 41,5 & 43,9 & 42,6 & 39,9 & 38,6 & 37,2 & 35,9 & 33,3 & 31,9 & 29,3 & 27,9 & 26,6 & 23,9 & 22,6 & 20,0 & 18,6 & 16,0 & 14,6 & 13,3 & 10,6 & 8,0 & 6,7 & 41,5 \\
\hline 42,0 & 42,6 & 39,9 & 38,6 & 37,2 & 35,9 & 33,3 & 31.9 & 30,6 & 27,9 & 26,6 & 23,9 & 22,6 & 21,3 & 18,6 & 17,3 & 14,6 & 13,3 & 10,6 & 9,3 & 6,7 & 5,3 & 42,0 \\
\hline
\end{tabular}

- Valeur limite d'entretien pour petits dëplacements de l'U.B.T.

----Valeur limite d'entretien pour grands déplacements de l'U.B.T. 
TABLEAU 8

Légunineuses (matières azotées digestibles)

\begin{tabular}{|c|c|c|c|c|c|c|c|c|c|}
\hline M.A.B. & M.A.D. & M.A.B. & M.A.D. & M.A.B. & M.A.D. & M.A.B. & M.A.D. & M.A.B. & M.A.D. \\
\hline 11,0 & 6,9 & 15,0 & 10,9 & 18,5 & 14,4 & 22,0 & 17,9 & 25,5 & 21,4 \\
\hline 11,2 & 7,1 & 15,1 & 11,0 & 18,6 & 14,5 & 22,1 & 18,0 & 25,6 & 21,5 \\
\hline 11,4 & 7,3 & 15,2 & $11, I$ & 18,7 & 14,6 & 22,2 & 18,1 & 25,7 & 21,6 \\
\hline 11,6 & 7,5 & 15,3 & 11,2 & 18,8 & 14,7 & 22,3 & 18,2 & 25,8 & 21,7 \\
\hline 11,8 & 7,7 & 15,4 & 11,3 & 18,9 & 14,8 & 22,4 & 18,3 & 25,9 & 21,8 \\
\hline 12,0 & 7,9 & 15,5 & 11,4 & 19,0 & 14,9 & 22,5 & 18,4 & 26,0 & 21,9 \\
\hline 12,1 & 8,0 & 15,6 & 11.5 & 19,1 & 15,0 & 22,6 & 18,5 & 26,1 & 22,0 \\
\hline 12,2 & 8,1 & 15,7 & 11,6 & 19,2 & 15,1 & 22,7 & 18,6 & 26,2 & 22,1 \\
\hline 12,3 & 8,2 & 15,8 & 11,7 & 19,3 & 15,2 & 22,8 & 18,7 & 26,3 & 22,2 \\
\hline 12,4 & 8,3 & 15,9 & 11,8 & 19,4 & 15,3 & 22,9 & 18,8 & 26,4 & 22,3 \\
\hline 12,5 & 8,4 & 16,0 & $11,9^{\circ}$ & 19,5 & 15,4 & 23,0 & $.18,9$ & 26,5 & 22,4 \\
\hline 12,6 & 8,5 & 26,1 & 12,0 & 19,6 & 15,5 & 23,1 & 19,0 & 26,6 & 22,5 \\
\hline 12,7 & 8,6 & 16,2 & 12,1 & 19,7 & 15,6 & 23,2 & 19,1 & 26,7 & 22,6 \\
\hline 12,8 & 8,7 & 16,3 & 12,2 & 19,8 & 15,7 & 23,3 & 19,2 & 26,8 & 22,7 \\
\hline 12,9 & 8,8 & 16,4 & 12,3 & 19,9 & 15,8 & 23,4 & 19,3 & 26,9 & 22,8 \\
\hline 13,0 & 8,9 & 16,5 & 12,4 & 20,0 & 15,9 & 23,5 & 19,4 & 27,0 & 22,9 \\
\hline 13,1 & 9,0 & 16,6 & 12,5 & 20,1 & 16,0 & 23,6 & 19,5 & 27,1 & 23,0 \\
\hline 13,2 & 9,1 & 16,7 & 12,6 & 20,2 & 16,1 & 23,7 & 19,6 & 27,2 & 23,1 \\
\hline 13,3 & 9,2 & 16,8 & 12,7 & 20,3 & 16,2 & 23,8 & 19,7 & 27,3 & 23,2 \\
\hline 13,4 & 9,3 & 16,9 & 12,8 & 20,4 & 16,3 & 23,9 & 19,8 & 27,4 & 23,3 \\
\hline 13,5 & 9,4 & 17,0 & 12,9 & 20,5 & 16,4 & 24,0 & 19,9 & 27,5 & 23,4 \\
\hline 13,6 & 9,5 & 17,1 & 13,0 & 20,6 & 16,5 & 24,1 & 20,0 & 27,6 & 23,5 \\
\hline 13,7 & 9,6 & 17,2 & 13,1 & 20,7 & 16,6 & 24,2 & 20,1 & 27,7 & 23,6 \\
\hline 13,8 & 9,7 & 17,3 & 13,2 & 20,8 & 16,7 & 24,3 & 20,2 & 27,8 & 23,7 \\
\hline 13,9 & 9,8 & 17,4 & 13,3 & 20,9 & 16,8 & 24,4 & 20,3 & 27,9 & 23,8 \\
\hline 14,0 & 9,9 & 17.5 & 13,4 & $, 21,0$ & 16,9 & 24,5 & 20,4 & 28,0 & 23,9 \\
\hline 14,1 & 10,0 & 17,6 & 13,5 & 21,1 & 17,0 & 24.6 & 20,5 & 28,2 & 24,1 \\
\hline 14,2 & 10,1 & 17,7 & 13,6 & 21,2 & 17,1 & 24,7 & 20,6 & 28,4 & 24,3 \\
\hline 14,3 & 10,2 & 17,8 & 13,7 & 21,3 & 17,2 & 24,8 & 20,7 & 28,6 & 24,5 \\
\hline 14,4 & 10,3 & 17,9 & 13,8 & 21,4 & 17,3 & 24,9 & 20,8 & 28,8 & 24,7 \\
\hline 14,5 & 10,4 & 18,0 & 13,9 & 21,5 & 17,4 & 25,0 & 20,9 & 29,0 & 24,9 \\
\hline 14,6 & 10,5 & 18,1 & 14,0 & 21,6 & 17,5 & 25,1 & 21,0 & 29,2 & 25,1 \\
\hline 14,7 & 10,6 & 18,2 & 14,1 & 21,7 & 17,6 & 25,2 & 21,1 & 29,4 & 25,3 \\
\hline 14,8 & 10,7 & 18,3 & 14,2 & 21,8 & 17,7 & 25,3 & 21,2 & 29,6 & 25,5 \\
\hline \multirow[t]{2}{*}{14,9} & 10,8 & 18,4 & 14,3 & 21,9 & 17,8 & 25,4 & 21,3 & 29,8 & 25,7 \\
\hline & & & & & & & & 30,0 & 25,9 \\
\hline
\end{tabular}


En appliquant le calcul des tables hollandaises à ces deux exemples, ces fourrages ne couvrent pas les besoins d'une ration avec grands déplacements. Les pailles sous pâture fournissent $2,4 \cup$. F. et en défens $2,9 \cup . F$.

Les plantes consommées par le bétail, sur sol non inondable, ne contenant généralement pas plus de 10 p. 100 de silice, ce taux de silice peut être considéré comme maximal et une correction peut être appliquée, en ramenant la composition du fourrage souillé de sable à 10 p. 100 de silice.

\section{Correction :}

Silice réelle : 37,9 p. 100

Silice théorique : 10,0 p. 100

Différence : 27,9 p. 100

Matières minérales théoriques :

$$
43,1-27,9=15,2
$$

Somme des éléments nutritifs :

$$
100-43,1=56,9
$$

Somme théorique des éléments nutritifs :

$$
100-15,2=84,8
$$

Matières protéiques brutes théoriques :

$$
\frac{3,56 \times 84,8}{56,9}=5,30
$$

Cellulose théorique : $\frac{20,90 \times 84,8}{56,9}=31,14$.

Ces nouvelles valeurs fournissent une valeur fourragère de $0,54 \mathrm{U}$. F. ef $25,8 \mathrm{~g}$ de $M$. A. D., pour le produit débarrassé du sable.

Mais lorsque l'animal ingère ce fourrage au pâturage, sur 97,4 parties de matière sèche, il y a 27,9 parties de sable.

Sur les $6,25 \mathrm{~kg}$ de matière sèche de la ration, il $y$ a donc $\frac{27,9 \times 6,25}{94,4}=1,84 \mathrm{~kg}$ de sable et il reste $6,25-1,84=4,41 \mathrm{~kg}$ de matıères nutritives sèches, soit $\frac{100 \times 4,41}{97,4}=4,52 \mathrm{~kg}$ d'aliment représentant : 2,4 U. F. $(2,44)$ et $117 \mathrm{~g}$ de M. A. D. $(116,6)$.

La ration théorique ne renfermant que $4,41 \mathrm{~kg}$ d'aliment net, sa valeur calculée sur les bases de l'équivalent-ration est également de :

$$
0,55 \times 4,41=2,4 \text { U. F. }
$$

ef : $27 \times 4,41=119 \mathrm{~g}$ de M. A. D.

Les résultats obtenus avec correction sont comparables aux résultats précédents et il n'est donc pas nécessaire d'effectuer ces calculs supplémentaires. En effet :

$6,25 \mathrm{~kg}$ de M.S. $=6,42 \mathrm{~kg}$ de fourrage à 2,60 p. 100 d'humidité.

$6,42 \times 0,38=2,44$ U. F.

$6,42 \times 18=115,6 \mathrm{~g}$ de M. A. D.

\section{III. - APPRÉCIATION DES PATURAGES ET ANALYSES FOURRAGËRES}

10 Application aux fourrages des Pays tempérés :

Pour comparer avec profit la valeur des parcours tropicaux et les plantes fourragères des pays tempérés, les calculs de l'Equivalent-ration ont été appliqués à la valeur fourragère des principales espèces citées dans les tables de Kellner (in 39 p. 160-5) (Tableau 9).

Légumineuses,

Le faux de matière sèche oscille entre 18,5 et 24 p. 100 ,

les matières azotées brutes entre 16,2 ef 29,6 p. 100 de M. S.,

la cellulose entre 28,0 et 34,5 p. 100 de M. S., les matières mınérales entre 6,0 ef 11,5 p. 100 de M. S.

L'équivalent-ration est toujours supérieur aux valeurs nécessaires à l'entretien de I'U. B. T. avec grands déplacements et les rapports M. A. D. allant de 125 à 200 sont favorables à la U. F. production de lait.

Graminées de pâture.

Le taux de matière sèche oscille entre 16 ef 46 p. 100 ,

les matières azotées brutes entre 7,3 et 20,6 p. 100 de M. S., la cellulose entre 18,3 et 40 p. 100 de M. S., les matières minérales entre 6 et 11,2 p. 100 de M. S.

L'équivalent-ration est toujours suffisant pour assurer l'entretien de I'U. B. T. avec grands

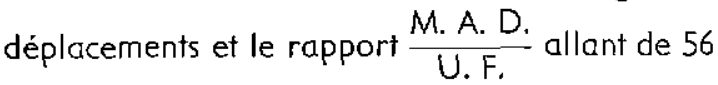
à 127 est très satisfaisant.

Foins.

Le taux de matière sèche est toujours voisin de 85 p. 100 , 
Retour au menu

TABLEAU 9

Extrait des tables de 0 . Kellner

\begin{tabular}{|c|c|c|c|c|c|c|c|c|c|}
\hline \multirow{2}{*}{$\cdot$} & \multirow{2}{*}{$\begin{array}{l}\text { Matière } \\
\text { sêche } \\
\text { p.100 }\end{array}$} & \multirow{2}{*}{$\begin{array}{l}\text { M.A.B. } \\
\text { P.100 } \\
\text { M.S. }\end{array}$} & \multirow{2}{*}{$\begin{array}{l}\text { Cellulose } \\
\text { p.100 } \\
\text { M.S. }\end{array}$} & \multirow{2}{*}{$\begin{array}{c}\text { Matiēre } \\
\text { minérale } \\
\text { p.100 } \\
\text { M.S. }\end{array}$} & \multicolumn{3}{|c|}{ Valeñ fourragère } & \multicolumn{2}{|c|}{ Equivalent ration } \\
\hline & & & & & $\mathrm{U}, \mathrm{F} \cdot / \mathrm{kg}$ & M.A.D. & $\frac{\text { M.A.D. }}{\text { U.F. }}$ & U.F. & M.A.D. \\
\hline \multicolumn{10}{|l|}{ Lëguminelises } \\
\hline Trèfle blanc, au début de la floraison & 18,5 & 23,78 & 23,24 & 11,4 & 0,12 & 19 & 158 & 0,65 & 103 \\
\hline Luzerne très jeune & 18,9 & 29,62 & 23,28 & 10,1 & 0,13 & 27 & 208 & 0,69 & 143 \\
\hline Sainfoin au début de la floraison & 19,0 & 18,94 & 28,94 & 7,4 & 0,13 & 19 & 146 & 0,68 & 100 \\
\hline Sanfoun en plcine floraison & 20,0 & 17,50 & 34,50 & 6,0 & 0,10 & 16 & 160 & 0,50 & 80 \\
\hline Trèrle rouge, en pleine floraison & 21,0 & 16,19 & 28,09 & 7,6 & 0,12 & 17 & 142 & 0,57 & 81 \\
\hline Luzerne avant la floraison & 24,0 & 18,75 & 28,33 & 9,6 & 0,13 & 17 & 130 & 0,54 & 71 \\
\hline Luzerne en pleine floraison & 24,0 & 16,25 & 32,50 & 9,2 & 0,12 & 15 & 125 & 0,50 & 62 \\
\hline \multicolumn{10}{|l|}{ Graminées de pâture } \\
\hline Avoine à 1 'êpiage & 16,1 & 14,28 & 23,60 & 9,3 & 0,11 & 14 & 127 & 0,68 & 87 \\
\hline Herbe de bonne prairie irriguée & 19,2 & 18,22 & 25,52 & 8,9 & 0,14 & 13 & 93 & 0,73 & 68 \\
\hline Herbe de pâturage ordinaire & 20,0 & 17,50 & 20,00 & 10,0 & 0,15 & 17 & 113 & 0,75 & 85 \\
\hline Dactyle pelotonne avant la floraison & 20,4 & 11,27 & 23,52 & 9,3 & 0,14 & 8 & 57 & 0,69 & 39 \\
\hline Herbe de pâturage d'engraissement & 21,8 & 20,64 & 18,34 & 10,1 & 0,19 & 23 & 121 & 0,87 & LOS \\
\hline Ray grass anglais pendant la floraison & 24,8 & 11,69 & 28,62 & 10,5 & $0,1 / 4$ & 13 & 93 & 0,56 & 52 \\
\hline Ray grass d'Italie pendant la floraison & 25,0 & 13,60 & 24,80 & 11,2 & 0,15 & 13 & 87 & 0,60 & 52 \\
\hline Herbe de pâturage, peu avant la floraison & 25,0 & 12,00 & 24,00 & 8,4 & 0,17 & 15 & 88 & 0,68 & 60 \\
\hline Dactyle pelotonné pendant la floraison & 27,0 & 9,25 & 27,03 & 7,8 & 0,17 & 10 & 59 & 0,63 & 37 \\
\hline Herbe de prafrie douce, pendant la floraison & 30,0 & 10,33 & 30,66 & 7,0 & 0,19 & 13 & 68 & 0,63 & 43 \\
\hline Avoine élevée & 31,5 & 10,78 & 32,02 & 9,2 & 0,20 & 17 & 85 & 0,63 & 54 \\
\hline Fléole des prês pendant la floraison & 33,1 & 9,36 & 27,79 & 6,3 & 0,18 & 10 & 56 & 0,54 & 30 \\
\hline Avoine mûre & 46.4 & 7,32 & 40,08 & 6,0 & 0,24 & 21 & 88 & 0,52 & 45 \\
\hline \multicolumn{10}{|l|}{ Folns } \\
\hline Foin de prë excellent & 85,2 & 13,46 & 26,33 & 9,8 & 0,63 & 56 & 89 & 0,74 & 66 \\
\hline Foin de pré mëdiocre & 85,7 & 8,70 & 38,86 & 5,8 & 0,28 & 25 & 89 & 0,33 & 29 \\
\hline \multicolumn{10}{|l|}{ Pailles } \\
\hline Paille d'avoine & 85,7 & 4,41 & 44,89 & 6,6 & 0,29 & 10 & 34 & 0,34 & 12 \\
\hline Paille d'orge de printemps & 85,7 & 4,06 & 45,82 & 6,3 & 0,34 & 6 & 18 & 0,40 & $i$ \\
\hline Pallle de blé d'hiver & 85,7 & 3,48 & 47,33 & 5,6 & 0,21 & 4 & 19 & 0,24 & 5 \\
\hline
\end{tabular}


les matières azotées brutes oscillant entre 8 ef 13 p. 100 de M. S.,

la cellulose entre 26 et 39 p. 100 de M. S., les matières minérales entre 6 et 10 p. 100 de M. S.

Avec un rapport $\frac{M . A . D .}{U . F .}$ de 89 , I'équivalentration est satisfaisant pour les $M$. A. D. mais il est insuffisant en énergie pour le foin de pré médiocre,

\section{Pailles.}

Le taux de matière sèche est toujours voisin de 85 p. 100 ,

les matières azotées brutes oscillent entre 3,5 et 4,4 p. 100 de M. S.,

la cellulose entre 45 et 47 p. 100 de M. S., les matières minérales entre 5,5 et 6,5 p. 100 de M. S.

Rapport $\frac{M . A . D .}{U . F .}$ et équivalent-ration dénotent l'insuffisance des pailles pour assurer l'entretien de I'U. B. T.

\section{$2^{\circ}$ Application aux pâfurages intertropicaux.}

Les parcours de la zone intertropicale concernent 2 grands types physionomiques de végétation : la steppe et la savane.

La steppe (36) est une formation herbeuse parfois parsemée de plantes ligneuses. Les gramtnées vivaces y sont largement espacées et ne dépassent pas $80 \mathrm{~cm}$ de hauteur. Leurs feuilles sont étroites, enroulées ou pliées, principalement basilaires. Les plantes annuelles sont souvent abondantes entre les plantes vivaces.

La savane (36) est une formation herbeuse comportant une strate herbacée supérieure, continue, d'au moins $80 \mathrm{~cm}$ de hauteur et une strate inférieure sous-jacente. Les graminées sont à feulles planes, basilaires et caulinaires; ces graminées brûlent ordinairement chaque année. Les plantes ligneuses sont généralement présentes.

\section{A. Parcours de steppe.}

En Afrique intertropicale, la steppe se rencontre surtout sous clımat sahélo-saharien (1) caractérisé par une pluviosité de 200 à $400 \mathrm{~mm}$ : elle émet des prolongements jusqu'à l'isohyète $150 \mathrm{~mm}$ au Nord et l'isohyète $550 \mathrm{~mm}$ au Sud.
Sous climat désertique saharien (1), caractérisé par une pluviosité inférieure (150-200 mm), répartie en tornades accidentelles, en juiliet et août, la végétation du domaine Sahara-Sindien est de type contracté avec rassemblement des espèces ligneuses (Acacio roddiana) dans les lits des ouadi et développement d'une steppe subdésertique sur les formations sableuses adjacentes avec des touffes d'Aristida plumoso, Aristida pungens ef Ponicum turgidum.

Sous climat subdésertique sahélo-saharien (1), caractérısé par une pluviosité de 200 à $300 \mathrm{~mm}$ répartie de juillet à septembre, la végétation du secteur sahélo-saharien du domaine sahélien est une steppe à graminées annueltes clairsemées (Aristida mutabilis) et à touffes de graminées vivaces (Panicum turgidum). Les arbustes y sont représentés par Acacia roddiana et Commiphora africono.

Le sud du climat sahélo-saharien avec 300 à $400 \mathrm{~mm}$ de pluie est favorable à la steppe. Les graminées annuelles y constituent un tapis dense (Aristida mutabilis sur dunes et Schoenefeldia gracllis sur bas de pente). Les graminées vivaces $y$ sont moins abondantes et plutît localisées sur les dunes à relief prononcé (Aristida longiflora). Les arbustes sont abondants (Acocia senegal et Acocio raddiana).

Entre les isohyètes 400 et $550 \mathrm{~mm}$, au Nord du climat tropical sec sahélo-soudanais (1), la steppe à Aristida mutabilis et Eragrostis tremula ovec Acacia senegal et Acacia albida fait souvent place à une savane constituée par des touffes d'Hyparrhenio dissoluta. Cympobogon giganteus et Andropogon gayanus et un tapis d'espèces annuelles (Aristida mulabilis, Schizachyrium exile).

a) Exploitation de cette végétation.

La steppe subdésertique du climat saharien est strictement exploitée par l'élevage nomade, les chameaux étant dirigés vers les pâturages qui se développent au gré des tornades.

Sous climat sahélo-saharien, I'élevage de type transhumant est la spéculation essentielle des habitants. Pendant la saison des pluies, les troupeaux éclatent, s'abreuvent aux mares temporaire set remontent le plus possible vers le nord en suivant le front de verdure. En fin des pluies, ils redescendent vers le sud et se concentrent progressivement aux abords des bas-fonds où l'eau de la nappe phréatique est exploitée par des trous 
de quelques mètres et ensuite, près des puits de plus en plus profonds.

Au Nord du clımat sahélo-soudanais, la population sédentaire cultive arachides et mil à chandelles. Les troupeaux n'y transhument qu'après les récoltes, consommant les résıdus de cultures (pallles de mil, restes de fones d'arachides), les repousses des graminées vivaces de la savane et les prairles aquatiques (bourgou) des mares temporaires et du lit majeur des grands fleuves (Sénégal, Niger).

b) Potentiel fourrager de la steppe.

Les bovins se trouvent en présence de jeunes pousses de graminées au début de la saison des pluies, mais ces graminées atteignent rapidement les stades montaison, floraison, fructification. Dès le début de la saison sèche le tapis graminéen n'offre plus que des pailles sèches et des inflorescences d'espèces annuelles, ef des repousses d'espèces vivaces. Les bovins recherchent alors, un complément de ration dans les feuilles, les fleurs ou les fruits d'espèces ligneuses.

La synthèse des études bromatologiques réalisées à I'I. E. M. V. T. dans cette zone : (2), (8), (22), (31), (32), (33), (34) aboutit au tableau récapitulatif ou sont indiqués (tableau $n^{0} 10$ ):

- l'époque de prélèvement et de consommation,

- la plante ef ses parties consommées,

- le nombre d'analyses ayant servi à l'établissement de la valeur moyenne,

- le taux de matières sèches en p. 100,

- le taux de matières azotées brutes en p. 100 de matière sèche, sèche,

- le taux de cellulose en p. 100 de matière

- le taux de matières mınérales en p. 100 de matière sèche,

- la valeur fourragère du $\mathrm{kg}$ de fourrage en U. F., les M. A. D. et le rapport $\frac{M . A . D}{U . F .}$,

- l'équivalent-ration d'un $\mathrm{kg}$ de $M . S$. de l'aliment en U. F. et M. A. D.

En saison des plutes.

Aux premières pluies, les animaux s'abreuvent aux flaques d'eau formées au cours des tornades, leurs déplacements sont limités et leur besoin d'entretien réduit à 0,43 U. F. et $24 \mathrm{~g}$ de M. A. D par $\mathrm{kg}$ de matière sèche ingérée.
Les jeunes plantes consommées à cette période autorisent un gain de poids de $500 \mathrm{~g} /$ jour ou une production laitière de plus de $3 \mathrm{I}$.

Ces fourrages présentent un excès de M. A. D. de plus de $50 \mathrm{~g}$ par $\mathrm{kg}$ de matière sèche et ce déséquilibre-peut être résorbé par la consommation d'une faible quantité de paille.

Dès que les pluies sont installées, les graminées annuelies lèvent et les espèces vivaces graminiformes (à port de gramınées incluant les Cyperacées), rejettent abondamment de souches; ces pousses sont recherchées par le bétail, autorisent gain de poids et production laitière, et ont l'avantage de présenter un équilibre U. F.-M. A. D. très favorable à la production laitière avec un

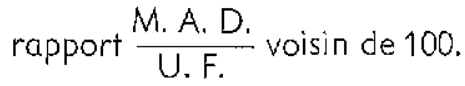

Les éleveurs recherchent d'ailleurs cette végétation le plus longtemps possible en conduisant leur troupeau vers le Nord, à mesure que s'avance le front de verdure.

Dès la pleme saison des pluies, les graminées annuelles forment leurs chaumes. Les espèces de dunes ne permettent plus qu'un gain de poids de $100 \mathrm{~g} /$ /jour ou une production laitière d'1 litre.

Les espèces d'ombre et de bas-fond, autorisent une grosse production de lat et de viande et leur excès de M.A.D. peut compenser le déficit des espèces de dunes. C'est d'alleurs à cette période de l'année qu'elles sont surtout recherchées par le bétail.

A la fin des pluies, vers le 15 coôt, les espèces graminiformes sont en floraison. Les graminées ne permettent plus qu'une production d'1 litre de lait ou 200 à $300 \mathrm{~g}$ de gain mais les cyperacées sont encore assez riches en protéines pour permettre une production de lait de 3 litres par jour.

En début de saison sèche, les espèces graminiformes sont en fructification mals permettent encore une production de 0,5 litre par jour ou un gain de $100 \mathrm{~g}$.

Quelques légumineuses, apparaissant tardivement dans la végétation, sont alors consommées comme espèces d'appoint. Elles fournissent une ration pouvant assurer une production de plus de 4 litres de lait par jour.

En pleine saison sèche.

La pleine saison sèche peut-être scindée en 3 périodes : 
TABLEAU 10

Pâturages de steppe

\begin{tabular}{|c|c|c|c|c|c|c|c|c|c|c|}
\hline \multirow{2}{*}{ Fourrages } & \multirow{2}{*}{$\begin{array}{l}\text { Nombre } \\
\text { analyse }\end{array}$} & \multirow{2}{*}{$\begin{array}{c}\text { Matière } \\
\text { sêche } \\
\text { p.100 }\end{array}$} & \multirow{2}{*}{$\begin{array}{c}\text { M.A.B. } \\
\text { P.100 } \\
\text { M.S. }\end{array}$} & \multirow{2}{*}{$\begin{array}{c}\text { CeIlulose } \\
\text { P.100 } \\
\text { M.S. }\end{array}$} & \multirow{2}{*}{$\begin{array}{l}\text { Matiêre } \\
\text { minêrale } \\
\text { p.ioo } \\
\text { M.S. } \\
\end{array}$} & \multicolumn{3}{|c|}{ Valeur fourragère } & \multicolumn{2}{|c|}{$\begin{array}{c}\text { Equivalent } \\
\text { ration }\end{array}$} \\
\hline & & & & & & U.F. $/ \mathrm{kg}$ & $\begin{array}{l}11 . \bar{A} \cdot \mathrm{D} \\
\mathrm{g} / \mathrm{kg}\end{array}$ & $\frac{\overline{M . A . D_{0}}}{\text { U..F. }}$ & U.F. & M.A.D. \\
\hline $\begin{array}{l}\text { 1. PREMITRES PLUIES : Soudure } \\
\text { Pailles de graminées dures } \\
\text { Jeunes plantes } \\
\text { (gtade } 3 \text { feul1les) }\end{array}$ & 22 & 94,60 & 2,11 & 41,31 & 9,3 & 0,33 & 1,0 & 3 & 0,35 & 1 \\
\hline Iribulus terrestris & 2 & 23,33 & 15,25 & 19,98 & 23,3 & 0,17 & 25,7 & 151 & 0,71 & 110 \\
\hline $\begin{array}{l}\text { Conmelina forskalaei } \\
\text { 2. DEBUT DES PLUIES } \\
\text { (avant } 15 \text { juillet) } \\
\text { Feuilles basilaires } \\
\text { (sp.vivaces gramlniformes) }\end{array}$ & 2 & 26,55 & 19,38 & 23,23 & 15,4 & 0,20 & 39,8 & 199 & 0,76 & 150 \\
\hline Cyperus roturdus & 1 & 15,50 & 20,98 & 23,00 & 15,6 & 0,12 & 25,6 & 213 & 0,77 & 165 \\
\hline Cuperus conglomeratus & 1 & 24,05 & 10,47 & 27,75 & 15,7 & 0,15 & 15,7 & 104 & 0,65 & 65 \\
\hline $\begin{array}{l}\text { Andropogon gayanus } \\
\text { Graminées annue11es }\end{array}$ & 3 & 26,53 & 10,99 & 29,55 & 9,0 & 0,19 & 18,6 & 98 & 0,71 & 70 \\
\hline $\begin{array}{l}\text { Aristida sp. } \\
\text { 3. PLEINE SAISON DES PLUIES } \\
\text { (15 juillet - I5 août) } \\
\text { Graminées } \\
\text { (stade monta1son) } \\
\text { sp.d'ombre et bas-fond }\end{array}$ & 2 & 33,95 & 7,89 & 35,20 & 8,1 & 0,19 & 13,6 & 32 & 0,55 & 40 \\
\hline $\begin{array}{l}\text { Brachiaria sp. } \\
\text { Eohinochloa colonum } \\
\text { sp. de dunes }\end{array}$ & 5 & 22,00 & 15,44 & 25,85 & 16,3 & 0,15 & 24,6 & 164 & 0,69 & 112 \\
\hline Aristida mutabilite & 2 & 32,65 & 12,59 & 33,65 & 14,1 & 0,16 & 27,8 & 173 & 0,50 & 85 \\
\hline $\begin{array}{l}\text { Aristida funicuitata } \\
\text { 4. FIN DES PLUIES } \\
\text { (E1n août) } \\
\frac{\text { sp.graminiformes en }}{\text { floratsan }} \\
\text { espèces de dunes }\end{array}$ & 2 & 34,33 & 10,30 & 34,13 & 11,7 & 0,18 & 21,6 & 120 & 0,51 & 63 \\
\hline Dactyloctenium aegyptium & 1 & 29,10 & 7,67 & 32,10 & 9,2 & 0,18 & 11,1 & 62 & 0,63 & 38 \\
\hline Tragus racemosus & 1 & 40,45 & 6,83 & 34,40 & 10,4 & 0,22 & 13,8 & 63 & 0,54 & 34 \\
\hline Axistida mutabilis & 6 & 33,17 & 7,73 & 34,54 & 8,9 & 0,19 & 12,8 & 67 & 0,56 & 39 \\
\hline $\begin{array}{l}\text { Cyperus conglomeratus } \\
\text { espèces de faciès très } \\
\text { pâturê }\end{array}$ & 1 & 26,60 & 11,25 & 30,70 & 8,4 & 0,18 & 19,2 & 106 & 0,69 & 72 \\
\hline $\begin{array}{l}\text { Cenchrus biflorus } \\
\text { espèces de couloirs } \\
\text { interdunaires }\end{array}$ & 3 & 26,55 & 8,64 & 34,10 & 13,5 & 0,13 & 12,5 & 96 & 0,50 & 47 \\
\hline Sohoenefetdia gracitis & 1 & 37,75 & 5,49 & 37,75 & 8,8 & 0,18 & 10,2 & 57 & 0,47 & 27 \\
\hline Cyperus rotundus & 1 & 28,55 & 9,11 & 21,35 & 11,4 & 0,25 & 14,8 & 59 & 0,87 & 52 \\
\hline
\end{tabular}




\begin{tabular}{|c|c|c|c|c|c|c|c|}
\hline 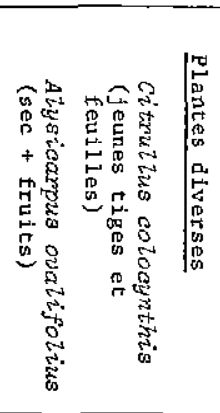 & 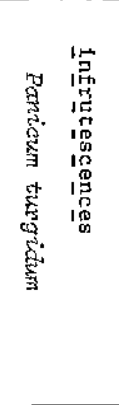 & 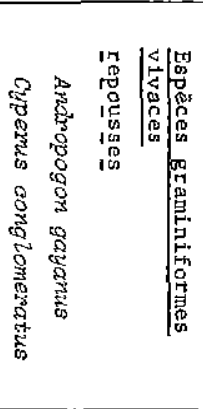 & 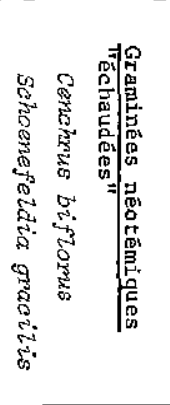 & 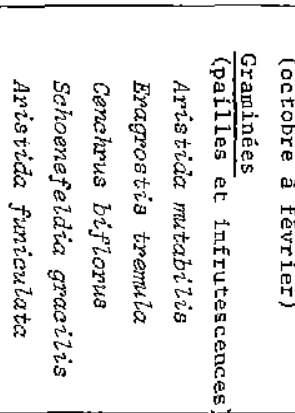 & 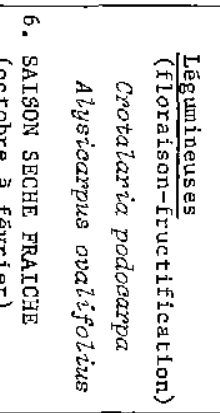 & 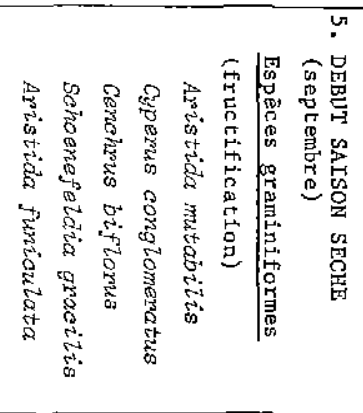 & 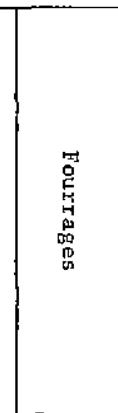 \\
\hline$r N$ & $n$ & $\omega=$ & $r$ & $5 \infty+f$ & $N$ & H w w o w o n & 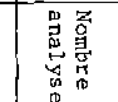 \\
\hline 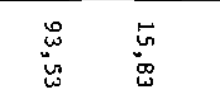 & $\stackrel{\stackrel{\sim}{N}}{\sim}$ & 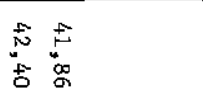 & 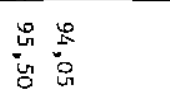 & 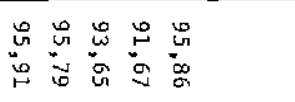 & 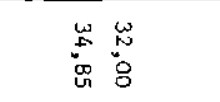 & 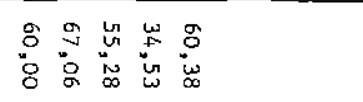 & 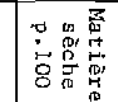 \\
\hline 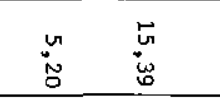 & $\stackrel{\infty}{\infty}$ & 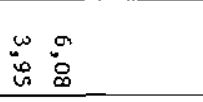 & $\stackrel{0}{\circ}$ & 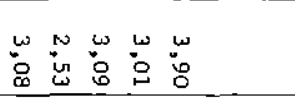 & 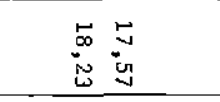 & 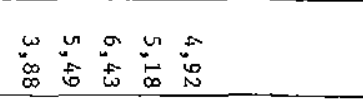 & 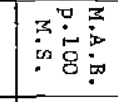 \\
\hline 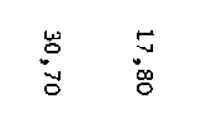 & $\stackrel{\Psi}{\ddot{~}}$ & 出 & 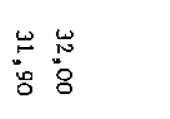 & 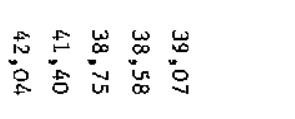 & 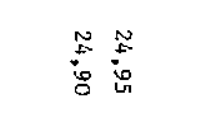 & 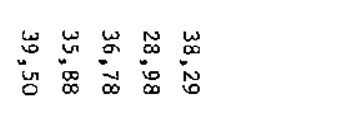 & 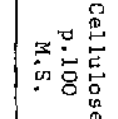 \\
\hline$\stackrel{\square}{\sim} \stackrel{5}{\square}$ & $\stackrel{\infty}{\omega}$ & $\stackrel{\infty}{\sim} \underset{\sim \infty}{\infty}$ & 点志 & 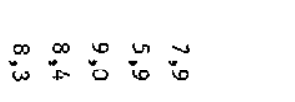 & 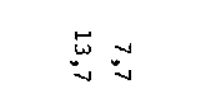 & $\therefore$ & 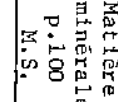 \\
\hline$\stackrel{\circ}{\circ}$ & 品 & 品 & 总品 & 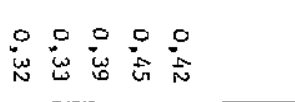 & 品总 & 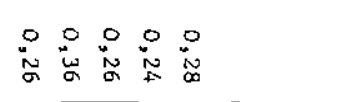 & 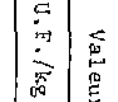 \\
\hline 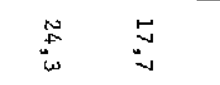 & $\underset{\infty}{\vec{N}}$ & $\infty$ & 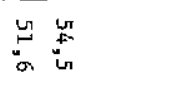 & 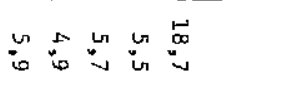 & 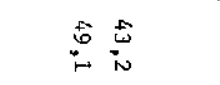 & 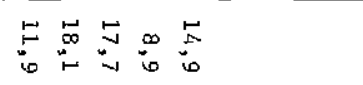 & 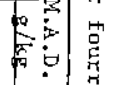 \\
\hline 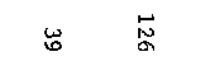 & 占 & $\ddot{\sim} \pm$ & $\stackrel{\circ}{\circ}$ & 品药它占占 & 号芯 & 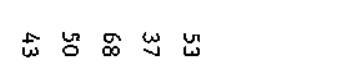 & (1) \\
\hline 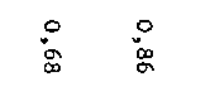 & 品 & $\begin{array}{l}\circ \\
\therefore\end{array}$ & $\therefore$ 品 & 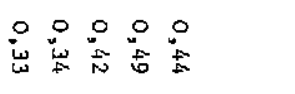 & $\stackrel{\circ}{\circ}$ & 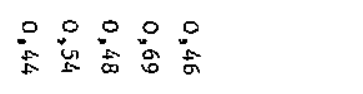 & 要 \\
\hline 品总 & $\approx$ & مै & $u_{\infty}$ & ด แก & 客点 & $\tilde{O} \tilde{\sim} \tilde{N} \widetilde{N}$ & $\int_{0}^{0}$ \\
\hline
\end{tabular}




\begin{tabular}{|c|c|c|c|c|c|c|c|c|c|c|}
\hline \multirow{2}{*}{ Fourrages } & \multirow{2}{*}{$\begin{array}{l}\text { Nombre } \\
\text { analyse }\end{array}$} & \multirow{2}{*}{$\begin{array}{c}\text { Mactère } \\
\text { sèche } \\
0.100\end{array}$} & \multirow{2}{*}{$\begin{array}{l}\text { M.A.B. } \\
\text { P.100 } \\
\text { M.S. }\end{array}$} & \multirow{2}{*}{$\begin{array}{c}\text { Cellulose } \\
\text { P.100 } \\
\text { M.S. } \\
\end{array}$} & \multirow{2}{*}{\begin{tabular}{|c|} 
Matière \\
minéra $1 \mathrm{e}$ \\
p.100 \\
M.S.
\end{tabular}} & \multicolumn{3}{|c|}{ Valeur fourragère } & \multicolumn{2}{|c|}{$\begin{array}{l}\text { Equivalent } \\
\text { ration }\end{array}$} \\
\hline & & & & & & U.F. $/ \mathrm{kg}$ & $\begin{array}{c}\text { M.A.D. } \\
\mathrm{g} / \mathrm{kg}\end{array}$ & \begin{tabular}{|l|} 
M.A.D. \\
U. \\
\end{tabular} & U.F. & M,A,D. \\
\hline $\begin{array}{l}\text { Mares gemi-permanentes } \\
\text { (repousses de graminées } \\
\text { aquatiques) }\end{array}$ & & & & & & & & & & \\
\hline oxyza barthii & 1 & 42,20 & 20,98 & 25,10 & 21,0 & 0,27 & 69,6 & 258 & 0,64 & 165 \\
\hline $\begin{array}{l}\text { Vossia cuspidata } \\
\text { Pâturages aêriens } \\
\text { Gousges vertes_et feuilless }\end{array}$ & 2 & 24,21 & 11,54 & 24,31 & 9,3 & 0,14 & 18,2 & 130 & 0,56 & 165 \\
\hline Salvadora persica & 1 & 27,40 & 16,27 & 14,85 & 30,2 & 0,20 & 32,9 & 165 & 0,73 & 120 \\
\hline Cadaba farinosa & 1 & 40,40 & 25,20 & 10,00 & 15,8 & 0,37 & 85,2 & 230 & 0,90 & 211 \\
\hline $\begin{array}{l}\text { Boseia senegalensis } \\
\text { Fru1tss_verts (pulpe) }\end{array}$ & 1 & 53,50 & 25,22 & 22,95 & 6,9 & 0,43 & 114,5 & 266 & 0,81 & 214 \\
\hline Acacia seyal & 1 & 35,70 & 19,65 & 19,95 & 6,2 & 0,31 & 55,3 & 178 & 0,86 & 155 \\
\hline $\begin{array}{c}\text { Acacia raddiana } \\
\text { Frults_nụ̂rs (pulpe) }\end{array}$ & 1 & 31,00 & 14,06 & 21,75 & 6,7 & 0,26 & 30,7 & 118 & 0,84 & 99 \\
\hline $\begin{array}{l}\text { Balanites aegyptiaca } \\
\text { 7. SAISON SECHE CHAUDE } \\
\text { (mars à ma1) } \\
\text { Pailies de graninées }\end{array}$ & 1 & 68,45 & 11,21 & 10,15 & 8,1 & 0,77 & 49,3 & 64 & 1,13 & 72 \\
\hline Aristida mutabilis & 9 & 95,11 & 2,10 & 40,97 & 9,0 & 0,34 & 1,0 & 3 & 0,36 & I \\
\hline Eragrostis tremula & 1 & 95,55 & 0,96 & 43,25 & 6,9 & 0,32 & 0,5 & 2 & 0,34 & $1 / 2$ \\
\hline Schoenefeldia gracilis & 9 & 93,51 & 2,33 & 41,73 & 8,5 & 0,32 & 1,0 & 3 & 0,35 & 1 \\
\hline $\begin{array}{l}\text { Aristida funiculata } \\
\frac{\text { Plantes diverses }}{\text { (Infrutescences sèches) }}\end{array}$ & 3 & 96,08 & 1,85 & 40,49 & 13,1 & $0,2 \mathrm{~B}$ & 1,0 & 4 & 0,29 & 1 \\
\hline $\begin{array}{l}\text { Blepharis Iineariffotia } \\
\text { pâturages aériens } \\
\text { Fruits_secs }\end{array}$ & 2 & 95,67 & 7,98 & 23,38 & 17,2 & 0,70 & 39,2 & 56 & 0,74 & 41 \\
\hline Acacia raddiana & 3 & 92,22 & 16,90 & 19,35 & 6,1 & 0,81 & 118,0 & 146 & 0,88 & 128 \\
\hline $\begin{array}{l}\text { Acacia senegal } \\
\text { Feutilies_sèches au_sol }\end{array}$ & 1 & 92,88 & 20,38 & 29,20 & 6,4 & 0,66 & 151,4 & 229 & 0,71 & 163 \\
\hline Grewia sp. & 1 & 84,20 & 7,37 & 17,80 & 14,2 & 0,76 & 31,0 & 41 & 0,90 & 37 \\
\hline Feretia apodanthera & 1 & 57,20 & 7,96 & 13,95 & 8,5 & 0.60 & 23,5 & 39 & 1,04 & 41 \\
\hline $\begin{array}{l}\text { Balanites aeguptiaca } \\
\text { 8. SAISON CHAUDE ET HUMIDE } \\
\text { (mai-juin) }\end{array}$ & 1 & 95,85 & 7,42 & 15,25 & 15,0 & 0,90 & 35,6 & 39 & 0,94 & 37 \\
\hline $\begin{array}{l}\text { Pailles de graminées } \\
\text { Pâturage aérien }\end{array}$ & 22 & 94,60 & 2,11 & 42,31 & 9,3 & 0,33 & 1,0 & 3 & 0,35 & 1 \\
\hline $\begin{array}{l}\text { Fruit } \\
\text { Acäoia albida } \\
\text { Pousses vertes_et jeunes } \\
\text { feuilites }\end{array}$ & 4 & 89,63 & 11,88 & 22,71 & 3,9 & 0,77 & 69,9 & 91 & 0,86 & $7 B$ \\
\hline Condia rothii & 1 & 41,65 & 10,78 & 17,65 & 16,0 & 0,36 & 28,3 & 79 & 0,88 & 68 \\
\hline $\begin{array}{l}\text { Balanites aegyptiaca } \\
\text { Extrémitës_de feulliles } \\
\text { de_edoum }\end{array}$ & 1 & 32,60 & 22,23 & 17,20 & 16,7 & 0,25 & 59,0 & 236 & 0,77 & 181 \\
\hline Byphaene thebaica & 1 & 42,75 & 6,91 & 28,25 & 11,4 & 0,30 & 14.7 & 49 & 0,70 & 35 \\
\hline
\end{tabular}


- une période fraîche d'octobre à février où les températures sont relativement basses :

- une période chaude de mars à mai où la température s'élève ;

- une période chaude et humide à partir de la mi-mai et jusqu'aux premières pluies où la température reste élevée et où l'humidité de l'aır s'élève favorisant la feuillaison et la floraison des espèces ligneuses.

Au cours de ces périodes, les troupeaux se déplacent beaucoup et les besoins d'entretien de I'U. B. T. atteignent $0,50 \mathrm{U}$. F. et $28 \mathrm{~g}$ de $M . A . D$. par $\mathrm{kg}$ de matière sèche ingérée.

Pendant la période fraiche de la saison sèche, seule la palle d'Eragrostis tremula peut combler les besoins d'entretien en énergie, les besoins en matières azotées ne sont jamais satisfaits par les pailles de graminées.

Les formes néotémiques (individus «échaudés ») des graminées, qui ne parviennent pas à faire mûrir leurs fruits par suite d'une insuffisance de pluviosité, constituent des aliments très riches, localisés aux secteurs nord de la zone où les pluies peuvent s'arrêter brutalement certaines années.

Les repousses et infrutescences des espèces graminiformes vivaces constituent une bonne ration d'entretien.

Les repousses des prairies aquatiques du Sud de la zone constituent une ration riche ef nettement excédentcire en protéines, de même que les feuilles et fruits verts des arbustes qui, surtout appréciés des caprins, sont également consommés en complément de ration, par les bovins.

Acacia seyal, le plus apprécié (photo 1), est localisé aux zones dépressionnaires argileuses ef les troupeaux se maintiennent en bon état dans la mesure où l'aire de parcours englobe des dunes pour assurer la ration énergétique et l'encombrement et des bas-fonds pour le complément en matières azotées.

Au cours de la période chaude, les palles de graminées n'apportent plus que les $2 / 3$ des besoins en énergie et l'apport d'azote est négligeable.

Les graminées vivaces n'émettent plus de jeunes pousses et les animaux recherchent alors des feuilies sèches d'arbustes, des infrutescences d'espèces herbacées et des fruits d'Acacia qui sont particulièrement riches.
Au cours de la pérlode chaude et humide, les. réserves en paille se raréfient mais les ressources du pâturage aérien se renouvellent avec la feuiliaison des arbustes, particulièrement dans. les dépressions.

\section{c) Appréciation de la charge possible.}

Au cours de la transhumance de saison des pluies, les troupeaux ne consomment que les pousses les plus appétibles et n'entament pratiquement pas les réserves fourragères alors que l'abandon de la transhumance par fixation des nomades près de points d'eau permanents, a pour effet de limiter le choix des animaux et de réduire les réserves de saison sèche.

Dans le cadre de l'élevage transhumant, le problème de charge ne se pose qu'en saison sèche au moment où les animaux sont concentrés près des points d'eau permanents.

Avec une production moyenne de $150 \mathrm{~kg}$ de fruits d'Acacia raddiana (15 kg par arbre), et $800 \mathrm{~kg}$ de paille dont la moitié est perdue par piétinement, un hectare de dune peut fournir en période chaude, 80 rations d'entretien sensiblement équilibrées avec $1,5 \mathrm{~kg}$ de gousses et le lest en pailles, la quantité de pailles étant l'élément limitant.

Il peut donc être justifié d'apprécier la charge possible de saison sèche d'une région de steppe par l'évaluation de la production de pailie à I'hectare de dunes en début de saison sèche, supposant perdue la moitié de cette production, et la consommation des 8 mois de saison sèche évaluée à 240 rations de $5 \mathrm{~kg}$ de pailles.

La charge possible de saison sèche serait alors : $\frac{I}{2} \mathrm{Rdt}$ en $\mathrm{kg} / 1200$, l'aire considérée présentant en plus des graminées vivaces et un pâturage aérien de dunes et bas-fonds.

Ainsi, pour une production de $800 \mathrm{~kg}$ de paille sur dunes, ef la présence de bas fonds pour 1/20 de la superficie, la charge peut être évaluée à 1 U. B. T. pour 3 ha de dunes.

Cependant des pertes de poids spectaculaires sont enregistrées à cette période de l'année bien que la charge saisonnière soit souvent limitée à'1 U. B. T. pour 7 d̀ 10 hectares.

Peuvent expliquer ces faits contradictoires:

- L'insuffisance de l'abreuvement, les animaux recevant souvent moins de 30 litres d'eau par jour. 
- La présence de caprins qui pillent littéralement les ressources du pâturage aérien dans le périmètre du point d'eau.

- L'installation autour du point d'eau d'une zone surpâturée proportionnelle à l'importance du cheptel qui oblige les animaux à s'éloigner pour trouver un pâturage convenable. Le temps passé en déplacements sur la zone stérile, et en attente près du puits est trop important et les animaux n'ont plus les 8 heures nécessaires à la pâture effective.

Pour limiter les pertes de poids il serait nécessaire de multiplier les points d'abreuvement ef de séparer les aires de parcours des bovins ef caprins.

Un ensemble de parcours équilibré, exploité en ranch d'entretien uniquement pendant la saison sèche, pourrait donc supporter dans les conditions optimales une charge d'un U. B. T. pour 4 ha, soit près de 2.000 U. B. T. par points d'abreuvement à la condition que ceux-ci soient distants de $10 \mathrm{~km}$, ce qui correspondrait à 7.850 ha par point d'abreuvement.

\section{B. Parcours de savane.}

La savane arbustive à arborée s'étale sur toute l'aire intertropicale comprise entre la steppe et la forêt dense :

- sous ćlimat sahélo-soudanais (1), la savane arbustive est dominante entre les isohyètes 550 à $750 \mathrm{~mm}$, et caractérise la végétation du secteur soudano-sahélien du domaine soudanien ;

- sous climat soudano-guinéen (1), climat tropical semi-humide à une seule saison des pluies de 6 à 8 mois et à pluviosité de 750 à $1.750 \mathrm{~mm}$, la savane très arborée peut faire place à la forêt claire et caractérise la végétation du secteur soudano-guinéen du domaine soudanien ;

- sous climat équatorial à deux saisons des pluies, la savane préforestière du domaine guinéen se caractérise par sa localisation topographique délimitée par les galeries forestières ef les forêts semi-caducifoliées de plateaux.

Pour l'Afrique de l'Ouesti, la savane «soudanienne » arbustive d̀ arborée correspond approximativement aux limites, des types de tapis graminéens à Andropogon «An » de RATTRAY (35) ef la savane « préforestière » aux types à Hyparrhenia $« H »$, bien que ces dernıers pénètrent dans la zone côtière ef les régions d'altiłude du climał soudano-guinéen.

\section{$B_{1}$ - Savanes soudaniennes.}

La différenciation des savanes est liée aux différents types de sol et à la variation de pluviosité.

Les sols cuirassés à gravillonnaire portent vers le Nord des buissons épars de Combretum micranthum et un fapis de graminées annuelles (Loudetia togoensis) et vers le Sud des graminées vivaces (Anadelphia ofzeliana).

Les sols à horizon induré profond portent vers le Nord une savane arbustive à graminées annuelles (Andropogon spp, Pennisetum) et vers le Sud une savane arborée ou une forêt claire à Bambou et graminées vivaces (Andropogon tecforum, Schizachyrium sanguineum).

Les sols colluviaux portent une savane arbustive à graminées vivaces (Andropogon gayanus), le couvert arbustif et la densité d'Andropogon augmentant vers le Sud.

Les sols alluviaux à inondation temporaire portent une végétation herbacée basse vers le Nord (Pospalum orbiculare) et une savane herbeuse haute vers le Sud (Hyparthenia rufa).

a) Exploitation de la végétation.

Les troupeaux de village exploitent en saison des pluies le tapis herbacé des sols gravillonnaires et des sols profonds lorsque ceux-ci ne sont pas occupés par les cultures. En saison sèche, ils pâturent les repousses après feux des sols alluviaux inondables, les résidus de, culture, les débris de paille, les repousses de vivaces, ef les jeunes pousses d'arbustes des sols profonds.

b) Potentiel fourrager (Tableau 11).

Références : 2-8-9-10-18.

Le temps de croissance (période comprise entre 2 coupes, ou entre la reprise de végétation aux premières pluies et la coupe) et la saison (saison des pluies, saison sèche fraîche, saison sèche chaude) ont une nette influence sur la valeur des fourrages consommés.

En savanes soudaniennes, les troupeaux de villages ont des déplacements limités et les besoins d'entretıen de I'U. B. T, sont réduits d̀ $0,43 \cup$. F. et $24 \mathrm{~g}$ de M. A. D. par $\mathrm{kg}$ de matière sèche ingérée.

Saison des pluies.

Les espèces annuelles en cours de montaison assurent l'entretien des animaux mais leurs 
TABLEAU 11

Pâturages de savane goudanteone

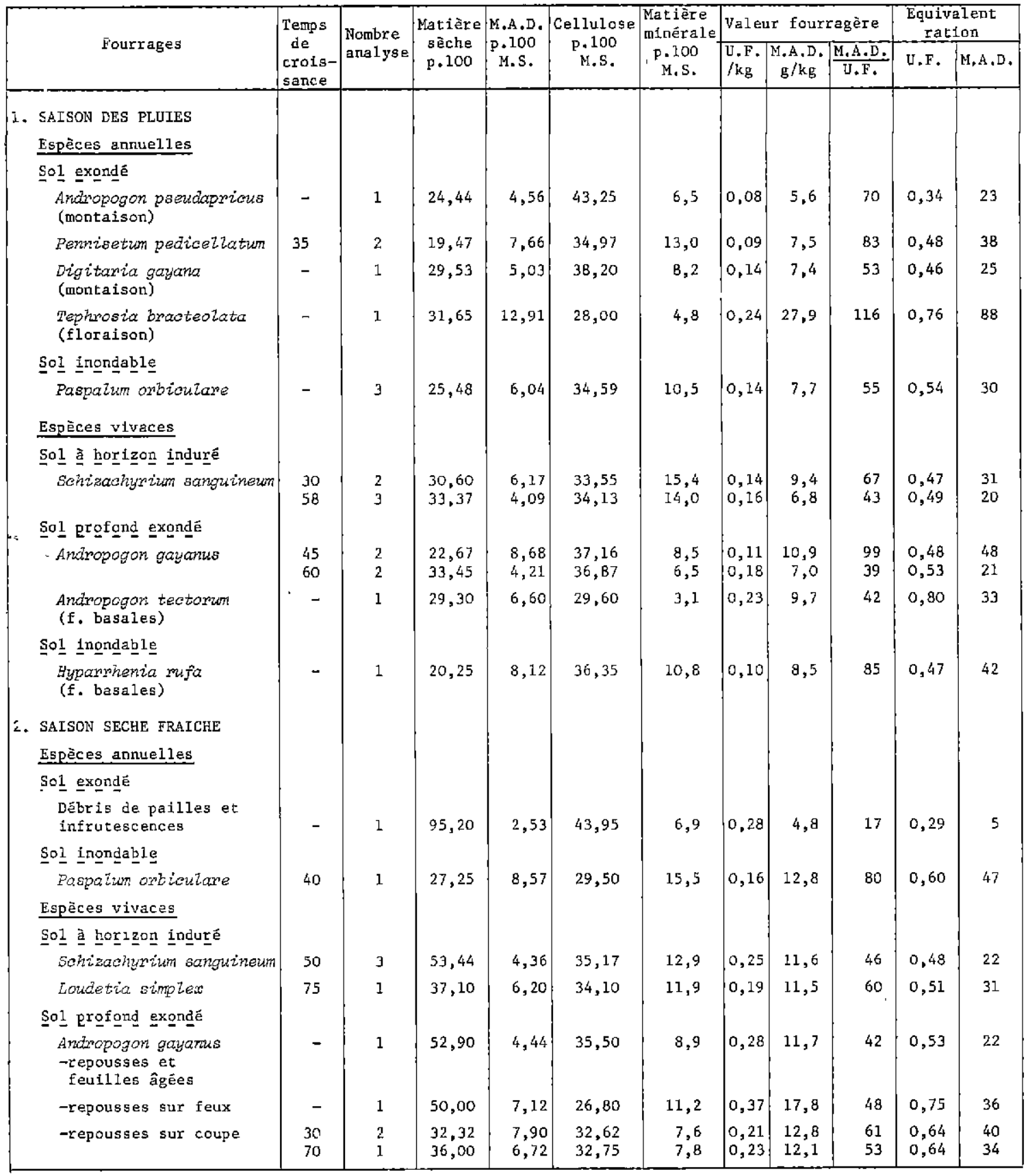


TABLEAU 11 (suize)

\begin{tabular}{|c|c|c|c|c|c|c|c|c|c|c|c|}
\hline \multirow{2}{*}{ Fourrages } & \multirow{2}{*}{$\begin{array}{l}\text { Temps } \\
\text { de } \\
\text { crot.s- } \\
\text { sance } \\
\end{array}$} & \multirow{2}{*}{$\begin{array}{l}\text { Nombre } \\
\text { analyse }\end{array}$} & \multirow{2}{*}{$\begin{array}{l}\text { Mat1ère } \\
\text { sèche } \\
\text { p.100 }\end{array}$} & \multirow{2}{*}{$\begin{array}{l}\text { M.A.D. } \\
\text { p.100 } \\
\text { M.S. }\end{array}$} & \multirow{2}{*}{$\begin{array}{c}\text { Cellulose } \\
\text { P.100 } \\
\text { M.S. }\end{array}$} & \multirow{2}{*}{$\begin{array}{c}\text { Matiêre } \\
\text { minérale } \\
\text { p.100 } \\
\text { M.S. }\end{array}$} & \multicolumn{3}{|c|}{ Valeur fourragère } & \multicolumn{2}{|c|}{$\begin{array}{l}\text { Equivalent } \\
\text { ration }\end{array}$} \\
\hline & & & & & & & $\begin{array}{l}\text { U. F. } \\
\mathrm{kg}\end{array}$ & $\begin{array}{c}M . A . D . \\
g / k g\end{array}$ & $\frac{\mathrm{M}, \mathrm{A} \cdot \mathrm{D} \cdot}{\mathrm{U} \cdot \overline{\mathrm{F}} \cdot}$ & U.F. & M.A.D. \\
\hline $\begin{array}{l}\text { Imperata oy lindrica } \\
\text { (repousses) }\end{array}$ & - & 3 & 32,85 & 7,21 & 40,24 & 5,7 & 0,14 & 11,8 & B4 & 0,44 & 36 \\
\hline Sol Inondable & & & & & & & & & & & \\
\hline Hyparshenia rufa & - & 1 & 46,90 & 2,44 & 34,25 & 15,9 & 0,21 & 0,6 & 3 & 0,45 & 1,2 \\
\hline $\begin{array}{l}\text { Andropogon schirensis } \\
\text { (feuilles basales) }\end{array}$ & - & 2 & 40,67 & 3,37 & 39,98 & 7,8 & 0,16 & 2,7 & 17 & 0,39 & 6,6 \\
\hline Setaria sphacelata & - & 1 & 27,10 & 7,38 & 38,75 & 10,0 & 0,11 & 10,0 & 91 & 0,41 & 37 \\
\hline $\begin{array}{l}\text { Mares temporaires } \\
\text { Echinoahtoa crus-pavonis } \\
\text {-feullles basales }\end{array}$ & - & 1 & 29,40 & 10,54 & 34,69 & 13,6 & 0,14 & 19,1 & 136 & 0,48 & 65 \\
\hline -Inflorescences & - & 1 & 23,10 & 10,39 & 29,00 & 8,2 & $0,17 \mid$ & 14,8 & 87 & 0,74 & 64 \\
\hline $\begin{array}{l}\text { Leeraia hexandra } \\
\text { (floratson) }\end{array}$ & - & 1 & 42,75 & 6,27 & 32,85 & 10,1 & 0,25 & 13,4 & 54 & 0,58 & 31 \\
\hline $\begin{array}{l}\text { 3. SAISON SECHE CHAUDE } \\
\text { EApèces vivaces }\end{array}$ & & & & & & & & & & & \\
\hline Sol grofond exondê & & & & & & & & & & & \\
\hline Andropogon gayanus & $\begin{array}{l}40 \\
70\end{array}$ & $\begin{array}{l}1 \\
3\end{array}$ & $\begin{array}{l}44,50 \\
67,67\end{array}$ & $\begin{array}{l}5,00 \\
4,30\end{array}$ & $\begin{array}{l}32,75 \\
35,25\end{array}$ & $\begin{array}{r}10,8 \\
9,6\end{array}$ & $\mid \begin{array}{l}0,26 \\
0,36\end{array}$ & $\begin{array}{l}11,1 \\
14,5\end{array}$ & $\begin{array}{l}43 \\
40\end{array}$ & $\begin{array}{l}0,58 \\
0,53\end{array}$ & $\begin{array}{l}25 \\
22\end{array}$ \\
\hline Mareg temporatres & & & & & & & & & & & \\
\hline Leersia hexandra & 50 & 1 & 36,85 & 13,15 & 29,70 & 11,2 & 0,24 & 33,2 & 138 & 0,66 & 90 \\
\hline Pâturage aêrín & & & & & & & & & & & \\
\hline Jeunes_tiges f feuilliées & & & & & & & & & & & \\
\hline Gardenia exubesceno & - & 1 & 89,89 & 5,37 & 17,95 & 6,8 & 0,90 & 24,1 & 27 & 1,00 & 27 \\
\hline $\begin{array}{l}\text { Pterocarpus lucenx } \\
\text { Jeunes_fol íoleg }\end{array}$ & - & 1 & 54,14 & 10,60 & 20,80 & $B, 3$ & 0,50 & 35,7 & 71 & 0,93 & 66 \\
\hline 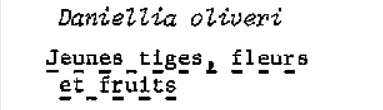 & - & 1 & 26,50 & 14,57 & 12,80 & 5,3 & 0,26 & 27,8 & 107 & 0,97 & 105 \\
\hline Guiera senegaienois & - & 1 & 60,74 & 9,93 & 32,70 & 6,6 & 0,41 & 36,4 & 89 & 0,67 & 60 \\
\hline Fru1tes & & & & & & & & & & & \\
\hline Piliostigma thonningii & - & I & 95,30 & 6,8 & 23,7 & 4,9 & 0,87 & 32,4 & 37 & 0,92 & 34 \\
\hline $\begin{array}{l}\text { Gelina arborea } \\
\text { ( } 5 \mathrm{p} .100 \text { de noyau) }\end{array}$ & - & 1 & 18,92 & 5,04 & 11,15 & 6,5 & 0,21 & 4,8 & 23 & 1,12 & 25 \\
\hline
\end{tabular}

repousses d'un mois autorisent un gain de poids et une faible production laitière.

Sur sol à inondation temporaire, Paspalum orbiculare, exploitable entre les périodes d'inondation, semble être la plante la plus intéressante.

Parmi les espèces vivaces, Andropogon tectorum est un fourrage riche et les repousses d'un mois à un mois et demi permettent gain de poids et production laitière.

Salson sèche fraîche (novembre à mars).

Pendant sa période de végéfatıon, Paspolum orbiculare conserve sa valeur.

Parmi les espèces vivaces, celles des terrains gravillonnaires permettent l'entretien de l'anımal et celles des terrains inondables pourraient être déficientes en azote mais il y a insuffisance de données pour ces dernières.

Les plantes des mares temporaires constituent des fourrages d'appoint de qualité.

Les repousses d'Andropogon goyonus sont très riches mass leur rendement n'assure guère qu'une journée de pâture à l'hectare et par mois.

La consommation de cette espèce à l'état de réserve sur pied permettrait une charge d'un $1 / 2$ animal à l'hectare tout en assurant son entretien.

Saisan sèche choude (mars à mai).

Les espèces de mares temporaires conservent leur valeur alors que les repousses d'Andropogon 
TABLEAU 11 ( $\mathrm{fin}$ )

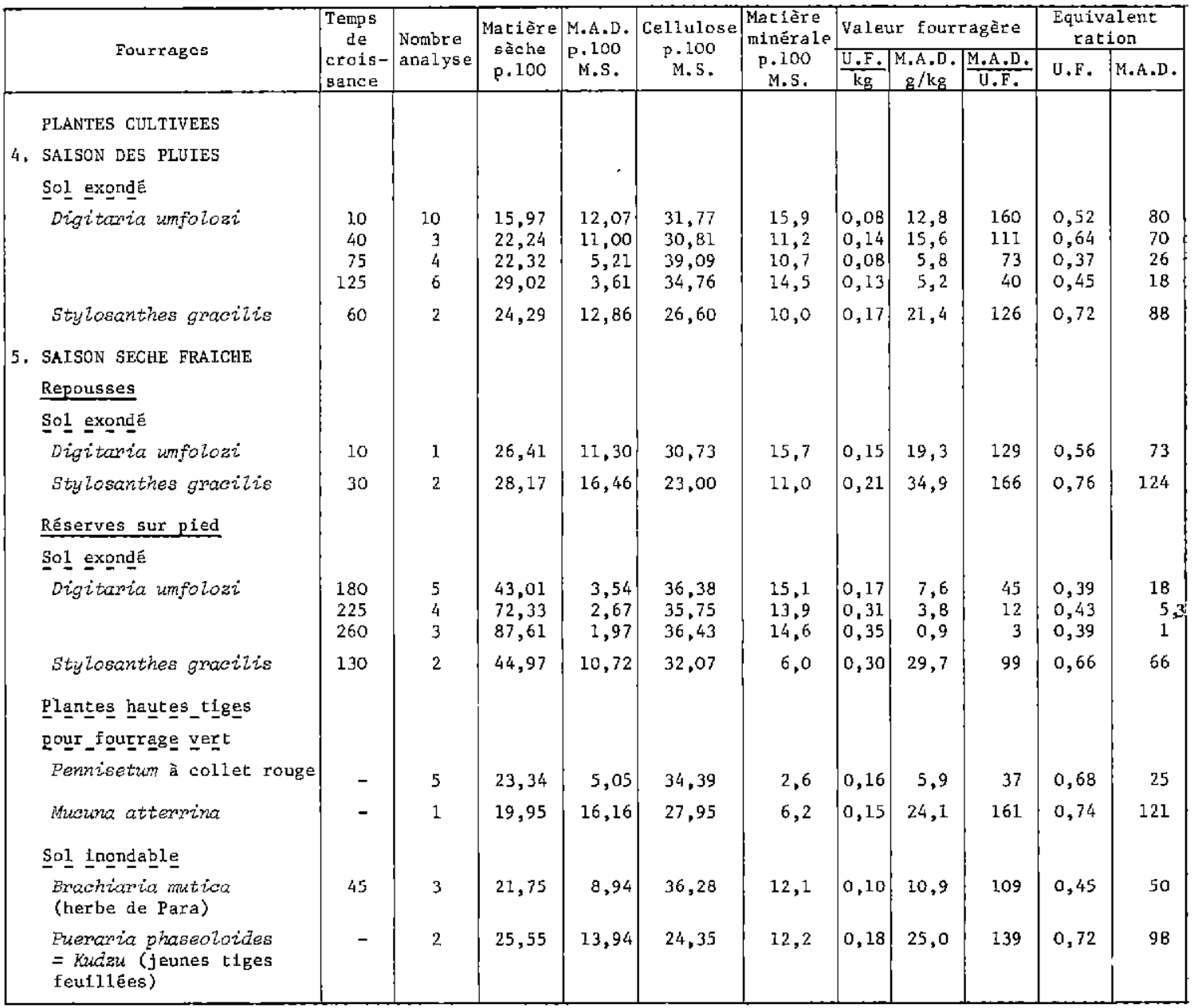

gayanus n'assurent plus que l'entretien de l'animal

Avec l'élévation du degré hygrométrique de l'arr, la sortie des jeunes tiges et feuilles d'arbustes assure un aliment d'appoint appréciable à cette période de l'année.

c) Amélioration de l'exploitation des parcours.

Adapter les techniques d'exploitation aux conditions économiques locales pour rentabiliser l'élevage, oblige à proscrire dans l'ımmédiat les moyens mécanıques d'entretıen des parcours (girobroyeur, débroussalleur), et limite les procédés onéreux de mise en réserve (foin, ensilage).

L'utilisation traditionnelle des parcours semble en définitıve une technique très judicieuse méri- tant l'attention des spécialistes pour l'améliorer sans la mutiler :

Rythme de pâture :

Pâture continue de saison des pluies sur sol exondé avec une charge d'1/2 U. B. T. à I'hectare.

Pâture semi-continue de saison sèche sur sol inondable avec une charge d'1/4 U. B. T. à l'hectare et passage itinérant sur sol exondé.

\section{Feux :}

Suppression des feux dans la mesure du possible afin que le bétail puisse consommer progressivement le stock de pailles et de repousses tout au long de la saison sèche (photo 2), les 
parcours étant débarrassés des refus par des feux différés de début des pluies.

Cependant les animaux ne consommeront les vieilles repousses que dans la mesure où ils n'auront pas goûté aux jeunes pousses après feux précoces. Dans ce dernier cas, ils les refusent et la mise à feu générale devient une nécessité.

\section{Débroussement :}

Débroussement sélectif des parcours sur sol exondé, les espèces inutilısées étant recépées au collet et les espèces consommées rabattues à un mètre du sol.

Les espèces les plus recherchées (Gulera, Doniellia) sont multipliées par le bétail ef deviennent envahissantes.

Leur recépage en fin des pluies favorisera les repousses appétées tout en dégageant le sol pour maintenir le couvert herbacé. Les porte-graines de Daniellia doivent être détruits pour éviter la prolifération dangereuse de cette espèce.

\section{Coexistence agriculture-élevage :}

Pour éviter l'intrusion des troupeaux dans les cultures, les terroirs de villages seront divisés en zone pastorale et zone agricole, cette dernière pouvant être exploitée en «Ley-Farming», des parcelles étant retirées de la rotation culturale pour constituer des prairies permanentes ef les jachères pourront aussi être aménagées en jachères fourragères.

d) Plantes fourragères cultivées.

Sol exondé :

En saison des pluies, un temps de croissance d'un mois à un mois $1 / 2$ pour les graminées basses et de 2 mols pour Stylosonthes fournissent le meilleur fourrage.

En saison sèche fraîche, Digitaria «umfolozi» fournit encore des repousses intéressantes ef Stylosonthes d'excellentes repousses.

La conservation de la production sur pied permet sans travaux supplémentalres, $d$ 'assurer avec Digitaria, l'entretien du bétal jusqu'en décembre et l'apport d'énergie en saison chaude. Avec Stylosanthes, le complément azoté est largement assuré et la réserve sur pied d'un pâturage constıfué de ces plantes associées, permettraientl'entretien du troupeau jusqu'en saison chaude.

Si la distribution en vert de tiges de Pennise- tum (photo 3) n'assure que l'entretien, le mélange Mucuna-Pennisetum constifuerait un fourrage riche susceptible d'assurer la nourrifure de bceufs de trayail.

\section{Sol inondable :}

Les repousses d'herbe de para (Brochioria mutica) n'assurerait que l'entretien dụ bétail, alors que les jeunes tiges feuillées de Kudzu (Pueraria phaseoloïdes) sont excellentes.

\section{Utilisotion possible.}

Sur les prairies artificielles permanentes de sol exondé et pâturées en saison des pluies, l'associatıon graminée-légumineuse ne semble pas favorable, un rythme de pâture d'un mois pour Digitoria ef de deux mols pour Stylosanthes assurant une ration optimale.

Cette association serait, en revanche, à préconiser sur jachère fourragère où la production pourrait être aisément conservée en réserve sur pied et pâturée par le béta!l après l'enlèvement des récoltes.

Sur sol inondable, les zones peu ou accidentellement recouvertes par l'eau (bords de cuvettes) sont impropres à l'installation des rizières et seraient avaniageusement aménagées en Kudzu pâturable après la récolte du riz. Les rizières envahies par les Cyperacées et les riz sauvages pourraient être mises hors culture pendant quelques années et complantées en herbe de para (photo 4) pâturée également après la récolte du riz. Lorsque ces rizières présentent un faible niveau d'inondation, l'association boutures d'herbe de para et boutures d'extrémités non aoûtées de tiges de Stylosonthes seralt bénéfique à l'entretien du bétail en saison sèche.

\section{$\mathrm{B}_{2}$. - Savanes préforestières et d'altitude.}

Les strates ligneuses de ces savanes sont clairsemées, pauvres en espèces et le tapis herbacé varie selon que le sol est profond ou présente un horizon concrétionné affleurant ou subaffleurant.

Loudetia kagerensis domıne sur sol gravillonnaire en surface ; Hyparrhenia chrysargyrea, Loudefia arundinaceo et Panicum phragmitordes constituent la base du pâturage sur sol à horızon gravillonnaire peu profond.

- Hyparrhensa diplandra domine sur sol argilosableux peu perméable et se trouve remplacé par Andropogon macrophyllus sur sol profond 
mieux drainé. Sur ces sols profonds, Andropogon fectorum et Beckeropsis uniseta se localisent aux stations ombragées.

a) Exploitation de la végétation.

En région d'altitude, l'absence de tryponosomiase, favorise l'élevage du zébu et les troupeaux transhument vers le bas pays en salson sèche.

En régıon préforestière proprement dite, l'élevage des taurins est peu développé. Les troupeaux de village sont rares et un effort particulier est porté sur la création de «ranches» de production.

b) Potentiel fourrager (tableau 12).

Références : 3-4-5-12.

Les déplacements journaliers des troupeaux sont toujours limités ef les besoins d'entretien de I'U. B. T. sont réduits à $0,43 \mathrm{U}$. F. et $24 \mathrm{~g}$ de M. A. D. par $\mathrm{kg}$ de matière sèche ingérée, tant en saison des pluies et en petite saison sèche qui ne modifie guère la croissance des plantes fourrages, qu'en grande salson sèche qui dure de 2 à 4 mols selon les régıons.

Sarson des pluies et petite sarson sèche.

Quel que soit le temps de croissance des repousses, les graminées vivaces assurent toujours l'entretien du bétail sur sol peu profond. Un temps de croissance d'un mois assure le meilleur gaın de poids et la meilleure production laitière avec une charge possible de 2 U. B. T./ha.

Sur sol profond, la ration d'entretien est toujours satisfaite et le temps de croissance d'un mois environ est le plus favorable, alliant meilleur rendement et valeur fourragère optimale, avec une charge possible de 2 U. B. T./ha.

Un temps de croissance de 3 semaines serait toutefois préférable pour Hyparrhenra diplandro et la pâture continue risque de favoriser cette espèce au détriment des autres.

\section{Saison sèche.}

La repousse des graminées vivaces n'est Importante que pendant les deux premiers mois de saison sèche et un feu de pleine saison sèche ne produit qu'une repousse négligeable.

En début de saison sèche la repousse d'un mois présente une valeur excellente. Les jeunes repousses assurent un gain de poids et la produc- tion du lait. Au bout de 2 mois de salson sèche l'entretien est encore, ou assuré, ou largement sotisfait.

Le fourrage produit se conserve ensuite au cours de la saison sèche, avec une augmentation progressive du taux de matière sèche, une diminution des matıères azotées et une constance du taux de cellulose.

Au 4 e mois de saison sèche, les besolns en énergie sont seuls couverts mais les jeunes pousses et folioles de Daniellia oliveri sur sol gravilIonnaire et d'Albizıa zygia sur sol profond peuvent apporter un appoint très satisfaisont en matières azotées.

Les pousses basilaires de saison des pluies, telles que celles d'Hyparhenia chrysargyrea constituent un fourrage non négligeable assurant I'entretien de I'U. B. T.

Grâce à la forte humidité atmosphérique de cette zone climatique, les feux précoces ont la particularité de permettre la germınation de gramınées annuelles comme Hyparrhenia confinis, avec une production de $800 \mathrm{~kg}$ de matière sèche consommable tout au long de la saison sèche.

La production des repousses de début de saison sèche est de 60 rations environ et comparable sur sol profond et sur sol gravillonnaire.

La charge possible est donc fonction de la longueur de la saison sèche et pourra être d'1/2 U. B. T./ha pour une saison sèche de 4 mois.

Une pâture continue des parcours est préférable car elle assure un certain regain dont la valeur fourragère est excellente.

c) Amélioration de l'exploitation des parcours.

- Charges ef rythmes d'explatation.

2 types d'exploitation peuvent être proposés. $S_{1}$ les troupeaux sont peu importants par rapport à la surface de savanes laissée libre par suite du nombre restreint d'agriculteurs, la tronshumance précédée de feux précoces est la technique la plus valable.

En saison des pluies, une charge de 2 U. B. T./ha peut être envisagée à la condition d'exécuter ou mınimum une rotation grossière sur 2 ensembles de parcours, les animaux pâturant un mols sur l'un, un mois sur l'autre, Le nettoyage des parcours est réalisé par un feu différé de début des pluies tous les 2 ans, soit la moitié chaque 
TABLEAU 12

Pâturages de savane préforestière et d'altitude

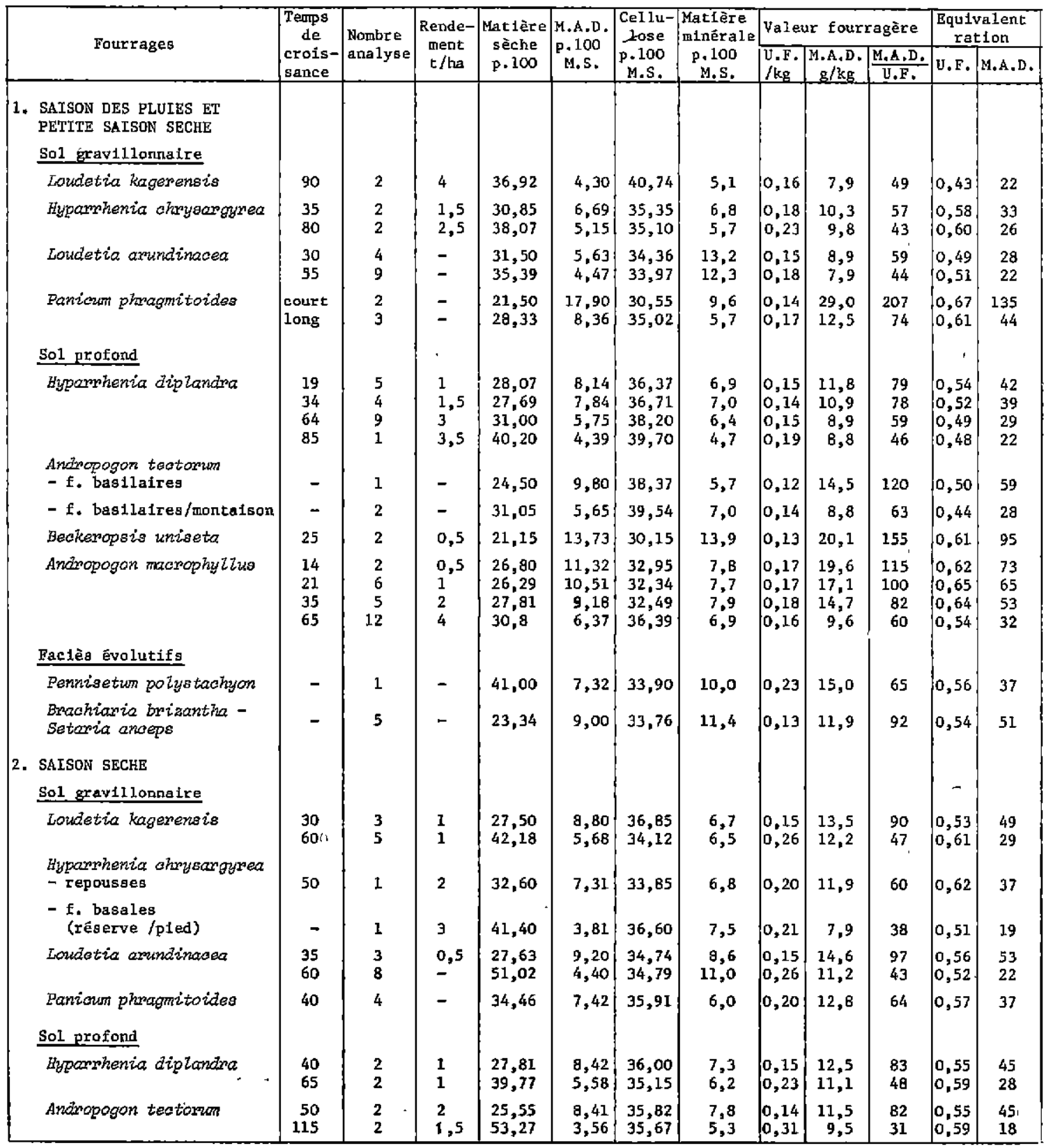


TABLEAU 12 (suite)

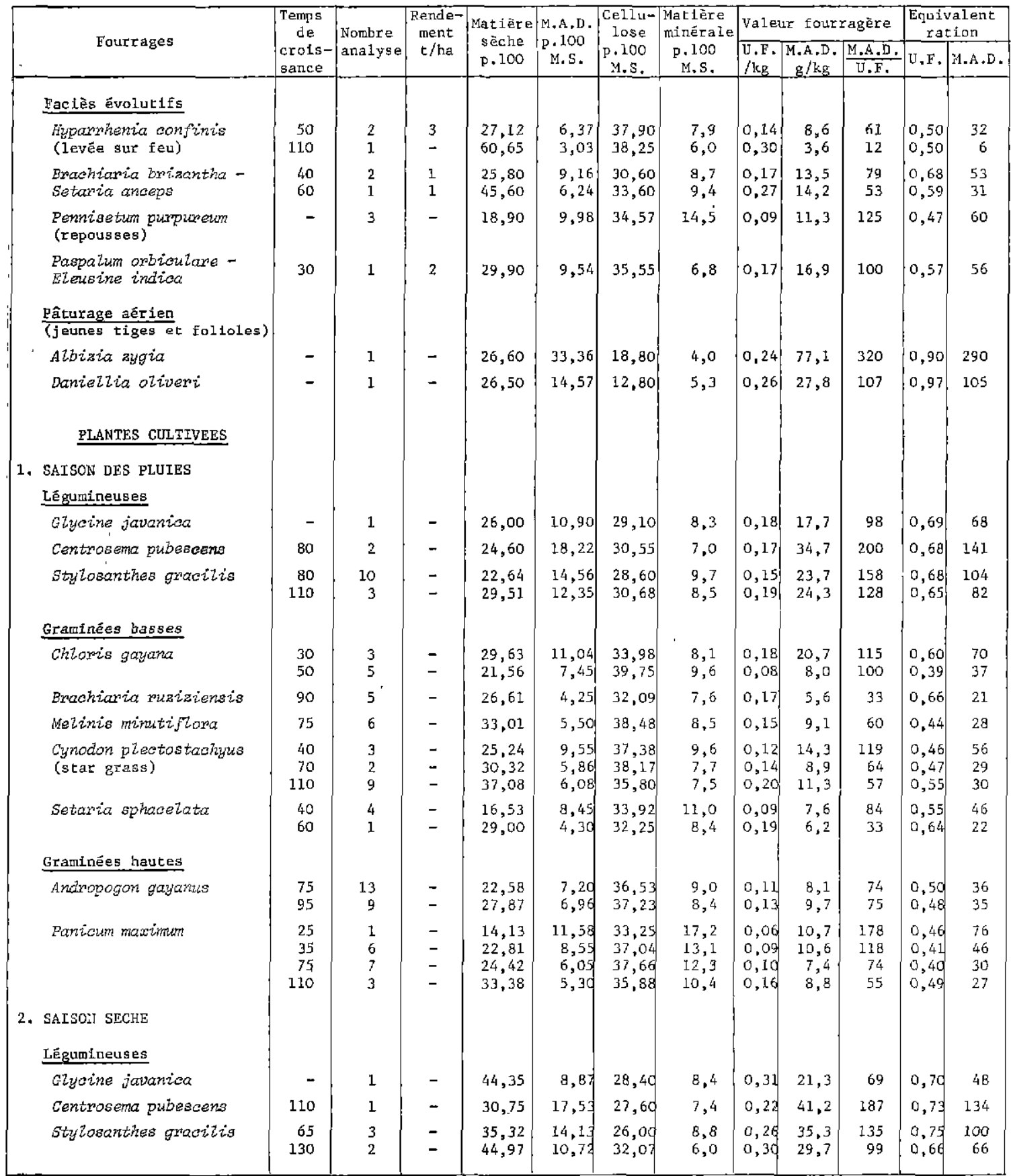


TABLEAU 12 (fin)

\begin{tabular}{|c|c|c|c|c|c|c|c|c|c|c|c|c|}
\hline \multirow{2}{*}{ Fourrages } & \multirow{2}{*}{\begin{tabular}{|l} 
Temps \\
de \\
crols- \\
sance \\
\end{tabular}} & \multirow{2}{*}{$\begin{array}{l}\text { Nombre } \\
\text { analy'se }\end{array}$} & \multirow{2}{*}{$\begin{array}{c}\text { Rende- } \\
\text { ment } \\
\text { t/ha }\end{array}$} & \multirow{2}{*}{$\begin{array}{l}\text { Matière } \\
\text { sèche } \\
\text { p.100 }\end{array}$} & \multirow{2}{*}{$\begin{array}{l}\text { M.A.D. } \\
\text { P. } 100 \\
\text { M.S. }\end{array}$} & \multirow{2}{*}{$\begin{array}{c}\text { Cellu- } \\
10 \text { ese } \\
\text { P.100 } \\
\text { M.S. } \\
\end{array}$} & \multirow{2}{*}{$\begin{array}{c}\text { Matlère } \\
\text { minérale } \\
\text { p.100 } \\
\text { M.S. } \\
\end{array}$} & \multicolumn{3}{|c|}{ Valeur fourragère } & \multicolumn{2}{|c|}{$\begin{array}{c}\text { Equivalent } \\
\text { ration }\end{array}$} \\
\hline & & & & & & & & \begin{tabular}{|l|} 
U.F. \\
$\mathrm{kg}$
\end{tabular} & $\begin{array}{r}\text { M.A.D. } \\
\mathrm{g} / \mathrm{kg}\end{array}$ & $\frac{\mathrm{M} . \mathrm{A} \cdot \mathrm{D} .}{\mathrm{U} . \mathrm{F} .}$ & U.F. & M.A.D. \\
\hline \multicolumn{13}{|l|}{ Graminées basses } \\
\hline Chior is gayana & 60 & 4 & - & 27,03 & 8,89 & 36,91 & 7,8 & 0,14 & 13,5 & 96 & 0,51 & 50 \\
\hline Brachiaria ruziziensis & 120 & 1 & - & 50,30 & 3,72 & 30,60 & 9,2 & 0,34 & 9,4 & 28 & 0,67 & 19 \\
\hline lezinis minutiflora & $\begin{array}{l}65 \\
40\end{array}$ & $\begin{array}{l}5 \\
1\end{array}$ & - & $\begin{array}{l}35,60 \\
45,50\end{array}$ & $\begin{array}{l}4,86 \\
3,94\end{array}$ & $\begin{array}{l}38,54 \\
34,00\end{array}$ & $\begin{array}{l}7,2 \\
8,3\end{array}$ & $\begin{array}{l}0,17 \\
0,27\end{array}$ & $\begin{array}{l}8,7 \\
9,0\end{array}$ & $\begin{array}{l}51 \\
33\end{array}$ & $\begin{array}{l}0,46 \\
0,59\end{array}$ & $\begin{array}{l}24 \\
20\end{array}$ \\
\hline Cynodon plectostachyus & $\begin{array}{l}55 \\
65\end{array}$ & $\begin{array}{l}2 \\
3\end{array}$ & 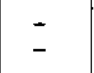 & $\begin{array}{l}32,05 \\
45,11\end{array}$ & $\begin{array}{l}7,36 \\
5,71\end{array}$ & $\begin{array}{l}38,62 \\
34,98\end{array}$ & $\begin{array}{l}7,5 \\
6,9\end{array}$ & $\mid \begin{array}{l}0,15 \\
0,26\end{array}$ & $\begin{array}{l}11,8 \\
12,9\end{array}$ & $\begin{array}{l}79 \\
50\end{array}$ & $\left|\begin{array}{l}0,46 \\
0,59\end{array}\right|$ & $\begin{array}{l}37 \\
29\end{array}$ \\
\hline $\begin{array}{l}\text { Setaric sphaceiata } \\
\text { Graminees hautes }\end{array}$ & 55 & 1 & - & 27,30 & 9,37 & 28,85 & 12,8 & 0,18 & 15,0 & 83 & 0,66 & 55 \\
\hline Andropogon gayanus & 90 & 9 & - & 36,16 & 6,29 & 32,20 & 8,3 & 0,23 & 11,4 & 50 & 0,64 & 31 \\
\hline $\begin{array}{l}\text { Panicum maximum } \\
\text { Plante haute tige } \\
\text { (fourtage vert) }\end{array}$ & 65 & 5 & - & 37,19 & 5,34 & 35,50 & 9.7 & 0,19 & 9,9 & 52 & 0,52 & 27 \\
\hline $\begin{array}{l}\text { Tripsacum laxum } \\
\text { (Guatemala grass) }\end{array}$ & 150 & 3 & - & 28,36 & 4,34 & 34,10 & 7,6 & 0,17 & 6,2 & 36 & 0,60 & 22 \\
\hline
\end{tabular}

année, la partie non brôlée étant remise la 1 re en exploitation.

En saison sèche, les feux seront allumés 15 jours à 3 semaines après les dernières pluies et les troupeaux seront introduits sur les terrains de transhumance 3 semanes plus tard. La surface d̀ préparer esł d'environ 1 ha par U. B. T. et par mois de saison sèche, et l'exploitation se fera en pâture continue.

La charge globale est alors de 4,5 ha par $U$. B. T. pour une zone à 4 mois de saison sèche.

$\mathrm{Si}$ les surfaces sont restreintes et la transhumance difficilement réalisable, la zone de parcours peut être subdivisée en 3 parcelles $A, B, C$, la charge globale étant de 1,5 ha par U. B. T. 2 parcelles $A$ et $B$ sont exploitées en saison des pluies avec rotation du troupeau chaque mols et une charge saisonnière d' 1 U. B. T./ha.

Cette rotation est maintenue en sasson sèche alors qu'une $3^{\mathrm{e}}$ parcelle $C$ est brûlée 3 semaines après les pluies et ne sera mise en pâture qu'au $3^{\mathrm{e}}$ mois de saison sèche.

A la reprise des pluies, la parcelle $A$ est remise en exploitation pendant que $B$ subit un feu différé, puis $A$ est retirée de la rotation au profit de $C$ et sera à son tour brôlée en début de saison sèche.

Cette technique a pour inconvénient le brûlis d'une parcelle par feu précoce où de jeunes pousses sont tentantes et pour le bétail et pour les bergers qui sont plus soucieux de l'appétibilité du moment que d'assurer la soudure de fin de saison sèche.

La technique du feu de contre-saison (photos 5 et 6) appliquée au cours de la petite saison sèche est plus judicieuse mais nécessite une maîtrise absolue des feux courants de pleine scison sèche:

La parcelle $C$, n'ayant pas brûlé en saıson sèche et présentant des refus importants sera brôlée au cours de la petıte saison sèche.

$A$ et $B$ sont exploitées comme précédemment jusqu'au stade montaison avancé du tapis graminéen.

Cest alors soumise à la pâture pendant 1 mois, B durant un moss, et les 3 parcelles seront livrées à la pâture continue pendant la sasson sèche.

En début des pluies, la pâture commence sur $C$, pendant que $B$ subit un feu différé et $A$ est mise en différé avec tous ses refus qui alımenteront le feu de contre-saison.

\section{- Aménagement des parcours.}

Les pâturages préforestiers ont une productivité supérieure et plus uniforme que celle des pâturages soudanıens, maıs leur résistance d̀ la pâture est généralement plus faible.

Hyparrhenio chrysorgyreo sur sol gravillonnaire et Andropogon macrophyllus sur sol profond présentent un mauvais enracinement et sont arrachés au broutage. 
Un surpâturage aura donc pour effet de dénuder rapidement le sol avec entraînement subséquent des éléments fins et damage des sols argileux.

La dénudation du sol favorise également la germination des espèces pionnières de forêt dans les stations ombragées (photo 7) et Harungana madagascariensis, en particulier, peut se multiplier rapidement et transformer la savane en hallier improductif (photo 8 ).

L'évolution du couvert ligneux doit être suivie avec attention bien que la mise en différé périodique des parcours suivie de feu, devrait normalement assurer l'équilibre entre strates herbacées et strates ligneuses.

Le débroussement sélectif des parcours devrait également contribuer à la lutte contre les espèces envahissantes en réduisant les surfaces ombragées. Il y a cependant lieu de conserver les espèces ligneuses très utiles comme fourrages d'appoint de pleine saison sèche.

Daniellia oliveri (avec élimination des portegraines).

Albizia zygia.

Nauclea latifolia.

Hymenocardia acida.

Ficus capensis.

Piliostigma thonningii.

Une diminution du couvert herbacé pourra être l'occasion d'un enrichissement du parcours en début des pluies par semis de Stylosanthes gracilis à $3 \mathrm{~kg}$ de semences à l'hectare précédé d'un griffage du sol aux disques ou au rouleau à lames, type «Marden ».

d) Pâturages artificieis - Plantes fourragères.

Les conditions agro-climatiques des savanes préforestières ef d'altitude sont assez favorables à l'élevage d'animaux améliorés, qui rentabiliseraient une production intensive de fourrages avec leur grande productivité en viande et en laił.

En saison des pluies, le fourrage produit par les 3 légumineuses est toujours riche et le temps de croissance le plus favorable est de 2 mois et demi.

Pour les graminées, le temps de croissance d'un mois et demi donne le fourrage le plus nutritif. Après 4 mois, il y a pour Cynodon plectostachyus et Panicum maximum, une production de pousses de $2^{\circ}$ génération et la valeur broma- tologique devient supérieure à celle obtenue au bout de 40 jours.

En saison sèche, les légumineuses conservent leur valeur, même après 4 mois de végétation. Les graminées assurent une production de viande et de lait après 2 mois de croissance mais Melinis minutiflora ne satisferait que les besoins d'entretien. Les repousses de saison sèche d'Andropogon gayonus conservent encore toute leur valeur au bout de 3 mois, d'où l'intérêt de cette plante pour assurer la pâture en fin de saison sèche.

Enfin, Tripsacum laxum conservé sur pied pendant 5 mois, peut encore assurer l'entretien de I'U. B. T. ce qui est très intéressant pour l'affouragement à l'auge de bétail amélioré.

L'évolution de la valeur fourragère en fonction de l'âge des repousses permet d'envisager l'installation de chaînes de pâture pour les établissements d'élevage d'animaux améliorés, selon les principes suivants :

- éviter l'association graminées-légumineuses, les rythmes optimaux de croissance n'étant pas concordants,

- pâture des légumineuses avec un rythme de 2 mois et plus soit moitié de la saison des pluies, fin de saisons des pluies, fin de saison sèche,

- pâture des graminées basses avec un rythme voisin d'un mois en saison des pluies et de 2 mois en début de saison sèche,

- pâture d'Andropogon goyonus avec un rythme de 3 mois toute l'année,

- pâture de Cynodon plectostachyus avec un rythme de 4 mois en saison des pluies et de 2 mois en saison sèche,

- réserve de foin, d'ensilage et de fourrage à distribuer en vert pour la pleine saison sèche.

Pour une saison des pluies de 7 mois s'étalant d'avril à octobre, une chaîne de pâturage basée sur une charge annuelle d'1 U. B. T./ha, pourrait être envisagée avec les espèces suivantes:

- graminées basses :

Cynodon plectostachyus: 1/5 de la surface.

Setaria sphacelata : 3/10 de la surface.

- graminée haute:

Andropogon gayanus : $1 / 5$ de la surface.

- légumineuse :

Stylosanthes gracilis $: 1 / 5$ de la surface. 
Tableau 13

Chaîne de pâturage et rythme d'exploitation

\begin{tabular}{|c|c|c|c|c|c|c|c|c|c|c|c|c|c|}
\hline Mois & 4 & 5 & 6 & 7 & 8 & 9 & 10 & 11 & 12 & 1 & 2 & 3 & 4 \\
\hline Saison des pluies & & & & & & & {[} & & & & & & \\
\hline Explo1tation & & & & & & & & & & & & 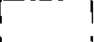 & \\
\hline Setaria sphacelata & & & & & & & 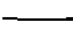 & & & & & 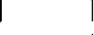 & \\
\hline Cynodon plectostachyu & & & & & & & & & & & & 1 & \\
\hline Andropagon gayanus & & & & & & & foln & & & & & & \\
\hline Stylosanthes gracilio & & & & & & & & & & & & & \\
\hline Mripsaoum lasum & & & & & & & lage & & & & coupe & en vert & \\
\hline Complément & & & & & & & & & & & & & \\
\hline Foin & & & & & & & & & & & & & \\
\hline Ensilage & & & & & & & & & & & & & \\
\hline Tripsaewn en vert & & & & & & & & & & & & & \\
\hline
\end{tabular}

- graminée haute tige pour ensilage de septembre et fourrage vert de pleine saison sèche :

Tripsacum laxum : $1 / 10$ de la surface, cette espèce pourrait être rempiacée en région d̀ saison sèche très marquée par l'hybride «Pennisetum dे collet rouge ».

\section{CONCLUSION}

Les taux de matière sèche, de mattères azotées brutes, de cellulose et de cendres constituent les éléments de calcul de la valeur bromatologique des fourrages.

Ce calcul peut être réalisé en affectant au fourrage analysé les coefficients de digestıbilité d'un fourrage voisin botaniquement et ayant des taux de matière sèche, de matières azotées brutes et de cellulose comparables. Les analyses de fourrages et leurs coefficients de digestibilité peuvent être extraits des tables de KELLNER (39) ou des tables de SCHNEIDER (12).

A partir de résultats expérimentaux, les tables hollandaises (28) donnent directement la valeur bromatologique d'un $\mathrm{kg}$ de matière sèche de fourrage en fonction du taux de cellulose et de cendres pour la valeur énergétique et en fonction du taux de matières azotées brutes pour les matières azotées digestibles.

Pour une série d'analyses d'une plante dont la composition varie progressivement en fonction du temps de croissance, l'utilisation des tables hollandaises est à la fois rapide et évite l'évolu- tion de la valeur bromatologique en dents de scie dues aux changements successif́s d'éléments de référence.

Par analogie à l'unité gros bétail (U. G. B.) des pays tempérés, un animal de référence de $250 \mathrm{~kg}$ pour les pays tropicaux peut être adopté comme Unité-Bétail tropical (U. B. T.).

La consommation journalière théorique étant évaluée à $2,5 \mathrm{~kg}$ de matière sèche pour $100 \mathrm{~kg}$ de polds vif, les besoins de I'U. B. T. sont rapportés au $\mathrm{kg}$ de matière sèche ingérée sous le nom d'Equivalent-Ration exprimé en unité fourragère et matière azotée digestible.

La lecture directe des tables hollandaises fournit la valeur Equivalent-Ration du $\mathrm{kg}$ de matière sèche de l'aliment. Cette valeur peut être comparée aux besoins théoriques de l'Unité Bétail Tropical ef servir à la classification immédiate des fourrages en fonction de leur valeur bromatologique.

Cette classification pourra ultérieurement servir à l'établissement d'une échelle de valeur relative des fourrages comparables à celle de Vries (24) reprise par Delpech (17) pour les fourrages des pays tempérés. La cotation de la valeur d'une espèce associée à la proportion relative de cette espèce, soit en poids (38), soit en présence (16) permettrait d'affecter à chaque pâturage une note sur 100 , les possibilités de charge ayant été appréciées expérımentalement.

Le dépovillement de plus de 500 analyses bromatologiques de plantes fourragères tropicales. a mis en évidence : 


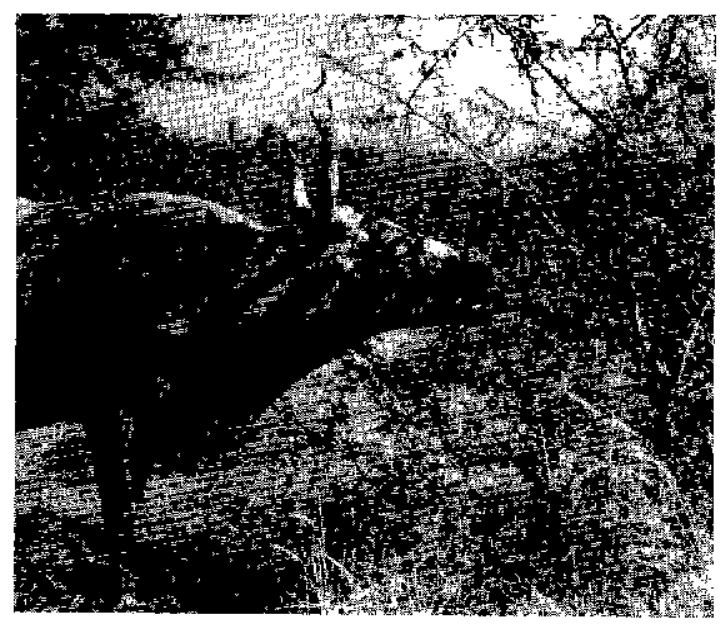

1. - Consommation, sur steppe, de jeunes fruits d'Acacia seyal Del. par les zébus, en saison sèche et fraîche.

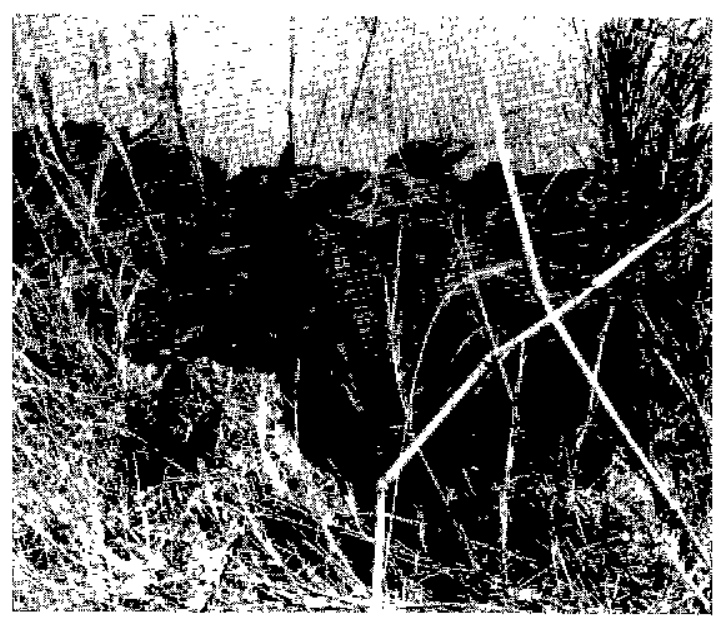

2. - Consommation de jeunes pousses sur nouds, d'Hyporrhenia diplandra (Hack.) Stapf, non brûlé en saison sèche.

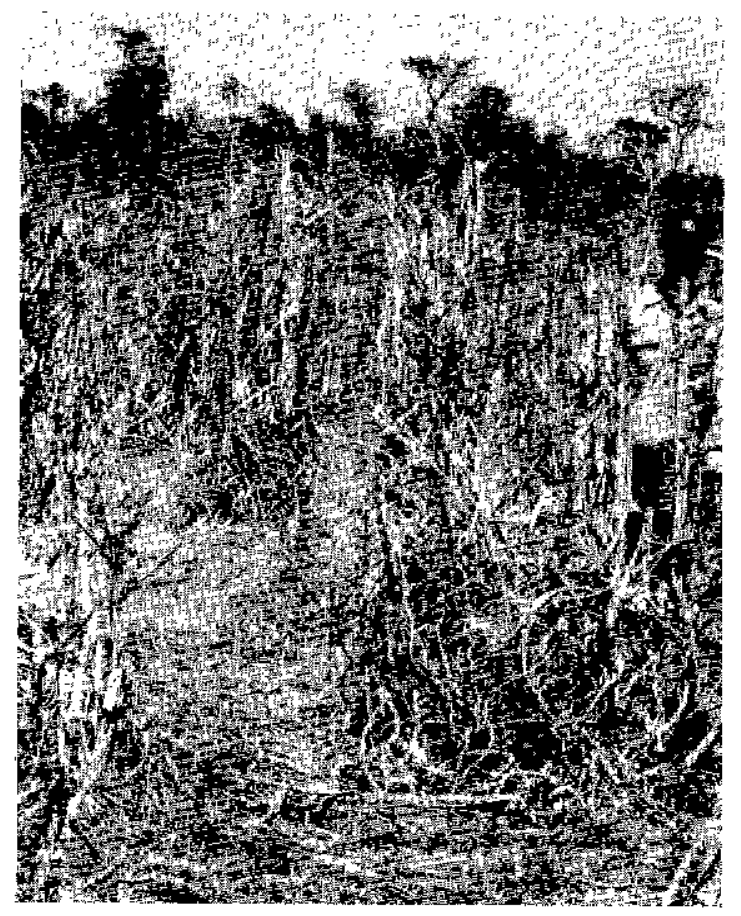

3. - Réserve sur pied pour saison sèche de Pennisetum hybride «à collet rouge». Les extrémités des tiges sont distribuées à l'auge ef les cannes tronçonnées à 3 yeux, serviront de boutures en début des pluies.

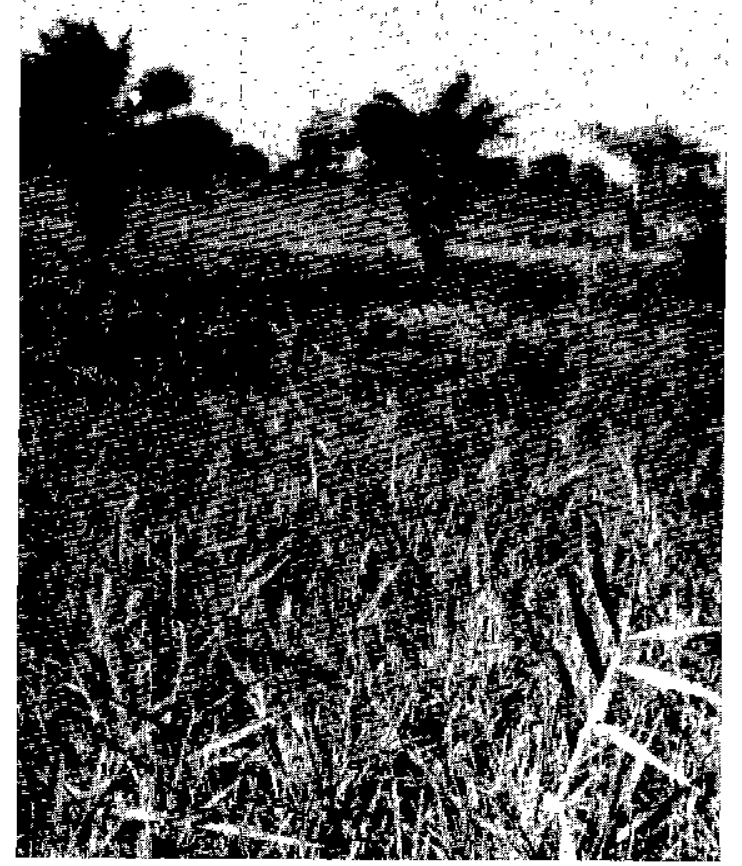

4. - Pâturage artificıel à Brachiaria mutica (Forsk.) Stopf « herbe de Para » sur bas-fond pâturable en saison sèche. 


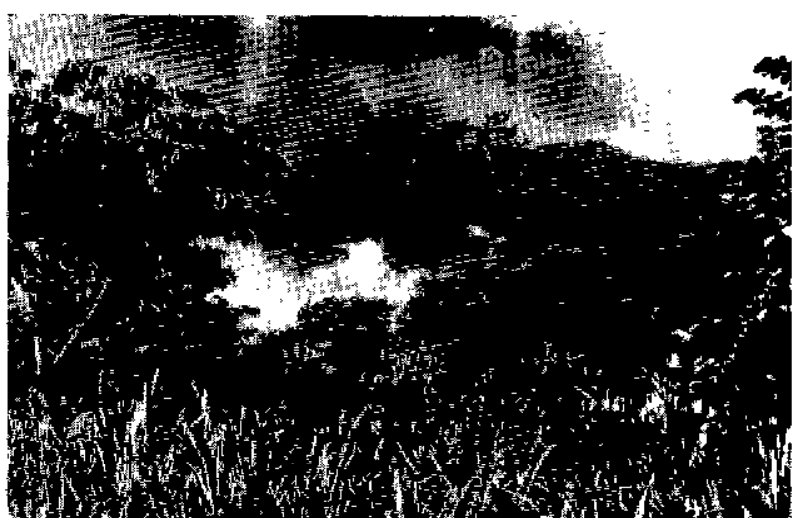

5. - Dans une savane préforestière sur sol profond, d̀ Andropogon macrophylius Stapf, feu de contre-saison alimenté par les pailles de l'année précédente.

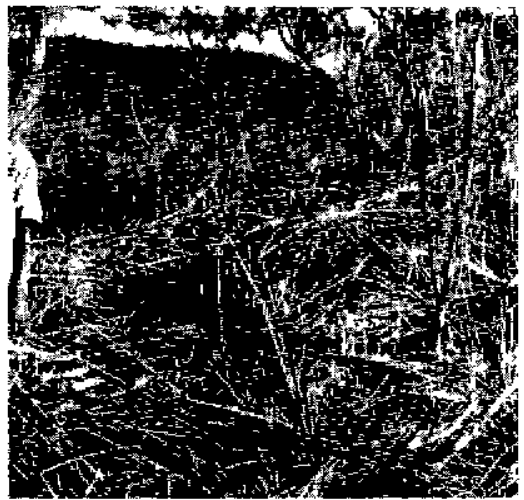

6. - Repousses après feu de contresalson, restes de choumes non calcinés et défolıation des arbustes. Le pâturage sera exploitable en début de saison sèche.

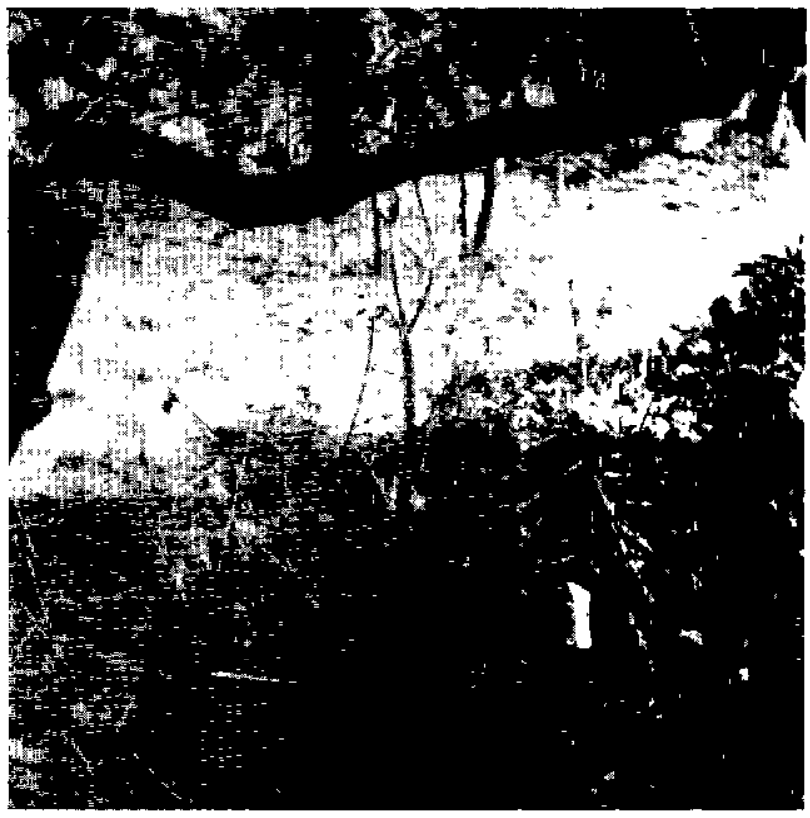

7. - Plantule d'Harungana modagascariensis Lam. ex Poir., installée à l'ombre d'Annona arenarı Thonn., après diminution du couvert herbacé à la sulte du pâturage.

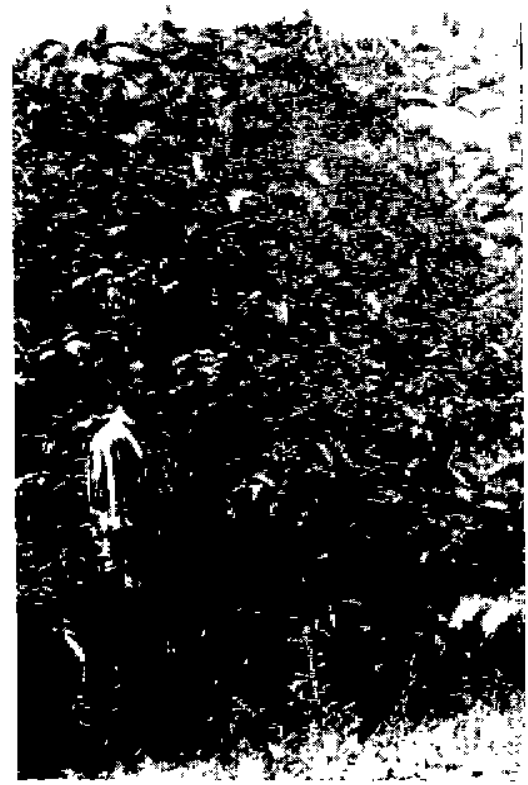

8. - Hallier d'Harungana quelques années plus tard. 
- l'importance des pâturages aériens comme complément de la ration en matières azotées digestibles au cours de la saison sèche tant sur steppes que sur savanes,

- l'importance périodique des espèces d'appoint pour assurer la nourriture du bétail sur steppes,
- le nombre lımité d'espèces assurant une ration d'entretien pendant une longue période sur steppes,

- l'importance du temps de croissance pour les espèces vivaces de savanes, la valeur bromatologique des repousses dépendant plus de ce facteur que de la date de récolte.

\section{SUMMARY}

Practical use of fodder analysis to assess the value of tropical pastures

Percentages of dry matter, crude nitrogen content, cellulose and ashes constitute the bases of the bromatologic value determination of the fodder. From experimental results, the Dutch tables give directly the bromatologic value of one kilogramme of fodder dry matter according to the cellulose and ashes percentages to respect with the energetic value, and according to the crude nitrogen rate to respect with the digestible nitrogen.

On the analogy of livestock unit (U, G. B.) of the temperate countries, a reference animal of $250 \mathrm{~kg}$ can be taken as livestack unit in tropical countries (U. B. T.). The theoretical daily consumption has been estimated at $2.5 \mathrm{~kg}$ of dry matter per $100 \mathrm{~kg}$ of live weight, and the needs of U. B. T. are refered to the kilogram of ingested dry matter under the name of « Equivalent-ration 》 expressed in fodder unit and digestible nitrogen.

The analysis of more than 500 feeding values of tropical fodder plants showed:

- The importance of woody pastures as feeding complement in digestible nitrogen during the dry season in the steppe as well as in the savannah.

- The periodical importance of some make up species in order to secure the feeding of cattle in the steppe.

- The limited number of species which are able to secure the maintenance requirements during a long period in the steppe.

- The importance of the time of growth of the perennial species in savannah, since the feeding value of the innovations depends more on this factor than on the time of harvesting.

\section{RESUMEN}

Utılizacıón práctica de los ánálisis foirajeros para la valoración de los pastos tropicales

Los contenidos en materas secas, en materias nitrogenadas brutas, en fibra bruta y en cenizas constıtuyen los elementos de cálculo del valor bromatologico de los forrajes. A partir de los resultados experımentales, las tablas holandesas directamente dan el valor bromatologico de un $\mathrm{kg}$ de materias secos de forraje según el contenido de fibra y de cenizas en la concerniente el valór energetico y según el contenido de materias nitrogenadas brutas en lo concerniente las materias nitrogenadas digestıbles. Referiendose a la unidad ganadera U. G. B. de los paises templados, se puede adoptar como unidad ganadera tropical U. B. T. un animal de referencıa de $250 \mathrm{~kg}$ en los paises tropicales. Siendo evaluado el consumo diario teórico a $2,5 \mathrm{~kg}$ de materia seca para $100 \mathrm{~kg}$ de peso vivo, se relacionan con un $\mathrm{kg}$ de materia seca ingerida las necesidades del U. B. T. llamadas « equivalent-ration», expresado en unıdad forrajera y materıa nitrogenada digestible.

El examen de más de`500 análisis bromatologicas de plantas forrajeras tropiccles mostró : 
- la importancia de los pastos aéreos empleados como aditivos de materias nitrogenadas digestıbles en la ración durante la estación seca en estepa tan como en sabanas.

- la importancia periódica de las especies complementarias para asegurar la alimentación del ganado en la estepa.

- el número lımitado de las especies constituyendo la ración de mantenimiento durante un largo tiempo en la estepa.

- la ımportancla del tiempo de crecimiento de las especies vivaces de sabana, el valor bromatologico de las nuevas brotas dependıendo más de este factor que de la fecha de cosecha.

\section{BIBLIOGRAPHIE}

1. AUBreVILLE (A.) - Climats, forêts et désertification de l'Afrique tropicale. Paris, Sce Editions Geog. marit. et col. 1949.

2. AUDRU (J.). - Etude des pâturages naturels et des problèmes pastoraux dans, le Delta du Sénégal (République du Sénégal). I. E. M. $\checkmark . T$. Etude agrostologique no 15 . Miméogr., $1966: 359,1 \mathrm{c}$.

3. AUDRU (J.). - Ensembles pastoraux du Logone et du Moyen Chari (République du Tchad). I. E. M. V. T. Etude agrostologique no 16. Miméogr., 1966, $1 \mathrm{c}$.

4. AUDRU (J.). BOUDET (G.). - Pâturages de la zone Sud de la République Centrafricaine. I. E. M. V. T. Etude agrostologique no 8. Miméogr., $1964: 213,1 \mathrm{c}$.

5. BILLE (J. C.). - Pâturages du Secteur occidental d'élevage de la République Centrafricaine. I. E. M. V. T. Etude agrostologique no 9. Miméogr. $1964: 286,2 \mathrm{c}$.

6. BOUDET (G.). - Etude agrostologique du ranch de Sipilou (République de Côted'(voire). I. E. M. V. T. Ełude agrostologique no 14. Miméogr., $1966: 150,1 \mathrm{c}$.

7. BOUDET (G.), BAYENS (F.). - Une méthode d'étude et de cartographie des pâturages tropicaux. Rev. Elev. Méd. vét. Poys trop., 1963, 16 (2) : 191-219.

8. BOUDET (G.), DUVERGER (E.). - Etude des paturages naturels sahéliens. Le Hodh (Mauritanie). I. E. M. V. T. Etude agrostologique no2, Paris, Vigat, $1961: 160$.

9. BOUDET (G.), RIVIERE (R.), CLEMENSAT (J.) PAGOT (J.), LAHORE (J. F.). Les possibilités fourragères de Digitoria « umfolozi » en zone soudanienne. Rev. Elev. Méd. vét. Pays trop., 1961, 14 (4), 449-68.

10. BOWDEN (B. N.). - Studies on « Andropogon gayanus Kunth. ». I. The use of Andropogon gayanus in agriculture. (Makerere university college, Kampola, Uganda.) Emp. j. of Exp. Agric., 1963, 31 (123) : 267-73.

11. BUCK (G.), CARRE (J.), METZGER (G.).Le Pennisetum à collet rouge. Bull. Madagoscar, 1962, $188:$ 73-81.

12. BURCH HART SCHNEIDER (Ph. D.).Feeds of the world. Their digestibility and composition. Morgantown, West Virginia university, 1947.

13. CADOT (R.). - Expérimentation sur les plantes fourragères. I. E. M. V. T. Centre de recherches zootechniques de MinankroBouaké (Rép. de Côte-d'lvoire). Miméogr., $1965: 51$.

14. Centre de Recherches zootechniques de Bamako-Sotuba (Mali). Rapport annuel, 1958.

15. CRAPLET (C.). - Traité d'Elevage moderne, Tome V. La vache laitière. Paris, Vigot, 1960.

16. DAGET (P.), POISSONNET (J.). - Etude phyto-écologique de la commune de Thoras (Haute-Loire). Document no 28, C. E. P. E. Montpellier. C. N. R. S. 1966.

17. DELPECH (R.). - Critères de jugement de la valeur agronomique des prairies. Fourrages $4-1960: 83-98$.

18. DIJKSTRA (N. D.). - What has the State Agricultural Experiment Station at Hoorn contributed to research into the feeding value of roughage? Neth. J. Agric. Sc. 2 (1954) 273.

19. DIJKSTRA (N. D.). - Research into the digestibility and feeding value of some grass species and grass of leys. Versl. Landb. Onderz. 63 (1957) no 1.

20. DIJKSTRA (N. D.) et BRANDSMA (S.). Research into the digestibility and feeding value of fresh lucerne. Versl. Londb. Onderz. 61 (1965) n०5. 
21. FOTIUS (G.), VALENZA (J.). - Etude des pâturages du Ferlo oriental (République du Sénégal). I. E.M. V.T. Etude agrostologique no 13. Miméogr., 1966:180, 2 c.

22. GASTON (A.). - Etude agrostologique du Kanem (République du Tchad). I. E.M.V.T. Etude agrostologique no 11. Miméogr., $1966: 176,1 \mathrm{c}$.

23. GRANIER (P.), LAHORE (」.). - Amélioration de l'alimentation du bétail. Consommation d'herbe et charge d̀ l'hectare avec le Stylosanthes gracilis. Inédit. I. E. M. V. T. Tananarive.

24. HART (M. L.), VRIES (D. M. de). - La prairie ef l'exploitation de la prairie aux Pays-Bas. Bull. Tech. inf. Ingrs. servs, agricoles, 52-1950: 547-51.

25. LABOUCHE (C.), MAINGUY (P.). - Aspects physiologiques ef nutritionnels de l'alimentation du bétail en Afrique Occidentale Française. Rev. Elev. Méd. vét. Pays trop., 1954, 7 (4) : 221-307.

26. LANDER (P. E.). - The Feeding of Farm Animals in India. Calcutta Mac Millan Co Ltd, 1949.

27. LEROY (A.). - Elevage rationnel des animaux domestiques. Paris, Hachette, 1929, rééd. 1951.

28. Manual for the calculation of the nutritive value of roughages. (Bedrijfs laboratorium voor grond en gewa son derzoeck) Mariendaal, Oosterbeck-The Netherlands, 1957.

29. Ministère de I'Agriculture, France. - L'élevage bovin, Vues actuelles et perspectives. Office des relations culturelles et commerciales, 22, r. Drouat, Paris (9e), 1967.
30. MORRISON (F, B.). - Feeds and Feeding. Ithaca. New York, Morrison. Publishing company, 1950.

31. MOSNIER (M.). - Pâturages naturels sahélıens. Région de Kaedi (Mauritanie). I. E. M. $\checkmark$. T. Etude agrostologique no 3 . Miméogr., $1961: 169,2 \mathrm{c}$.

32. PEYRE de FABREGUES (B.). - Etude des pâturages naturels sahéliens. Ranch de Nord-Sanam (République du Niger). I. E. M. V.T. Etude agrostologique no 5. Miméogr., $1963: 135,1 \mathrm{c}$.

33. PEYRE de FABREGUES (B.). - Etude des pâturages naturels sahéliens de la région de Nord-Gouré (République du Niger). I. E. M. $\checkmark . T$., Etude agrostologique no 10 . Miméogr., $1965: 163,1 \mathrm{C}$.

34. PEYRE de FABREGUES (B.). - Etude des pâturages de la zone nomade de Zinder. O. N. U.-I. E. M. V. T. - Etude agrostologique n 17. Mıméogr., $1967: 188,1 \mathrm{C}$.

35. RATTRAY (J. M.). - Tapis graminéens d'Afrique. Rome F. A. O. Etudes agricoles no 49-1960.

36. TROCHAIN (J. L.). - Accord interafricain sur la définition des types de végétation de l'Afrique Tropicale. Bull. Inst. Etud. Centrafr., Brazzoville, 1957, 13-14: 55-93.

37. VOISIN (A.). - Productivité de l'herbe. Paris, Flammarion, 1957.

38. VRIES de (D. M.), BOER de (Th. A.), Methods used in botanical grassland research in the Netherlands and their application. Herb. abstr. 29-1-1959:1-7.

39. WERY (G.), TISSOT (P.). - Aide-mémoire agricole et viticole. Paris, Baillière, 1953.

\section{ERR A T A}

\section{Tome XXI 2 - 1968}

Article BOUDET (G.) et RIVIERE (R.). - Emploi pratique des analyses

fourragères pour l'appréciation des pâturages tropicaux.

p. 239 tableau 6

4 e colonne (M.A.D.) 1re ligne : ajouter 8,5

p. 249 tableau 10 (fin)

5e colonne : ligne Blepharis lineariffolia au lieu de 23,38 lire 23,28

1re colonne: au lieu de Grewia sp., lire Grewia spp.

p. 253 tableau 11 (suite)

1 re colonne, au lieu de Pterocarpus lucenx, lire Pterocarpus lucens.

p. 261 tableau 13

ligne Stylosanthes gracilis, ajouter un trait dans la colonne mois 11. 